\title{
Design, Characterization, X-ray Single-crystal, Potentiometric Measurements, Molecular Modeling and Biomedical Applications of Thiosemicarbazones
}

\author{
Ahmed El-Sherif ( $\nabla$ aelsherif@sci.cu.edu.eg ) \\ Cairo University \\ Abeer A. El-Sisi \\ Cairo University \\ Mohamed Ali \\ Cairo University \\ Sohair F. Ramdan \\ Cairo University \\ Osama AlTaweel \\ Cairo University \\ Ahmed I. A. Abd El-Mageed \\ Minia University
}

\section{Research Article}

Keywords: Thiosemicarbazones, antimicrobial, antitumor, modeling, X-ray

Posted Date: June 30th, 2021

DOI: https://doi.org/10.21203/rs.3.rs-647955/v1

License: (c) (i) This work is licensed under a Creative Commons Attribution 4.0 International License.

Read Full License

Version of Record: A version of this preprint was published at Journal of Chemistry on July 9th, 2022. See the published version at https://doi.org/10.1155/2022/1241470. 


\section{Design, Characterization, X-ray Single-Crystal, Potentiometric Measurements, Molecular Modeling and Biomedical applications of thiosemicarbazones}

Ahmed A. El-Sherif ${ }^{1 *}$, Abeer A. El-Sisi ${ }^{2}$, Mohamed Ali $^{1}$, Sohair F. Ramdan ${ }^{3}$, Osama AlTaweel $^{4}$, Ahmed I. A. Abd El-Mageed ${ }^{5,6}$

${ }^{1}$ Department of Chemistry, Faculty of Science, Cairo University, Cairo, Egypt.

${ }^{2}$ Forensic medicine authority, Ministry of Justice, Egypt.

${ }^{3}$ Department of Zoology, Faculty of Science, Cairo University, Cairo, Egypt.

${ }^{4}$ Department of Forensic medicine, Faculty of Veterinary, Cairo University, Cairo, Egypt.

${ }^{5}$ Chemistry Department, Faculty of Science, Minia University, Minia 61519, Egypt.

${ }^{6}$ Nanoscience and Technology, Advanced Basic Science, GALALA University, Galala City, Egypt.

*Author of correspondence: e-mail: aelsherif72@yahoo.com, Mobile No. 00201060160168, Office No. 00235676636 


\begin{abstract}
series of thiosemicarbazone compounds ((E)-2-((E)-1-(2-(p-tolyl)hydrazono)propan2-ylidene)hydrazine-1-carbothioamide (TSC1),

(E)-N-ethyl-2-((E)-1-(2-(ptolyl)hydrazono)propan-2-ylidene)hydrazine-1-carbothioamide (TSC2) and (E)-N-phenyl-2((E)-1-(2-(p-tolyl)hydrazono)propan-2-ylidene)hydrazine-1-carbothioamide)(TSC3) were synthesized and fully characterized by assistance of diverse physicochemical and spectroscopic tools like X-ray single-crystal, IR, mass, ${ }^{1} \mathrm{HNMR}, \mathrm{Uv}-\mathrm{Vis}$, ... etc. potentiometric measurements, molecular modeling, as well as biological and antitumor activities screening. We have calculated and discussed the thermodynamics and protonation constants of TSC1 compound as a representative from the novel synthesized thiosemicarbazones. The solution speciation of different species was studied in accordance with $\mathrm{pH}$. Molecular parameters of the optimized structures were calculated and discussed. The X-ray single crystal of TSC2 and TSC 3 compounds have been established where TSC2 crystallizes in P21/c, a = 11.2343 (6) A, $\mathrm{b}=11.2575$ (7) $\AA, \mathrm{c}=11.8995$ (8) $\AA, \alpha=90.00^{\circ}, \beta=94.476(7)^{\circ}, \gamma=90.0^{\circ}, \mathrm{V}=1500.34$ (16) $\AA^{3}, Z=4$, however, TSC3 crystallizes in the space group P21/c, a = 27.958 (12) $\AA, b=12.072$ (5) $\AA, c=9.833$ (4) $\AA, \alpha=90.0^{\circ}, \beta=93.117(11)^{\circ}, \gamma=90.0^{\circ}, V=3486.75 \AA^{3}, Z=7$. Considering the antimicrobial activities and correlating structure-activity relationship for the synthesized compounds, TSC1 molecule behaves as a promising candidate as an antifungal agent versus Candida albicans. Consequently, that would be very helpful in the field of medicinal chemistry especially as antimicrobial agents. The results are of vital significance to the chemistry of antimicrobial agents.
\end{abstract}

Keywords: Thiosemicarbazones; antimicrobial; antitumor, modeling; X-ray. 


\section{Introduction}

From the most global problems, infectious diseases represent a high burden in public health worldwide. Due to the high resistance of some Gram-positive and Gram-negative bacteria to many drugs, large number of infection diseases become a real dangerous that threaten the human life worldwide [1]. Globally, from more than 50 million infected people up to 110.000 of them die annually. By the middle of $21^{\text {st }}$ century, it is expected that the mortality rate caused by Gram-negative bacterial infection alone could possibly be increased up to ten million deaths a year [2]. Antibiotics are the main base for microbial (bacterial and fungal) infection therapy. Antibiotic overuse, indeed, has become the main cause in the appearance and spread of multi-drug resistant strains of many microbes [3]. Emergence and increasing prevalence of antibiotic resistant bacterial strains to available antibiotics urge the discovery of new therapeutic approaches [4] additionally; the available drugs are also expensive or have a lot of unwanted side effects [5]. Therefore, the necessary to get novel antimicrobial agents is of vital significance given the evidence of fast global spread of resistant clinical isolate. Taking into consideration, the relation between bacterial infection and multi-drug resistant, the present investigation was developed to search for a new antimicrobial effective drug. Nowadays, there is a significant concern in the medicinal chemistry of Schiff-base compound like hydrazones and thiosemicarbazones due to their wide biological activities [6,7]. The groups of $\mathrm{C}=\mathrm{N}$ and $\mathrm{N}-\mathrm{C}=\mathrm{S}$ are of great interest in chemotherapy and are responsible for the pharmacological activity. Perhaps the most essential step in the metal complexes implementation is the synthesis of a novel compounds that exhibit unique properties as well as reactivity, in this regards thiosemicarbazones were a topic of interest to researchers of various profiles. Thiosemicarbazone compounds and their complexes have been widely investigated as they display very interesting properties in the field of biomedicine as well as potential medicinal applications [8-12] which comprise antiparasital [13], antibacterial [14] antitumor [15], antiviral [16], fungicidal [17], antineoplastic [18] and antiamebic [19] activities. Thiosemicarbazones (TSCNs) may have thione (A) and thiol (B) forms (Scheme 1).

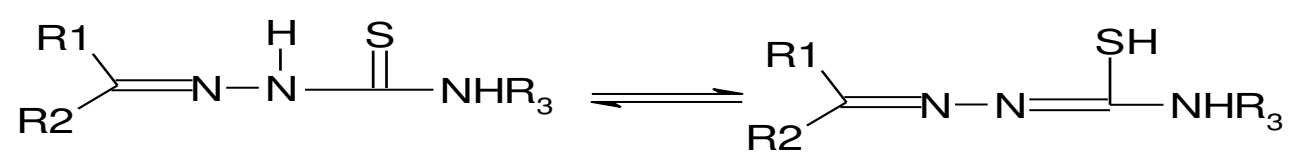

Scheme 1. Thione (A)-thiol (B) tautomers of thiosemicarbazones 
Hydrazones were a crucial class of compounds; these compounds have impressive ligation characteristics due to the existence of several coordination sites [20]. The literature also reports hydrazine and its derivatives that have anti-inflammatory, analgesic [21], antibacterial [22] and antitumor [23] activity.

Nevertheless, cadmium is a very toxic metal ion that poses both human and animal health hazards. Its toxicity is done by its easy localization inside the liver, and then by binding of metallothionein, which eventually forms a complex and is transmitted into the blood stream to be lodged in the kidney.

The cause of Cd-toxicity is the negative effect on cell enzyme systems that are the consequence of metallic ion substitution (mainly $\mathrm{Zn}(\mathrm{II}), \mathrm{Cu}(\mathrm{II})$, and $\mathrm{Ca}(\mathrm{II})$ ) into metalloenzymes and its large affinity to thiol group compounds [24]. Zn(II) replacement with a chemically analogous $\mathrm{Cd}(\mathrm{II})$ ion usually causes apoprotein catalytic activity to break down $[25,26]$. Therefore, it is of paramount importance to discover novel compounds that can form stable complexes with $\mathrm{Cd}(\mathrm{II})$, because they can be used as detoxifiers. Referable to the broad scope of pharmacological properties of thiosemicarbazone compounds and their compounds, these compounds can also very well fit for this role. Recently, the experimental studies were supplemented by computational studies [27] owing to their crucial role in recognizing the likely attitudes of the compound during reactions and recognition of valuable information on the compounds under examination, such as total energy, binding energy, electronic energy, dipole moment, bond length, HOMO and LUMO [28]. With this in mind and in the perpetuation of our studies in the subject area of bioactive compounds [29,30], it seems of great interest to synthesize and identify novel compounds involving both thiosemicarbazone and hydrazo moieties. In addition, our aim is to explore biological activities of identified compounds.

\section{Experimental}

\subsection{Materials and reagents}

All the chemicals used in this study were supplied by Aldrich Chemicals Company and used with no extra purification.

\subsection{Synthesis}

\subsubsection{Synthesis of 1-(p-tolylhydrazono)-propan-2-one (PTHP) compound}

We have synthesized 1-(p-tolylhydrazono)-propan-2-one (PTHP) compound using reported method [31,32]. Chemical equations for preparation shown below in Scheme 2. 


$$
\begin{gathered}
\mathrm{CH}_{3} \mathrm{COCH}_{2} \mathrm{CO}_{2} \mathrm{C}_{2} \mathrm{H}_{5}+\mathrm{KOH} \rightarrow \mathrm{CH}_{3} \mathrm{COCH}_{2} \mathrm{CO}_{2} \mathrm{~K}+\mathrm{C}_{2} \mathrm{H}_{5} \mathrm{OH} \\
\mathrm{CH}_{3} \mathrm{COCH}_{2} \mathrm{CO}_{2} \mathrm{~K}+\mathrm{HCl} \rightarrow \mathrm{CH}_{3} \mathrm{COCH}_{2} \mathrm{CO}_{2} \mathrm{H}+\mathrm{KCl} \\
\mathrm{CH}_{3} \mathrm{COCH}_{2} \mathrm{CO}_{2} \mathrm{H}+\mathrm{p}-\mathrm{Me}-\mathrm{C}_{6} \mathrm{H}_{5} \mathrm{~N}=\mathrm{NCl} \rightarrow \mathrm{p}-\mathrm{Me}-\mathrm{C}_{6} \mathrm{H}_{5} \mathrm{NH}-\mathrm{N}=\mathrm{CHCOCH}_{3}+\mathrm{CO}_{2}+\mathrm{HCl}
\end{gathered}
$$

Scheme 2. Preparation of 1-(p-tolylhydrazono)-propan-2-one compound

\subsubsection{Synthesis of thiosemicarbazone compounds}

Equimolar amounts of (PTHP) $(0.1760 \mathrm{~g}, 1 \mathrm{mmol})$ in $30 \mathrm{ml}$ ethanol with an ethanolic solution $(30 \mathrm{ml})$ of thiosemicarbazide $(0.091 \mathrm{~g}, 1 \mathrm{mmol})$, N-ethylthiosemicarbazide $(0.119 \mathrm{~g}$, $1 \mathrm{mmol})$ and $\mathrm{N}$-phenylthiosemicarbazide $(0.167 \mathrm{~g}, 1 \mathrm{mmol})$ were refluxed on hot plate for 3-5 h. The precipitate was separated out, filtered off, washed with $\left(\mathrm{C}_{2} \mathrm{H}_{5}\right)_{2} \mathrm{O}$ and desiccated all night using silica gel. The target compounds are shown in Figure 1.

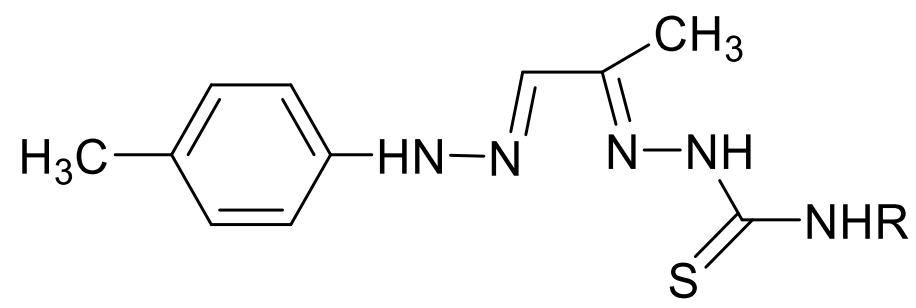

Fig. 1. Structural formulae of thiosemicarbazone compounds; TSC1, TSC2 and TSC3 with $\mathrm{R}=\mathrm{H}$, Et, $\mathrm{Ph}$, respectively.

2.2.2.1.

((E)-2-((E)-1-(2-(p-tolyl)hydrazono)propan-2-ylidene)hydrazine1carbothioamide (TSC1). Yield, 77\%. Colour, Brown. Anal. Calc. for $\mathrm{C}_{11} \mathrm{H}_{15} \mathrm{~N}_{5} \mathrm{~S}$ : C, 52.99; H, 6.06; N, 28.09; S, 12.86. Found: C, 52.93; H, 6.01; N, 28.03; S, $12.79 \%$. IR $\left(\mathrm{KBr}, \mathrm{cm}^{-1}\right)$ : 3386, $3234\left(\mathrm{NH}_{2}\right)$, 1507, 1251, 1017, 805 (Thioamide bands, I-IV respectively), 3501, 3177 $(\mathrm{N} 2 \mathrm{H}), 1100(\mathrm{~N}-\mathrm{N}), 1603(\mathrm{C}=\mathrm{N}), 1553(\mathrm{C}=\mathrm{C}), 3045(\mathrm{C}-\mathrm{H}) . \mathrm{MS}(\mathrm{m} / \mathrm{z}): 251\left(\mathrm{M}^{+}+2,6.03 \%\right)$, $250\left(\mathrm{M}^{+}+1,18.07 \%\right) 249\left(\mathrm{M}^{+}, 100 \%\right), 234$ (2.58 \%), 232 (38.20\%), 159 (2.07\%) 157 (0.59 \%) 118 (3.81\%). ${ }^{1} \mathrm{H}$ NMR (DMSO): 11.32 (s, 1H, NH), 10.89 (s, 2H, NH), 7.8 (s, 2H, NH $)$, $7.48(\mathrm{~s}, \mathrm{H}, \mathrm{CH}=\mathrm{N}), 6.94-7.01(\mathrm{~m}, 4 \mathrm{H},-\mathrm{Ar}), 2.21\left(\mathrm{~s}, 3 \mathrm{H},-\mathrm{CH}_{3}\right), 2.02\left(\mathrm{~s}, 3 \mathrm{H},-\mathrm{CH}_{3}\right) .{ }^{13} \mathrm{C}-$ NMR (DMSO): 11.02, 20.09, 112.21, 129.51, 130.80, 136.01, 142.21, 145.62, 178.3.

2.2.2.2. ((E)-N-ethyl-2-((E)-1-(2-(p-tolyl)hydrazono)propan-2-ylidene)hydrazine-1carbothioamide (TSC2). Yield, $69 \%$. Colour, Dark brown. Anal. Calc. for $\mathrm{C}_{13} \mathrm{H}_{19} \mathrm{~N}_{5} \mathrm{~S}$ : C, 55.52; H, 6.17; N, 25.25; S, 11.56. Found: C, 55.48; H, 6.12; N, 25.19; S, $11.51 \%$. IR (KBr, $\left.\mathrm{cm}^{-1}\right):$ 1532, 1251, 1079, 805 (Thioamide bands, I-IV respectively), 3444, 3338, $3230(3 \mathrm{NH})$, 
$1079(\mathrm{~N}-\mathrm{N}), 1615(\mathrm{C}=\mathrm{N}), 1535(\mathrm{C}=\mathrm{C}), 3019(\mathrm{C}-\mathrm{H}) . \mathrm{MS}(\mathrm{m} / \mathrm{z}): 279\left(\mathrm{M}^{+}+2,6.53 \%\right), 278$ $\left(\mathrm{M}^{+}+1,21.11 \%\right) 277\left(\mathrm{M}^{+}, 100 \%\right), 262$ (0.94\%), 173 (2.73\%) 118 (3.23\%). ${ }^{1} \mathrm{H}-\mathrm{NMR}: 11.33$ (s, 1H, NH), 10.33 (s, 1H, NH), 8.91 (s, 1H, NH), 7.54 (s, H, CH=N), 6.36-7.54 (m, 4H, -Ar), $3.60\left(\mathrm{q}, 2 \mathrm{H},-\mathrm{CH}_{2}\right), 2.4\left(\mathrm{t}, 2 \mathrm{H},-\mathrm{CH}_{3}\right), 2.23\left(\mathrm{~s}, 3 \mathrm{H},-\mathrm{CH}_{3}\right), 2.02\left(\mathrm{~s}, 3 \mathrm{H},-\mathrm{CH}_{3}\right),{ }^{13} \mathrm{C}-\mathrm{NMR}$ : $11.01,14.32,20.09,39.21,112.23,128.07,129.61,136.0 .142 .23,148.24,177.04$.

\subsubsection{3. (E)-N-phenyl-2-((E)-1-(2-(p-tolyl)hydrazono)propan-2-ylidene)hydrazine-1-} carbothioamide (TSC3). Yield, $67 \%$. Colour, Brownish yellow. Anal. Calc. for $\mathrm{C}_{17} \mathrm{H}_{19} \mathrm{~N}_{5} \mathrm{~S}$ : C, 62.74; H, 5.89; N, 21.50; S, 9.85. Found: C, 62.75; H, 5.85; N, 21.47; S, 9.81 \%. IR (KBr, $\left.\mathrm{cm}^{-1}\right):$ 1518, 1250, 1065, 748 (Thioamide bands, I-IV respectively), 3444, 3259, $3020(3 \mathrm{NH})$, $1065(\mathrm{~N}-\mathrm{N}), 1603(\mathrm{C}=\mathrm{N}), 1551(\mathrm{C}=\mathrm{C}), 3020(\mathrm{C}-\mathrm{H}) . \mathrm{MS}(\mathrm{m} / \mathrm{z}): 326\left(\mathrm{M}^{+}+1,1.78 \%\right) 325\left(\mathrm{M}^{+}\right.$, $7.41 \%$ ), 118 (5.63\%). ${ }^{1} \mathrm{H}-\mathrm{NMR}: 11.32$ (s, 1H, NH), 10.30 (s, H, NH), 7.70 (s, H, NH), 7.61 $(\mathrm{s}, \mathrm{H}, \mathrm{CH}=\mathrm{N}), 6.4-7.70(\mathrm{~m}, 9 \mathrm{H},-\mathrm{Ar}), 2.21\left(\mathrm{~s}, 3 \mathrm{H},-\mathrm{CH}_{3}\right), 2.03\left(\mathrm{~s}, 3 \mathrm{H},-\mathrm{CH}_{3}\right) .{ }^{13} \mathrm{C}-\mathrm{NMR}$ : $11.33,20.13,39.40,112.24,115.63,124.94,128.28,129.47,135.87,138.92,142.16,149.22$, 175.9 .

\subsection{Instrumentation}

All the chemicals used have been supplied by Aldrich. CHNS-automatic analyzer, Vario EII-Elementar was used to conduct elemental Microanalysis for C, H, N and S. A Perkin Elmer FTIR, type 1650 spectrophotometer with the potassium bromide disc was used to monitor IR spectra. On a spectrophotometer of schimadzu 3101 pc, electronic spectra are recorded. A Bruker ARX-300 device was applied to monitor the ${ }^{1} \mathrm{H}-\mathrm{NMR}$ spectra. Chemical shifts are recorded in ppm comparative to TMS using deuterated dimethylsulphoxide $\left(\mathrm{d}_{6}{ }^{-}\right.$ DMSO) as solvent. Mass spectrometry analyses have been carried out using Shimadzu GCMS-QP1000EX. The X-ray single-crystal of TSC2 molecule was performed by Rigaku VariMax RAPID FR-E diffractometer utilized by monochromator Mo Ka radiation with radiation wavelength of $\lambda=0.71075 \AA$ by the $\omega$ scan mode. By applying a cold $\mathrm{N}_{2}$ gas flow the crystal was cooled. By using the RAPID AUTO software (Rigaku), we have performed diffraction data scaling, cell refinement, indexing, collection as well as peak integration. The molecular structure was solved by Mercury 4.1.3 software. However, the X-ray crystallography data of TSC2 and TSC3 were collected by mounting a single sample crystal on glass fiber. The cell parameters and intensity data collection were done at $298 \mathrm{~K}$ using monochromator Mo K $\alpha$ radiation with radiation wavelength of $\lambda=0.71073 \AA$ Á. The crystal structure was solved by SIR-92 program [33] and was refined on $\mathrm{F}^{2}$ by full matrix least- 
squares technique using maXus processor program for solution and refinement of Crystal Structures [34]. ORTEP program was used for molecular graphics [35].

A Metrohm 848 Titrino supplied with a Dosimat unit (Switzerland-Herisau) have been utilized for potentiometric titrations as described previously in $50 \%$ water-DMSO mixture $[29,30,32]$.

\subsection{Potentiometric titrations}

Through potentiometric technique using the method depicted above in the literature [36], the formation constant of complex was estimated. The standard buffer solutions are used for accurately calibrating the glass electrode to NBS standards [37]. Standard solution of 0.05 $\mathrm{mol} / \mathrm{dm}^{3} \mathrm{NaOH}$, free from $\mathrm{CO}_{2}$, is used to titrate all samples in the $\mathrm{N}_{2}$ atmosphere. The sample solution developed to avoid hydrolysis during titration by mixing equal volumes of DMSO and $\mathrm{H}_{2} \mathrm{O}$. In addition, the ionic strength was kept constant during titration using $\mathrm{NaNO}_{3}$ as supporting electrolyte.

As known, the calculated formation constants using a potentiometric method have been carried out using a concentration of hydrogen ion expressed in molarity. Nevertheless, the concentration in $\mathrm{pH}-$ meter have been expressed in activity coefficient $-\log \mathrm{a}_{+}(\mathrm{pH})$. Thus, Van Uitert and Hass Eq. 1 was used to change $\mathrm{pH}$-meter reading (B) to $\left[\mathrm{H}^{+}\right][38,39]$

$$
-\log _{10}\left[\mathrm{H}^{+}\right]=\mathrm{B}+\log _{10} U_{H}
$$

Where $\log _{10} \mathrm{U}_{\mathrm{H}}=$ solvent composition correction factor and the ionic strength read by $\mathrm{B} . \mathrm{pK}_{\mathrm{w}}$ for titrated samples were estimated as previously described [40]. All precautions and procedures comply with literature requirements [41-43].

The protonation constants of TSC1 thiosemicarbazone compound were estimated potentiometrically by titrating $\left(40 \mathrm{~cm}^{3}\right)$ of $\left(1.25 \times 10^{-3} \mathrm{~mol} / \mathrm{dm}^{3}\right)$ TSC1 thiosemicarbazone solution with standard sodium hydroxide solution.

\subsection{Processing of data}

MINIQUAD-75 computer program has been applied to calculate ca. 100-150 readings for each titration [44]. Species distribution diagrams for the studied samples were given by the SPECIES program [45].

\subsection{Molecular modeling studies}

DFT calculations were performed using $\mathrm{DMOL}^{3}$ program [46,47] in Materials Studio package [48]. Calculations for DFT semi-core pseudopods (dspp) were created with dual numerical base sets and polarization properties (DNP) [49]. The RPBE model is focused on the (GGA) generalized gradient approximation as the best functional approximation [50,51]. 


\subsection{Biological activity}

\subsubsection{In vitro antibacterial activity}

Ability of the synthesized thiosemicarbazone compounds to suppress bacterial growth was checked by the disc diffusion process, [52,53]. Aerobic $G^{+}$bacteria: Staphylococcus aureus, Bacillus subtillis, Steptococcus faecalis and $G^{-}$aerobic bacteria: Pseudomonas aereuguinosa, E. coli, Neisseria gonorrhoeae are among the bacterial strains that were used in the present study. Additionally, two fungal strains (Aspergillus flavus, Candida albicans) were checked. The stock novel compounds solutions were prepared in DMSO. $100 \mu$ of each of the synthesized thiosemicarbazone compounds was inserted into discs $(0.8 \mathrm{~cm})$ and then they were allowed to dry. The discs were completely saturated with the synthesized compounds. The discs were then put into the upper layer of the medium at least $25 \mathrm{~mm}$ from the edge. The discs were then placed gently on the same plate surface. The plate was then incubated at $37{ }^{\circ} \mathrm{C}$ for $72 \mathrm{~h}$, and checked clear inhibition area. Eventually, by using the ruler millimeter we can determine the inhibition zone (an area where there is no growth around the discs).

\subsubsection{In vitro antitumor activity}

The synthesized thiosemicarbazone compounds were screened for their cytotoxicity against liver cancer (HepG2) and breast cancer (MCF-7) cells by using SRB assay protocol [54].

Potential cytotoxicity of the compounds was tested using the method of Skehan and Storeng. Cells were plated in 96-multiwell plate (104 cells/well) for $24 \mathrm{~h}$ before treatment with the compounds to allow attachment of cell to the wall of the plate. Different concentrations of the compounds under investigation $(0,5,25$ and $50 \mu \mathrm{g} / \mathrm{ml})$ were added to the cell monolayer and triplicate wells were prepared for each individual dose. The monolayer cells were incubated with the compounds for $48 \mathrm{~h}$ at $37{ }^{\circ} \mathrm{C}$ and in $5 \% \mathrm{CO}_{2}$ atmosphere. After 48 h, cells were fixed, washed and stained with SRB stain. Excess stain was washed with acetic acid and attached stain was recovered with tris-EDTA buffer. The optical density (O.D.) of each well was measured spectrophotometrically at $564 \mathrm{~nm}$ with an ELIZA microplate reader and the mean background absorbance was automatically subtracted and mean values of each drug concentration was calculated. The relation between drug concentration and surviving fraction is plotted to get the survival curve of breast and liver tumor cell line for each compound. 


\section{Calculation:}

The percentage of cell survival was calculated as follows:

Survival fraction $=$ O.D. (treated cells) $/$ O.D. (control cells). The $\mathrm{IC}_{50}$ values (the concentrations of the Schiff base ligand (L) or complexes required to produce 50\% inhibition of cell growth). The experiment was repeated 3 times.

\section{Results and discussion}

\subsection{Characterization of the synthesized thiosemicarbazone compounds}

Condensation of the 1-(p-tolylhydrazono)-Propan-2-one compound with thiosemicarbazide, N-ethylthiosemicarbazide and $\mathrm{N}$-phenylthiosemicarbazide readily gives rise to the corresponding TSC1, TSC2 and TSC3 thiosemicarbazone compounds. The isolated compounds are air stable and insoluble in $\mathrm{H}_{2} \mathrm{O}$, but easily soluble in DMF or DMSO. Different analytical tools were employed to identify the structure of prepared compounds. The results from the basic analysis are well in line with the calculated results for the proposed formula. The novel thiosemicarbazone compounds structure is revealed in Fig. 1.

\subsubsection{IR spectrum}

Preliminary allocations of major IR spectrum bands of thiosemicarbazone compounds display the following features:

1- Disappearance of the $v(>\mathrm{C}=\mathrm{O})$ and emergence of new band at $1603-1615 \mathrm{~cm}^{-1}$ that refers to $v(\mathrm{C}=\mathrm{N})$ stretching vibration [55] supporting condensation reaction and formation of thiosemicarbazone compounds.

2-Thiosemicarbazone compounds can exhibit thione $\leftrightarrow$ thiol tautomerism [56] as a result of the existence of $-\mathrm{NH}-\mathrm{C}=\mathrm{S}$ linkage but $v(\mathrm{~S}-\mathrm{H})$ absorption band at $2500-2600 \mathrm{~cm}^{-1}$ was absent with an appearance of $v(\mathrm{C}=\mathrm{S})$ band around $750 \mathrm{~cm}^{-1}$ indicating existence of the prepared thiosemicarbazone compounds as thione form in the solid state.

3-For the prepared thiosemicarbazone compounds, vibrational bands with the wave numbers of $3012 \mathrm{~cm}^{-1}\left(v_{\mathrm{C}-\mathrm{H}}, \mathrm{Ar}-\mathrm{H}\right), 1615 \mathrm{~cm}^{-1}\left(v_{\mathrm{C}=\mathrm{N}}\right), 1548 \mathrm{~cm}^{-1}\left(v_{\mathrm{C}=\mathrm{C}}\right), 1082 \mathrm{~cm}^{-1}\left(v_{\mathrm{N}-\mathrm{N}}\right)$ were detected. 4- Vibrational bands with the wave numbers of, 3019-3045 $\mathrm{cm}^{-1}\left(v_{\mathrm{C}-\mathrm{H}}, \mathrm{Ar}-\mathrm{H}\right), 1601-1615 \mathrm{~cm}^{-1}$ $\left(v_{\mathrm{C}=\mathrm{N}}\right), 1535-1553 \mathrm{~cm}^{-1}\left(v_{\mathrm{C}=\mathrm{C}}\right), 1065-1100 \mathrm{~cm}^{-1}\left(v_{\mathrm{N}-\mathrm{N}}\right)$ were observed for thiosemicarbazone compounds.

5- The $v_{\text {sym }}$ and $v_{\text {asym }}$ of TSC1 amino group were observed at 3234 and $3386 \mathrm{~cm}^{-1}$. 
6- In the thiosemicarbazone compounds spectra, the bands observed in the range 1494-1532, 1249-1251, 1017-1088,748-817 $\mathrm{cm}^{-1}$ are assigned to the thioamide bands, I, II, III and IV respectively [57].

\subsubsection{NMR spectrum}

${ }^{1} \mathrm{H}-\mathrm{NMR}$ spectra of novel TSC1, TSC2 and TSC3 compounds in DMSO-d $\mathrm{d}_{6}$ display no resonance at approximately $4.0 \mathrm{ppm}$ corresponding to $-\mathrm{SH}$ proton resonance [58], whereas the presence of a peak at $10.77 \mathrm{ppm}$ (signal field of existence of $\mathrm{NH}$ group next to $\mathrm{C}=\mathrm{S}$ ) suggests that they remain in the thione form even in polar solvent like DMSO. Signals for the methine proton of azomethine group for thiosemicarbazone compounds, $\mathrm{CH}=\mathrm{N}$ was detected at $\delta=7.48-7.61 \mathrm{ppm}$. In the region of 6.36-7.54 ppm chemical shifts were allocated for hydrogen of the aromatic ring. Methyl group was observed as a singlet signal at $\delta=2.02-2.20$. The spectra of TSC1 compound show signals at $\delta 7.80 \mathrm{ppm}$ assigned to the $\mathrm{NH}_{2}$ proton.

The ${ }^{13} \mathrm{C}$-NMR spectra of novel thiosemicarbazone compounds were carried out in DMSO-d6. Peaks of azomethine carbons and $\mathrm{C}=\mathrm{S}$ of thiosemicarbazone compounds were observed as singlet peaks. The signal for the carbon atom of $\mathrm{C}=\mathrm{S}$ was detected at 178.3, 177.8, 178.1 in TSC1, TSC2 and TSC3 respectively.

\subsubsection{UV-Vis spectrum}

The strong absorption band detected at $33003-32787 \mathrm{~cm}^{-1}$ were assigned to $\pi \rightarrow \pi^{*}$ transitions $(\mathrm{C}=\mathrm{N})$ azomethine group while the possible assignments for the bands at 26809-27548 $\mathrm{cm}^{-1}$ are attributed to the $\mathrm{n} \rightarrow \pi^{*}$ thiosemicarbazone compounds transitions, respectively. Forever $\pi \rightarrow \pi^{*}$ transitions occur at higher energy than $n \rightarrow \pi^{*}$ transitions [59].

\subsubsection{Mass spectra}

The proposed formulae can be further proven by mass spectroscopy. The electron impact mass spectrum of TSC 1 confirms the suggested formula by displaying a peak at 249 equivalents to $\left(\mathrm{C}_{11} \mathrm{H}_{15} \mathrm{~N}_{5} \mathrm{~S}\right)$ compound moiety in addition to a series of peaks which attributable to different fragments of TSC1 compound. These data suggest that a ketone PTHP group is condensed with the $\mathrm{NH}_{2}$ group of thiosemicarbazide or its derivatives. The mass spectra of TSC1, TSC 2 and TSC3 showed peaks at 249, 277 and 325 confirming the proposed structural formula of the synthesized TSC1, TSC2 and TSC3 compounds respectively.

\subsubsection{Crystallography}

The structure of the two of the representing thiosemicarbazone compounds (TSC2 and TSC3) was established through X-ray crystallography. Recrystallisation of the compounds 
from hot ethanol followed by slow evaporation leads to formation of single crystals. Data of TSC 2 and TSC3 are summarized in the Table 1, CCDC 2026108 and CCDC 2033322 contain the supplementary crystallographic data for this paper.

The X-ray single-crystal structures of monomeric TSC2 and TSC3 compounds were given in Fig. 2a and 2b, respectively. It suggested that TSC2 was crystallized in monoclinic crystal system with space $\mathrm{P} 2{ }_{1} / \mathrm{c}, \mathrm{a}=27.985$ (12) $\AA, \mathrm{b}=12.027$ (5) $\AA$, c = 9.833 (4) $\AA, \alpha=$ $90.0^{\circ}, \beta=93.117(11)^{\circ}, \gamma=90.0^{\circ}, \mathrm{V}=3486.57 \AA^{3}, \mathrm{Z}=7$ while TSC 3 was crystallized also in monoclinic crystal system with space $\mathrm{P} 2{ }_{1} / \mathrm{c}, \mathrm{a}=11.2343$ (6) $\AA$, b $=11.2575$ (7) $\AA$, c $=11.8995$ (8) $\AA, \alpha=90.00^{\circ}, \beta=94.476(6)^{\circ}, \gamma=90.0^{\circ}, V=1500.34(3) \AA^{3}, Z=4$.

$\mathbf{a}$

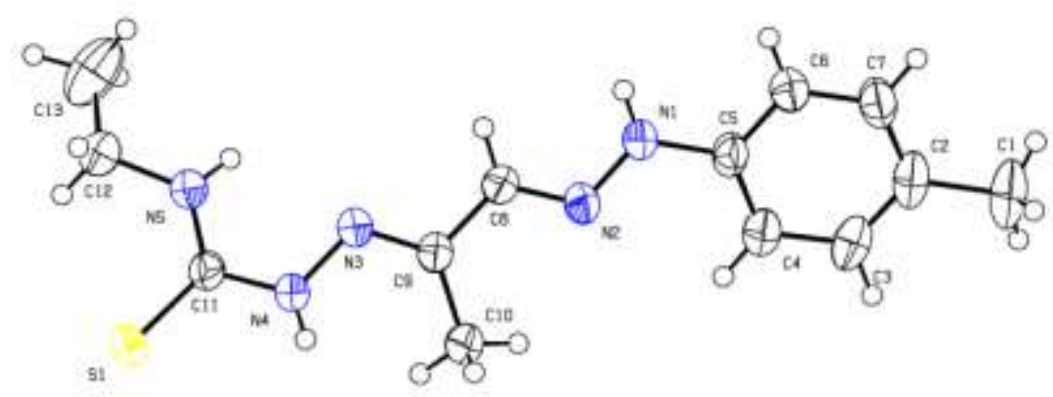

b

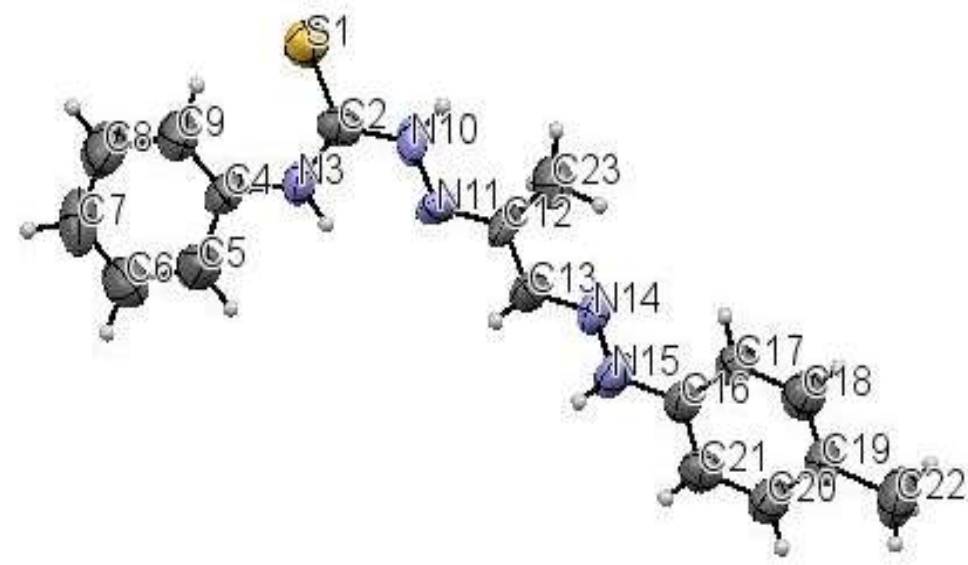

Fig. 2. X-ray structure of a) TSC2 b) TSC3 thiosemicarbazone compounds along with the atom numbering scheme.

It is worth to mention that TSC2 molecules are stacked non-covalently altogether via inter-molecular interactions i.e. van der Waals as well as H-bonding interactions. This is can be clearly illustrated in Fig. 3. The packing structures of TSC2 and TSC3 compounds is shown in the Supplementary Fig. S5a and S5b, respectively. In the packing structure of TSC2 and TSC3 molecules, the unit cell includes four and seven molecules stacked to each other's per unit cell, respectively. 


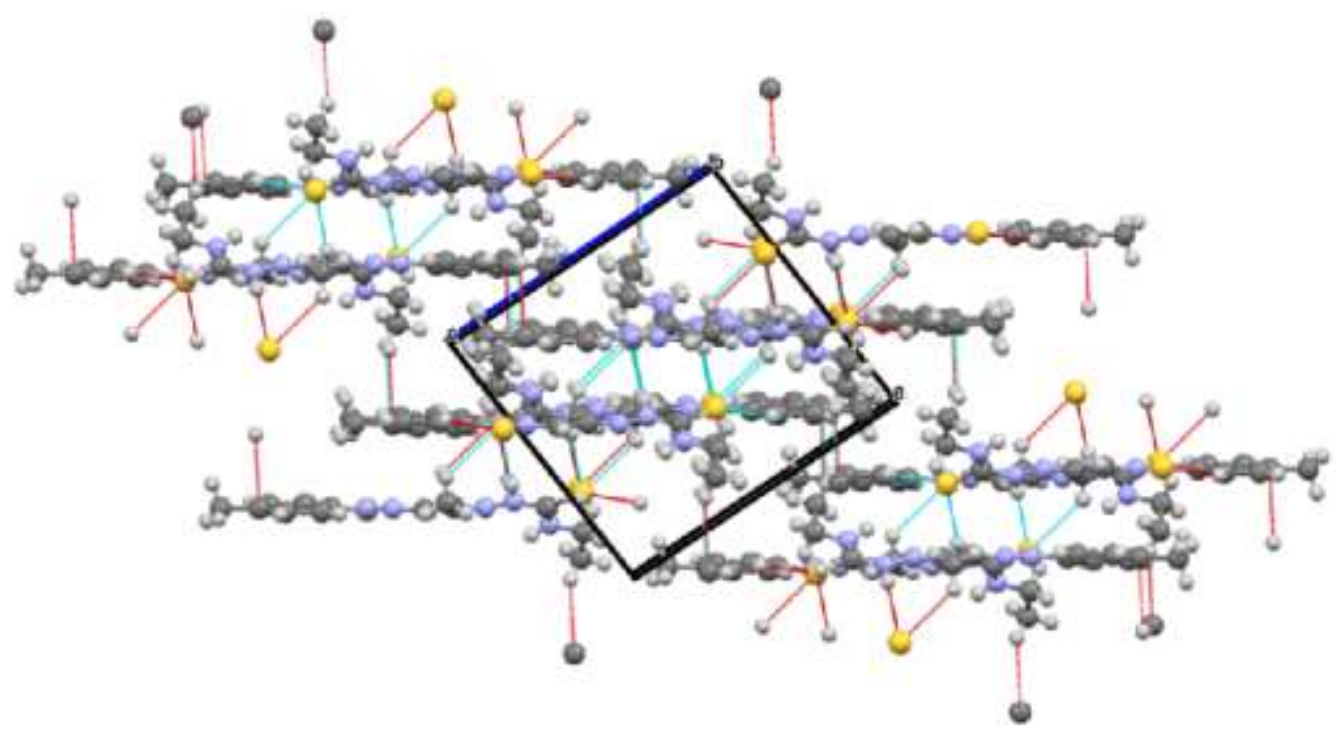

Fig. 3. Expansion of the intermolecular interactions (i.e. van der Waals interaction) between TSC2 molecules.

\subsubsection{Molecular modeling and/or Molecular parameters}

Quantum parameters like $\mathrm{E}_{\mathrm{HOMO}}, \mathrm{E}_{\mathrm{LUMO}}$, in addition to specific parameters like ionization potential (IP), absolute softness $(\sigma)$, absolute hardness $(\eta)$, electron affinity (EA), separation energy $(\Delta \mathrm{E})$, absolute electronegativity $(\chi)$, global softness (S), electrophilicity (w), electron accepting power $\left(\mathrm{w}^{+}\right)$, electron donating power $\left(\mathrm{w}^{-}\right)$and additional electronic charge ( $\left.\Delta \mathrm{N}_{\max }\right)$ [60-64] have been computed according to Eqs 2-11 as shown below [60-65]. The inverse of the global hardness is called softness $\sigma$ [66].

$\chi=-1 / 2\left(\mathrm{E}_{\mathrm{LUMO}}+\mathrm{E}_{\mathrm{HOMO}}\right)$

$\mathrm{IP}=-\mathrm{E}_{\mathrm{HOMO}}$

$\eta=1 / 2\left(\mathrm{E}_{\mathrm{LUMO}}-\mathrm{E}_{\mathrm{HOMO}}\right)$

$\mathrm{S}=1 / 2 \eta$

$\Delta \mathrm{N}_{\max }=-\mathrm{IE} / \eta$

$\sigma=1 / \eta$

$\mathrm{EA}=-\mathrm{E}_{\text {LUMO }}$

$\omega=\mathrm{IE}^{2} / 2 \eta$

$\omega^{-}=(3 * \mathrm{IE}+\mathrm{EA})^{2} / 16(\mathrm{IE}-\mathrm{EA})$

$\omega^{-}=(\mathrm{IE}+3 * \mathrm{EA})^{2} / 16(\mathrm{IE}-\mathrm{EA})$ 
Since the geometric optimization of the prepared compounds can be characterized using theoretical calculations; therefore, the optimized structure for the synthesized compounds could be obtained by calculating theoretical physical parameters like bond lengths and bond angles using DFT calculations.

Quantum parameters of the synthesized TSC1, TSC2 and TSC3 compounds have been calculated using Eqs. 2-11. From data given in Table 2 and Table 3, we can deduce each of the following:

a) HOMO and LUMO are frontier molecular orbitals (FMOs). The energies of HOMO and LUMO are -ve, which designate the studied TSC1, TSC2 and TSC3 thiosemicarbazones are stable molecules [65].

b) HOMO and LUMO act as an electron donor and acceptor respectively. [66,67].

c) Hard and soft nucleophiles have low and high HOMO energies respectively while hard and soft electrophiles have high and Low LUMO energies respectively.

d) The energies of HOMO of (TSC1), (TSC2) and (TSC3) are closely spaced (EHOMO, (TSC1) -8.501 eV; Еномо, (TSC2) -8.561 eV and Еномо (TSC3) -8.556 eV).

e) Soft molecules are characterized by small energy gap ( LUMO- $_{\text {HOMO }}$ ) and higher reactivity than hard ones as a result of their ease donation of electrons to an acceptor $[68,69]$.

f) Large values of the HOMO-LUMO energy gap (7.410-7.667) means good stability and a large chemical hardness for the synthesized thiosemicarbazone compounds.

g) Absolute hardness $(\eta)$ and softness $(\sigma)$ are essential characteristics in calculation of molecular stability and reactivity. Hard molecules have a large energy gap with less reactivity $\left(\Delta \mathrm{E}=\mathrm{E}_{\mathrm{HOMO}}-\mathrm{E}_{\mathrm{LUMO}}\right)$, whereas the soft molecules have a smaller energy space and a greater reactivity. This means that $\Delta \mathrm{E}$ is an indicator of stability and can be used to measure the chemical reactivity and kinetic stability of the compound $[67,70]$.

h) When HOMO energy decreases, the molecule's ability to donate electron decreases while high HOMO energy means that the molecule is an efficient donor of electrons. LUMO energy indicates a molecule's ability to receive an electron.

i) The electrophilicity index $(\omega)$ follow the trend: $\operatorname{TSC} 1(\omega=3.104)>\operatorname{TSC} 2(\omega=2.936)>$ TSC3 $(\omega=2.933)$. Thus, compound (TSC1) shows the maximum value of electrophilicity which confirms its largest capability to accept electrons.

j) The HOMO level in the thiosemicarbazone compounds are commonly localized on the $\mathrm{C}=\mathrm{N}$ groups demonstrating they are the favored sites for $\mathrm{Nu}$ attack at the central metal ion. 
k) Negativity of $\mathrm{E}_{\mathrm{HOMO}}$ and $\mathrm{E}_{\text {LUMO }}$ indicates thiosemicarbazone compounds stability [71].

\subsection{Biological activity}

\subsubsection{Antibacterial and antifungal activities:}

Antimicrobial activities of thiosemicarbazone compounds were screened. Results of antimicrobial activity of thiosemicarbazone compounds versus all tested microbes are shown in Table 4. The following observations were deduced:

a) The investigation of the biological action of TSC3 on Gram-negative and Gram-positive bacteria indicated that TSC3 was inactive against the tested organisms.

b) The thiosemicarbazone compound TSC1 possess effective antibacterial activity versus the tested bacterial strains

c) TSC2 has a moderate antibacterial activity versus Steptococcus faecalis as gram-positive and Escherichia coli as gram-negative bacteria

d) According to results of antifungal activity screening, the TSC1 compound possesses a very higher antifungal activity versus Candida albicans more than Amphotericin as standard antifungal agent.

\subsubsection{Antitumor activities:}

Cytotoxic study of thiosemicarbazones was investigated versus liver cancer cell line (HepG2) and breast cancer cell line (MCF-7). IC $_{50}$ is the concentration which can diminish cancer cells growth by $50 \%$ (Supplementary Fig. 7c). The results of cytotoxic study indicate that, TSC1 compound shows significant activity versus HepG2 and MCF-7 cells with $\mathrm{IC}_{50}$ value of 29.4 and $122 \mu \mathrm{g} / \mathrm{ml}$ respectively (Table 5) while the IC $_{50}$ towards HepG2 and MCF-7 cells for TSC2 are 46 and $172.9 \mu \mathrm{g} / \mathrm{ml}$ respectively. Furthermore, the $\mathrm{IC}_{50}$ towards HepG2 and MCF-7 cells for TSC3 are 25 and $107 \mu \mathrm{g} / \mathrm{ml}$ respectively. The antitumor results indicate that the synthesized thiosemicarbazone compounds are more effective versus HepG2 than MCF-7. The antitumor activity of the synthesized thiosemicarbazone compounds towards both HepG2 and MCF-7 cell lines obeys this order TSC3 > TSC1 > TSC2.

\subsubsection{Molecular modeling and biological activity}

Theoretical calculations were performed with the purpose of physicochemical properties investigation that possibly correlated to the antimicrobial action of investigated thiosemicarbazones. From the obtained data, we can deduce that: 
a) TSC1 thiosemicarbazone compound, which offered the lowest value of HOMO energy among the synthesized thiosemicarbazone compounds, showed the highest biological activity among the synthesized compounds.

b) Inverse relation between dipole moment and lipophilicity indicates that as dipole moment decreases, the lipophilic nature of the compound increases, which favors its penetration more powerfully via lipid layer of microorganism [72,73], thus destroying them more violently. From the results in Table 3, the lipophilicity of the TSC1 is larger than the other thiosemicarbazone compounds, which sequentially deactivates enzymes accountable for respiration process of the investigated microbes more than other compounds and accordingly increase its cellular uptake by bacterial cells.

c) Thiosemicarbazone compounds have antibacterial activity due to existence of toxophorically essential imine groups $(-\mathrm{C}=\mathrm{N})$ where the action mode of these compounds could include formation of H-bonds via azomethine group with an active center of cells which may interfere with ordinary cell processes [74].

\subsection{Equilibrium Studies}

The protonation constants of TSC1 ligand are calculated (Table 6). These ligands behave as triprotic as shown by Eqs. 15-17.

$$
\begin{array}{ll}
\mathrm{L}^{-}+\mathrm{H}^{+} \rightleftharpoons \mathrm{HL} ; & \mathrm{K}_{1}=\frac{[\mathrm{HL}]}{\left[\mathrm{L}^{-}\right]\left[\mathrm{H}^{+}\right]} \\
\mathrm{HL}+\mathrm{H}^{+} \rightleftharpoons \mathrm{H}_{2} \mathrm{~L}^{+} ; & \mathrm{K}_{2}=\frac{\left[\mathrm{H}_{2} \mathrm{~L}^{+}\right]}{[\mathrm{HL}]\left[\mathrm{H}^{+}\right]} \\
\mathrm{H}_{2} \mathrm{~L}^{+}+\mathrm{H}^{+} \rightleftharpoons \mathrm{H}_{3} \mathrm{~L}^{2+} ; & \mathrm{K}_{3}=\frac{\left[\mathrm{HL}^{2+}\right]}{\left[\mathrm{H}^{+}\right]\left[\mathrm{H}_{2} \mathrm{~L}^{+}\right]}
\end{array}
$$

We can conclude that the $1^{\text {st }}$ and $2^{\text {nd }}$ deprotonation constants correspond to the deprotonation of the two N-imino sites in TSC ligand as given in Scheme $3 \mathrm{a}$. While the $3^{\text {rd }}$ deprotonation constant correspond to the thiolate group site in TSC ligand as shown in Scheme 3b. However, a similar conclusion was obtained in literature [75]. 
a

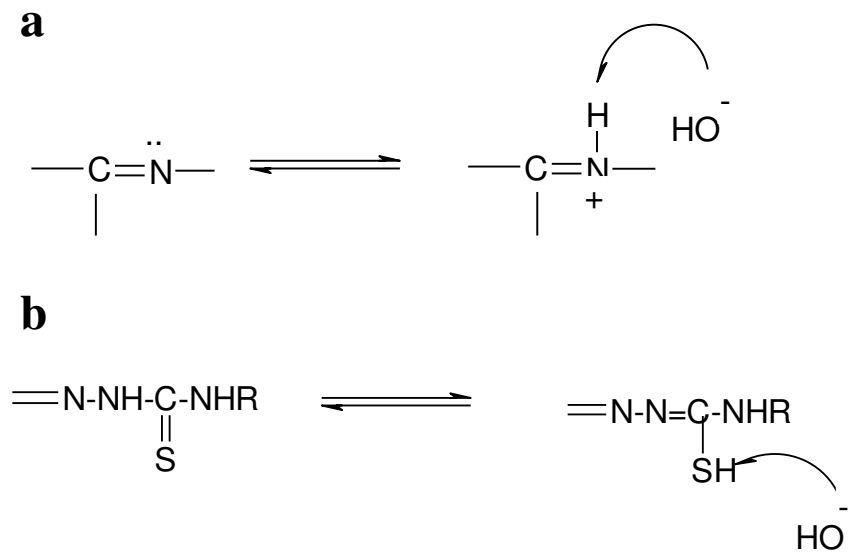

Scheme 3. a) Possible deprotonation pathway of the imino groups, b) Possible deprotonation pathway of the thiolate group.

The $\log \mathrm{K}_{\mathrm{N} \text {-imino }}$ values ranges from (2.97-3.35) are similar to those found in the literature for the imino group (4.40) [76]. The $\log \mathrm{K}_{\mathrm{SH}}$ value ranges from (7.65-8.05) are similar to those described in the literature for the thiolate group (5.5-9.0) [77].

Protonation equilibria study for the TSC ligands under study cannot be performed in aqueous solution since it is insoluble in $\mathrm{H}_{2} \mathrm{O}$. DMSO solvent has been extensively used for potentiometric studies of both protonation and formation equilibria. The mixture DMSOwater $50 \%: 50 \%$ was best-preferred solvent to give soluble and stable Schiff base solution $[58,79]$. 
a

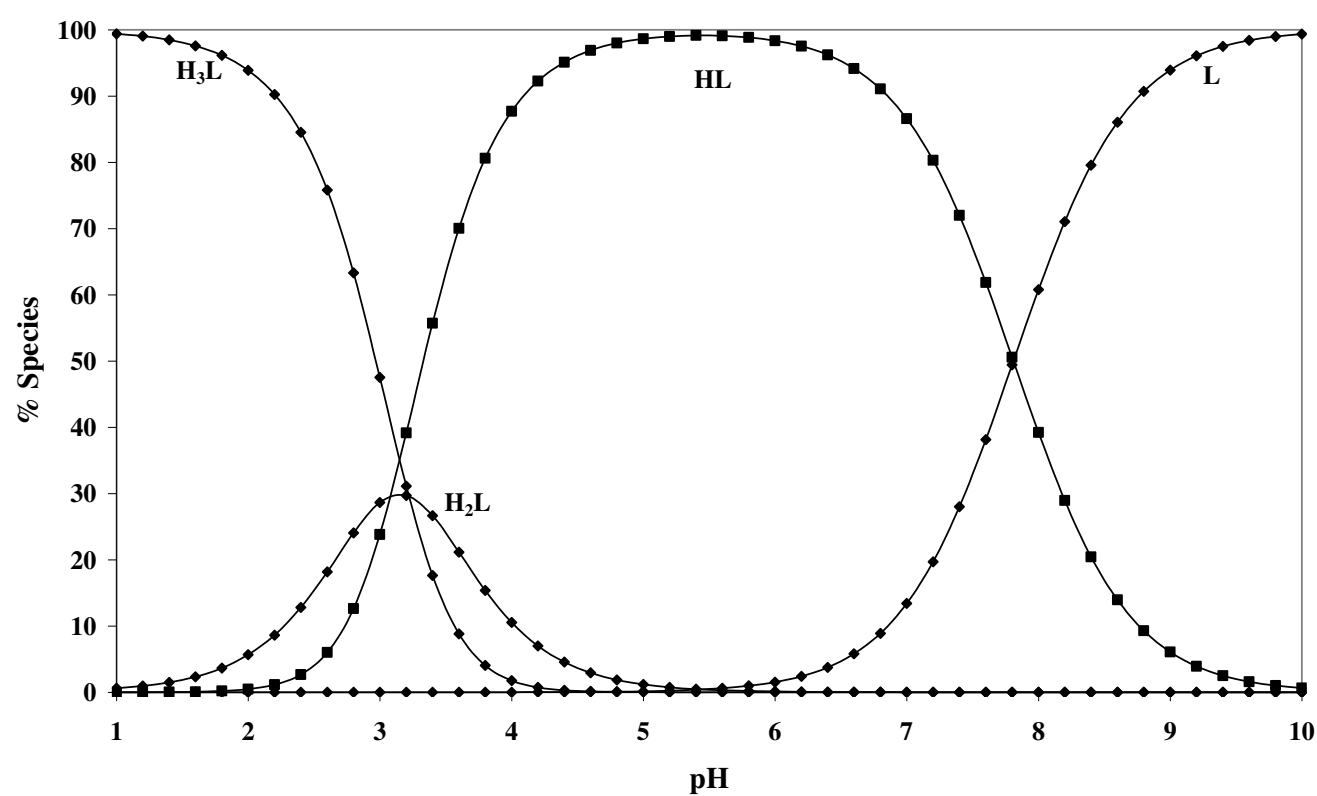

b

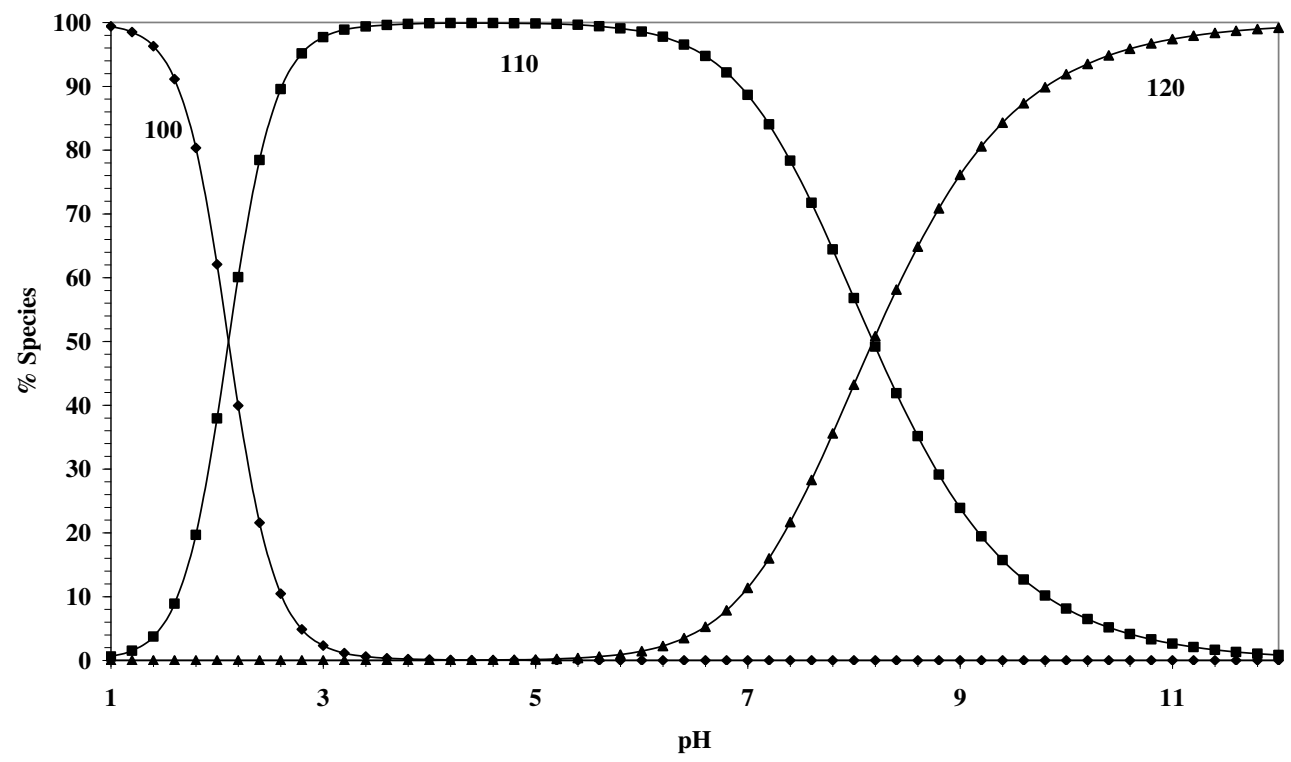

Fig. 4. a) Concentration distribution diagram of various species as a function $\mathrm{pH}$ in the TSC1 system (at concentration of TSC1 $=1.25 \mathrm{mM} \mathrm{T}=25^{\circ} \mathrm{C}$ ), b) Concentration distribution diagram of various species as a function $\mathrm{pH}$ in the $\mathrm{Cd}-\mathrm{TSC} 1$ system

Herein, three protonation constants were calculated for TSC1 ligand and the SPECIES program was utilized to give the distribution of TSC1 ligand species as a function of $\mathrm{pH}$. In Fig. 4a a classic species distribution diagram is reported; it is possible to highlight, at the mentioned experimental conditions, the $\mathrm{pH}$ ranges at which the various species are formed 
and/or where they coexist, as well as their relative formation percentages. Thus, the species distribution graph is a good tool for obtaining complete picture about the concentration of each species present as a function of $\mathrm{pH}$. It enables us to obtain the best conditions for preparation a solid complex as $\mathrm{pH}$, concentration and ligand: metal ratio. At low $\mathrm{pH}$, (TSC1) exists initially in a fully protonated form with maximum percent of $100 \%$ as $\mathrm{H}_{3} \mathrm{~L}$ below $\mathrm{pH}<$ 2. On addition of base, $\mathrm{pH}$ value increases so the $\left(\mathrm{H}_{3} \mathrm{~L}\right)$ species loses its first proton from an imino group to form $\left(\mathrm{H}_{2} \mathrm{~L}\right)$, which is the major species at $\mathrm{pH}=3.3$. As conditions become more alkaline, the second proton released from the second imino group begins deprotonation to HL ligand accomplish highest percent of $99.1 \%$ at $\mathrm{pH}=5.8$. More increase of $\mathrm{pH}$ is followed by liberation of the third $\mathrm{H}^{+}$forming the fully deprotonated ligand $\mathrm{L}$ with maximum percent species $98.4 \%$ at $\mathrm{pH}=10.0$.

\subsubsection{Species distribution curves}

The calculation of equilibrium complex concentrations of Cd(II) with TSC1 (Table 7) as a function of $\mathrm{pH}$ gives a valuable picture of metal(II) binding in the biological system. As an illustrative example of metal complexes, Fig. 4b showed a concentration distribution diagram for the complex $\mathrm{Cd}$ (II)-TSC1. The Cd-TSC1 complex begins to form in acidic $\mathrm{pH}$ range reaching a constant concentration of $99.9 \%$ at $\mathrm{pH}=5.0$, whereas $\mathrm{Cd}(\mathrm{TSC} 1)_{2}$ complex species reaches a maximum concentration of $45 \%$ at $\mathrm{pH} 9.8$.

\subsubsection{Thermodynamics}

The data derived for $\Delta \mathrm{H}^{\mathrm{o}}, \Delta \mathrm{S}^{\mathrm{o}}$ and $\Delta \mathrm{G}^{\mathrm{o}}$ related to protonation of TSC1 and $\mathrm{Cd}(\mathrm{II})-$ complex formation were calculated from the data tabulated in tables 8 and $9 . \Delta \mathrm{H}^{\mathrm{o}}$ for the ligand protonation or complexation was determined from the plot slope (Fig. 5a-b) through graphical representation of the Van't Hoff equation

$$
-2.303 \mathrm{R} T \log _{10} \mathrm{~K}=\Delta \mathrm{H}^{\mathrm{o}}-\mathrm{T} \Delta \mathrm{S}^{\mathrm{o}}
$$

or

$$
\log \mathrm{K}_{10}=-\left(\Delta \mathrm{H}^{\mathrm{o}} / 2.303 \mathrm{R}\right)(1 / \mathrm{T})+\Delta \mathrm{S}^{\mathrm{o}} / \mathrm{R}
$$

With the well-known relations (6) and (7), from the values of $(\Delta G)$ and enthalpy change $(\Delta \mathrm{H})$, one can calculate $(\Delta \mathrm{S})$ :

$$
\begin{aligned}
& \Delta \mathrm{G}^{\mathrm{o}}=-2.303 \mathrm{RT} \log _{10} \mathrm{~K} \\
& \Delta \mathrm{S}^{\mathrm{o}}=\left(\Delta \mathrm{H}^{\mathrm{o}}-\Delta \mathrm{G}^{\mathrm{o}}\right) / \mathrm{T}
\end{aligned}
$$


$\mathbf{a}$
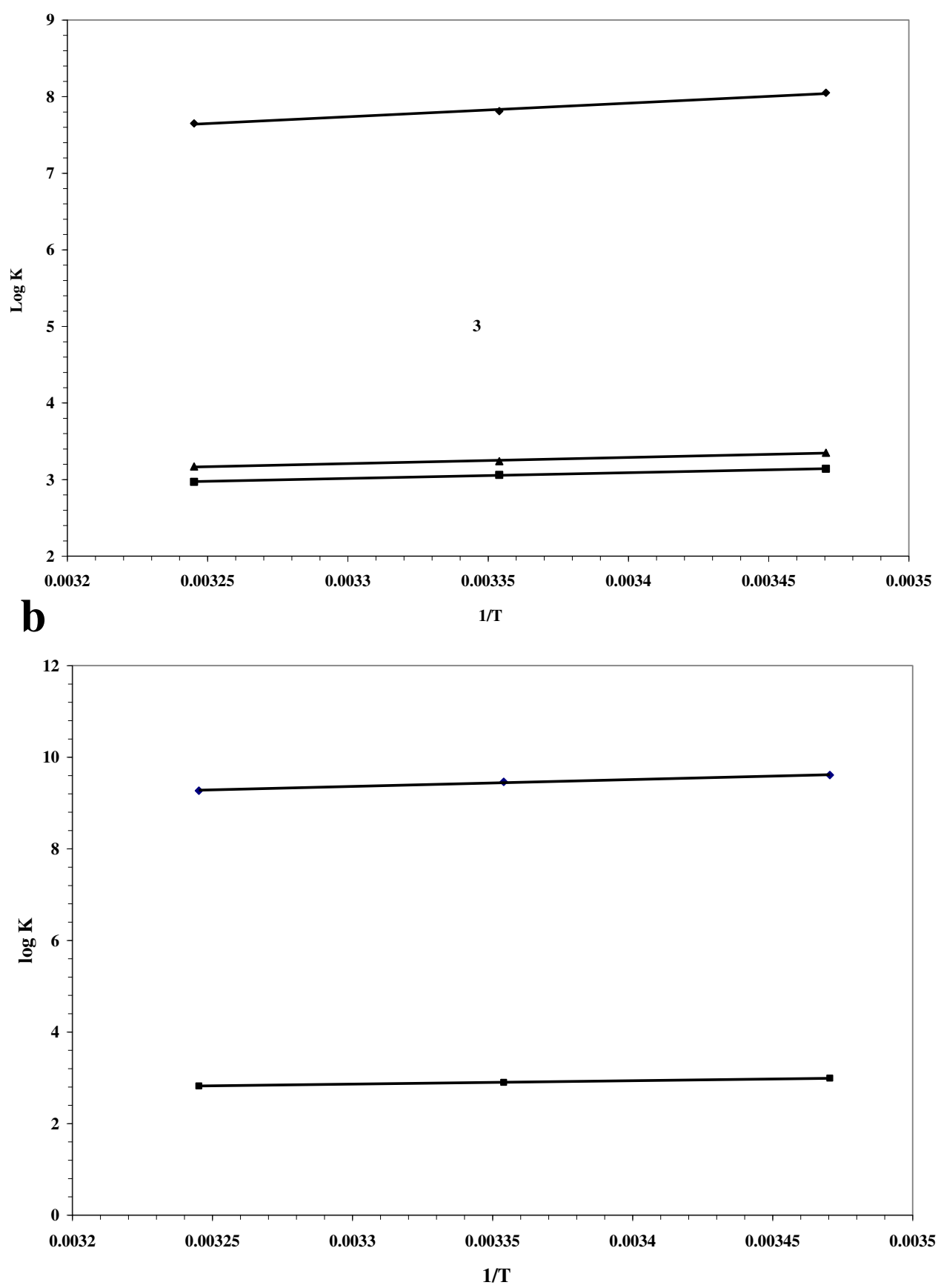

Fig. 5. a) Effect of temperature on the protonation constant of TSC1 compound, b) Effect of temperature on the formation constant of $\mathrm{Cd}(\mathrm{II})-\mathrm{TSC} 1$ complexes.

The main reasons for the protonation constant determination can be explained as follows:

(1) The ratio and $\mathrm{pH}$ of the various substance forms can be determined using its protonation constants. 
(2) Very useful in preparation of newly synthesized compounds. The suggested structure can be reliable where protonation constants are theoretically well calculated according to the experimental values.

(3) Because different types of substances have different UV spectrums, quantitative spectrophotometric analysis can be performed by choosing the appropriate $\mathrm{pH}$ value. To choose the $\mathrm{pH}$ values, the known protonation constants are required.

(4) Buffer solutions preparations at different $\mathrm{pH}$ values needs determination of protonation constants $[43,80]$,

(5) Measurements of the stability constants for the complicated formation reactions of bioactive ion compounds require protonation constants to be determined.

Additionally, their protonation constants are used for calculating the stability constants of the dynamic formation of bioactive compounds with metal ions [81].

(6) The equilibrium constants of certain compounds must be understood to measure concentration of each ionized species at $\mathrm{pH}$ which is fundamental to understand their physiochemical behavior [81].

Tables 8, 9 describes the thermodynamic functions measured and can be interpreted as:

1. The corresponding thermodynamic processes for the protonation reactions are:

a) Exothermic processes for neutralization reactions;

ii) Endothermic for ions desolvation;

iii) Structure alteration and alignment of $\mathrm{H}$-bonds around protonated and free ligands.

2. When the temperature rises the value of $\log _{10} \mathrm{~K}^{\mathrm{H}}$ decreases and its acidity rises as the temperature rises.

3. Negative $\Delta \mathrm{H}^{\mathrm{o}}$ for protonation of TSC1 ligand indicates that this process is exothermic followed by heat release.

4. Positive entropy of TSC1 protonation reaction indicates increased disorder due to desolvation processes and breakdown of H-bonds.

Table 7 includes the stepwise stability constants of the complexes formed at various temperatures. Such values decrease and confirm with increasing temperature that the phase of complexation is preferred at low temperature.

These results provide the following findings:

1-Negative $\Delta \mathrm{H}^{\mathrm{o}}$ show that the coordinating process is exothermic suggesting that the metalligand bonds are fairly strong and complexity reactions are preferred at low temperatures. 
2- Complexation reaction is spontaneous with negative $\Delta \mathrm{G}^{\circ}$.

3-It is commonly found that $\Delta \mathrm{G}^{\mathrm{o}}$ and $\Delta \mathrm{H}^{\mathrm{o}}$ values for the 1:1 complexes are more -ve than those corresponding to the $1: 2$ complexes.

4-This can be due to both steric hindrances caused by addition of $2^{\text {nd }}$ ligand in addition to principle of charge neutralization.

5-The electrostatic attraction in the 1:1 complex is larger than in the 1:2 complex since 1:1 complex is formed by dipositively charged $\mathrm{M}^{\mathrm{n}+}$ and mononegatively charged ligand anion interaction; while 1:2 complex is generated by monopositively charged 1:1 complex and mononegatively charged ligand anion interaction.

6-The $\Delta S^{o}$ values for all investigated complexes are +ve indicating that entropy increase resultant from release of bound solvent molecules on coordination is larger than the decrease resultant from coordination process itself due to the ordered arrangement of solvent molecules around the ligand and $\mathrm{M}^{\mathrm{n}+}$ gains a random coordination pattern. This is referred to as increase in entropy for configuration.

\section{Conclusions}

1-(p-tolylhydrazono)-propan-2-one (PTHP) is condensed with thiosemicarbazide, Nethylthiosemicarbazide and N-phenylthiosemicarbazide in the molar ratio (1:1) affording the novel TSC1, TSC2 and TSC3 thiosemicarbazone compounds. The novel series of thiosemicarbazones were characterized using different analysis tools. The IR spectra indicated that, thiosemicarbazone compounds present in thione form in the solid state. Antifungal activity showed equipotent antifungal activity of TSC1 or even more antifungal activity when matched to the reference standard amphotericin reference drug versus Candida albicans. Thus, TSC1 compound is considered as a hopeful compound for extra variation to get clinically valuable antifungal agent versus Candida albicans. SAR studies proved that there is an inverse relationship between dipole moment and antimicrobial activity which could help 
in the design of more powerful antibacterial substances. Potentiometric studies have shown that thiosemicarbazone compound (TSC1) form complexes 1:1 or 1:2 with $\mathrm{Cd}(\mathrm{II})$ ion. The $\log$ $\mathrm{K}_{1}$ and $-\Delta \mathrm{H}_{1}$, for $\mathrm{Cd}(\mathrm{II})-\mathrm{TSC} 1$ thiosemicarbazone complexes are to some extent larger than $\log \mathrm{K}_{2}$ and $-\Delta \mathrm{H}_{2}$, indicating a change in ligand dentate character from tridentate (SNNdonors) in 1:1 chelates to bidentate ( $\mathrm{SN}$-donors) in 1:2; M:L chelates in addition to steric hindrance generated by entry of $2^{\text {nd }}$ molecule. The coordination of Cd(II) to TSC1 has been found to be spontaneous, exothermic and entropically favorable. Molecular properties of the synthesized thiosemicarbazone compounds have been investigated by means of DFT calculations. These compounds may be considered as a good remedy for $\mathrm{Cd}^{2+}$ ion toxicity as it forms a highly stable complex with it. Variation of substitution in N-thiosemicarbazide moiety was considered as a vital key for functionalization of synthesized compounds owing to its significance in the inhibition process.

\section{Abbreviations}

PTHP: 1-(p-tolylhydrazono)-propan-2-one

TSC1: ((E)-2-((E)-1-(2-(p-tolyl)hydrazono)propan-2-ylidene)hydrazine-1-carbothioamide,

TSC2: ((E)-N-ethyl-2-((E)-1-(2-(p-tolyl)hydrazono)propan-2-ylidene)hydrazine-1-carbothioamide, TSC3: ((E)-N-phenyl-2-((E)-1-(2-(p-tolyl)hydrazono)propan-2-ylidene)hydrazine-1-carbothioamide 


\section{References}

[1] World health statistics, WHO Library Cataloguing-in-Publication Data (2014).

[2] A. Anandan, G.L.Evans, K. Condic-Jurkic, M.L. O'Mara, C.M. John, N.J., G.A. Jarvis, S.S. Wills, K.A. Stubbs, I. Moraes, C.M. Kahler, A. Vrielink, Proc Natl Acad Sci. 114(9) (2017) 2218-2223.

[3]. Harbottle, H.; Thakur, S.; Zhao, White, D. G. Anim. Biotechol. 2006, 17, 111-124.

[4] B. Li , T.J. Webster, J Orthop Res. 36(1) (2018) 22-32.

[5]. Berger, S. Horm. Metab. Res. 1985, 17, 111-115.

[6]. Lakshmi, B.; Avaji, P. G.; Shivananda, K. N.; Nagella, P.; Manohar, S. H.; Mahendra, K. N. Polyhedron 2011, 30, 1507-1515.

[7]. Chan, J.; Huang, Y.; Liu, G.; Afrasiabi, Z.; Sinn, E.; Padhye, S.; Ma, Y. Toxicol. Appl. Pharm. 2004, 197, 40-48.

[8] K.J. Duffy, A.N. Shaw, E. Delorme, S.B. Dillon, C. Erickson-Miller, L. Giampa, Y. Huang, R.M. Keenan, P. Lamb, N. Liu, S.G. Miller, A.T. Price, J. Rosen, H. Smith, K.J.Wiggall, L. Zhang, J.I. Luengo, J. Med. Chem. 45 (2002) 3573.

[9] J.R. Dilworth, R. Hueting, Inorg. Chim. Acta 389 (2012) 3.

[10] Sarah A.Andres, Kritika baja, Nicholas S.Vishnosky,.Peterson, Mark S. Mashuta, Robert M.Buchanan, Paula j.Bates and Craig A. Grapperhaus, inorg.chem.59,7,(2020), 4924-4935.

[11] Peter Heffeter etal, antioxidants and redox signaling 30, 8, (2017), 7487.

[12] R.J. Glisoni, M.L. Cuestas, V.L. Mathet, J.R. Oubina, A.G. Moglioni, A. Sosnik, Eur. J. Pharm. Sci. 47 (2012) 596.

[13] X. Du, C. Guo, E. Hansel, P.S. Doyle, C.R. Caffrey, T.P. Holler, J.H.McKerrow, F.E. Cohen, J. Med. Chem. 45 (2002) 2695.

[14] D. Kovala-Demertzi, M.A. Demertzis, E. Filiou, A.A. Pantazaki, P.N. Yadav, J.R. Miller, Y. Zheng, D.A. Kyriakidis, Biometals 16 (2003) 411.

[15] J.P. Scovill, D.L. Klayman, D.G. Franchino, J. Med. Chem. 25 (1982) 1261.

[16] L. Klayman, J.P. Scovill, J.F. Bartosevich, J. Bruce, J. Med. Chem. 26 (1983) 35.

[17] D.K. Demertzi, M.A. Demertzis, J.R. Miller, C. Papadopoulou, C. Dodorou, G. Filousis, J. Inorg. Biochem. 86 (2001) 555.

[18] P.K. Singh, D.N. Kumar, Spectrochim. Acta A 64 (2006) 853.

[19] N. Bharti, S.S. Sharma, A. Azam, J. Bioorganic and Medicinal Chemistry 11 (2003) 2923-2929. 
[20] A. Walcourt, M. Loyevsky, D.B. Lovejoy, V. R. Gordeuk, D.R. Richardson, J. Biochemistry and Cell biology, 36 (2004) 401-407.

[20] A.A. El-Sherif, A. Fetoh, Y. Kh. Abdulhamed, G. M. Abu El-Reash, Inorganica Chimica Acta 480 (2018) 1-15

[21] O.M.I. Adly, A.A.A. Emara, Spectrochim. Acta Mol. Biomol. Spectrosc. 132 (2014) 91101.

[22] O.A. El-Gammal, T.H. Rakha, H.M. Metwally, G.M. Abu, El-Reash, Spectrochim. Acta Mol. Biomol. Spectrosc. 127 (2014) 144.

[23] R. Kaplanek, M. Havlík, B. Dolensky, J. Rak, P. Dzub_ak, P. Konecny, M. Hajdúch, J. Kr_alova, V. Kral, Bioorg. Med. Chem. 23 (2015) 1651-1659.

[24] M. M. Brzoska and J. Moniusko-Jakoniuk, Toxicol. 39, 967-980 (2001).

[25] I. M. Armitage, A. J. M. Schoot Viterkamp, J. R. Chlebowski, J. E. Coleman, ${ }^{113}$ Cd NMR As A Probe of The Active Sites of Metalloenzymes J. of Magnetic Resonance (1969), 29, 375-392 (1978).

[26] H. Beinert, Structure and Function of Copper Proteins: Report, On the Fourth La Cura Conference Held at Villa Giulia, Manziana, Rome, Italy, 4-8 September 1979, Coord. Chem. Rev., 33, 55-85 (1980).

[27] F. Jensen, Introduction to Computational Chemistry, Wiley, Chichester, UK, 1999.

[28] Y.D. Scherson, S.J. Aboud, J. Wilcox, B.J. Cantwell, J. Phys. Chem. 115 (2011) 11036.

[29] A.A. El-Sherif, J. Coord. Chem. 64 (7) (2011) 1240-1253.

[30] A.A. El-Sherif, J. Solution Chem. 41 (2012) 392-409

[31] N. Rabjohn, Organic Synthesis, Collective Volume 4, John Wiley and Sons Inc., 1963.

[32] A.A. El-Sherif, Inorg. Chim. Acta 362 (2009) 4991-5000

[33] A. Altomare, G.Cascarano, C. Giacovazzo, A., Guagliardi, M.C. Burla, G. Polidori, M. Camalli, J. Appl. Cryst. 27 (1994) 435.

[34] S. Mackay, C.J. Gilmore, C. Edwards, N. Stewart, K. Shankland, maXus Computer Program for the Solution and Refinement of Crystal Structures. Bruker Nonius, The Netherlands, MacScience, Japan \& The University of Glasgow (1999).

[35] C. K. Johnson, ORTEP-II. A Fortran Thermal-Ellipsoid Plot Program. Report ORNL-5138. Oak Ridge National Laboratory, Oak Ridge, Tennessee, USA (1976).

[36] A.A. El-Sherif, J. Solution Chem. 39, 131-151 (2010). 
[37] Bates, R.G., Determination of pH, Theory and Practice, 2nd edn. John Wiley and Sons, New York (1975).

[38] E.M.Woolley, D.G. Hurkot, L.G. Hepler, J. Phys. Chem. 74, 3908-3913 (1970).

[39] G.L. Van Uitert, C.G. Hass, J. Am. Chem. Soc. 75, 451 (1971).

[40] E.P. Serjeant, Potentiometry and potentiometric titrations. Wiley, New York (1984).

[41] A. Golcu, M. Tumer, H. Demirelli, R.A. Wheatley, Inorg. Chim. Acta 358, 1785-1797 (2005).

[42] A.E. Martell, R.J. Motekaitis, The Determination and Use of Stability Constants. VCH, Weinheim (1988).

[43] M. Meloun, J. Havel, E. Högfelt, Computation of Solution Equilibria: A Guide to Methods in Potentiometry, Extraction andSpectrophotometry; Ellis Horwood Limited: Chichester, Wiley, New York (1988).

[44] P. Gans, A. Sabatini, A. Vacca, Inorg. Chim. Acta 18, 237-239 (1976).

[45] L. Pettit, University of Leeds, Personal Communication.

[46] B.A. Delley, Int. J. Quantum Chem. 69, 423-433 (1998).

[47] B. Delley, From molecules to solids with the DMol ${ }^{3}$ approach. J. Chem. Phys. 113, 7756-7764 (2000).

[48] Materials Studio (Version 5.0), Copyright 2009. Accelrys software Inc., San Diego, USA.

[49] W.J. Hehre, L. Radom, P.V.R. Schlyer, J.A. Pople, Ab Initio Molecular Orbital Theory, Wiley, New York, (1986).

[50] B. Hammer, L.B. Hansen, J.K. Nrskov, Phys. Rev. B 59, 7413-7421 (1999).

[51] A. Matveev, M. Staufer, M. Mayer, N. Rösch, Int. J. Quantum Chem. 75, 863-873 (1999).

[52] A. W. Bauer, M.D., W. M. M. Kirby, M.D., J. C. Sherris, M.D., M. Turck, M.D., American Journal of Clinical Pathology, 45(4) (1966) 493-496.

[53] A. A. El-Sherif, J Solution Chem. 39 (2010) 1562-1581

[54] P. Skehan, R. Storeng, D. Scudiero, A. Monks, J. McMahon, D. Vistica, J.T. Warren, H. Bokesch, S. Kenney, M.R. Boyd, J. Natl. Cancer Inst, 82 (1990) 1107-1112.

[55] M. P. Swami, D. Gupta, M. Mohan, A.K. Srivastava, Prog. Natl. Acad. Sci. India A 1980, 50(3), 176-181.

[56]. Kurup, M. R. P.; Joseph, M. Synth. React. Inorg. Met. Org. Chem. 2003, 33, 275-281.

[57] D.M. Wileasn, D.T. Suprunchuk, Candian J. of Chem.,47, (1969) 1087-1089. 
[58] M. Aljahdali, A.A. EL-Sherif, Inorganica Chimica Acta 407 (2013) 58-68

[59]. Philip, V.; Suni, V.; Kurup, M. R. P. Polyhedron 2006, 25, 1931-1938.

[60] R.G. Pearson, J. Org. Chem. 54 (1989) 1423.

[61] P. Geerlings, F. De Proft, W. Langenaeker, Chem. Rev. 103 (2003) 1793.

[62] R.G. Parr, J. Am. Chem. Soc. 121 (1999) 1922.

[63] P.K. Chattaraj, S.Giri, J. Phys. Chem. A 111 (2007) 11116.

[64] G. Speie, J. Csihony, A.M. Whalen, C.G. Pie-Pont, Inorg. Chem. 35 (1996) 3519

[65] S.W. Xia, X. Xu, Y.L. Sun, Y.L. Fan, Y.H. Fan, C.F. Bi, D.M. Zhang, L.R. Yang, Chin. J. Struct. Chem. 25 (2006) 197-203.

[66] S. Sagdinc, B. Koksoy, F. Kandemirli, S.H. Bayari, J. Mol. Struct. 917 (2009) 63-70.

[67] R.G. Pearson, Hard and Soft acids and bases, Dowden, Hutchinson and Ross,

Stroudsburg, PA, 1973.

[68] K.H. Kim, Y.K. Han, J. Jung, Theor. Chem. Acc. 113 (2005) 233.

[69] A. Ghosh, A. Sarkar, P. Mitra, A. Banerji, J. Banerjee, S. Mandal, Manosi Das, J. Mol. Struct. 980 (2010) 7.

[70] J.I. Aihara; J. Phys. Chem. A 103 (1999) 7487.

[71] J.A. Wellman, F.B. Hulsbergen, J. Verbiest, J. Reedijk, J. Inorg. Nucl. Chem. 40 (1978) $143-147$

[72] A.A. El-Sherif, A. Fetoh, Y. Kh. Abdulhamed, G.M. Abu El-Reash, Inorg. Chim. Acta 480 (2018) 1-15.

[73] C. Jayabalakrishnan and K. Natarjan, Synth. React. Inorg. Met. -Org. Chem. 31 (2001) 983-991.

[74] A.A. El-Sherif, J. Inorg. Chim. Acta 360 (2007) 473-487.

[75] M. A. Hassan, A. El-Roudi, M. T. J. Quenawy, Pharm. Sci. 34 (1993) 253

[76] T. Gunduz, E. Kilic, F. Koseoglu and E. Canel. Anal. Chim. Acta, 282 (1993) 489

[77] F.G. Bordwell, D.L. Hughes, J. Organic Chemistry 47(17) (1982) 3224-3232

[78] K.M. Honório, A.B.F. Da Silva, Inter. J. Quant. Chem. 95 (2003) 126-132.

[79] A.A. El-Sherif, M.M. Shoukry, M.M.A. Abd-Elgawad, J. Solution Chem. 42 (2013) $412-427$

[80] H. Rossotti, The Study of Ionic Equilibria, Longman, London, 1987.

[81] H. Sigel, R.B. Martin, Chem. Rev. 82 (1982) 385. 
Table 1. Crystal data and structure refinement of thiosemicarbazone compounds

\begin{tabular}{|c|c|c|}
\hline \multirow[t]{2}{*}{ Crystal data } & \multicolumn{2}{|r|}{ Compounds } \\
\hline & TSC2 & TSC3 \\
\hline Molecular formula & $\mathrm{C}_{13} \mathrm{H}_{19} \mathrm{~N}_{5} \mathrm{~S}$ & $\mathrm{C}_{17} \mathrm{H}_{19} \mathrm{~N}_{5} \mathrm{~S}$ \\
\hline Formula weight & 277 & 325 \\
\hline Crystal system & Monoclinic & Monoclinic \\
\hline Space group & $\mathrm{P} 2{ }_{1} / \mathrm{c}$ & $\mathrm{P} 2{ }_{1} / \mathrm{c}$ \\
\hline Wavelength $(\AA)$ & 0.71073 & 0.71073 \\
\hline Temperature (K) & 298 & 298 \\
\hline Colour & Brownish-yellow & Brownish-yellow \\
\hline Radiation type & Mo Ka & Mo K $\alpha$ \\
\hline Radiation source & Fine-focus sealed tube & Fine-focus sealed tube \\
\hline \multicolumn{3}{|l|}{ Unit Cell dimensions } \\
\hline $\mathrm{a}(\AA)$ & $11.2343(6)$ & $27.958912)$ \\
\hline b $(\AA)$ & $11.2575(7)$ & $12.072(5)$ \\
\hline c $(\AA)$ & $11.8995(8)$ & $9.833(4)$ \\
\hline$\alpha\left(^{\circ}\right)$ & 90.00 & 90.00 \\
\hline$\beta\left(^{\circ}\right)$ & $94.476(6)$ & $93.117(11)$ \\
\hline$\gamma\left({ }^{\circ}\right)$ & 90.00 & 90.00 \\
\hline Volume $\left(\AA^{3}\right)$ & $1500.34(16)$ & 3486.75 \\
\hline $\mathrm{Z}$ & 4 & 7 \\
\hline $\mathrm{D}_{\mathrm{x}}$ & $1.228 \mathrm{~g} / \mathrm{cm}^{3}$ & $1.498 \mathrm{~g} / \mathrm{cm}^{3}$ \\
\hline \multicolumn{3}{|l|}{ Data collection } \\
\hline Absorption correction & Multi-scan & Multi-scan \\
\hline Measured reflections & 2731 & 12163 \\
\hline Independent reflections & 3427 & 3113 \\
\hline
\end{tabular}

Table 2. Some energetic properties of the synthesized thiosemicarbazone compounds.

\begin{tabular}{|c|l|l|l|l|l|l|}
\hline Compound & $\begin{array}{l}\text { Total } \\
\text { energy } \\
\text { (kcal/mol) }\end{array}$ & $\begin{array}{l}\text { Binding } \\
\text { energy } \\
\text { (kcal/ } \\
\text { mol) }\end{array}$ & $\begin{array}{l}\text { Electronic } \\
\text { energy (kcal/ } \\
\text { mol) }\end{array}$ & $\begin{array}{l}\text { Dipole } \\
\text { Moment } \\
\text { (Debyes) }\end{array}$ & HOMO & LUMO \\
\hline TSC1 & -58321.2 & -3178.9 & -368233.1 & 6.55 & -8.501 & -1.091 \\
\hline TSC2 & -65214.1 & -3735.7 & -441527.7 & 6.82 & -8.561 & -0.915 \\
\hline TSC3 & -79668.2 & -4295.6 & -566955.2 & 6.94 & -8.556 & -0.889 \\
\hline
\end{tabular}


Table 3. The calculated quantum chemical parameters of the synthesized thiosemicarbazone compounds

\begin{tabular}{lcccccccccc}
\hline Compound & $\Delta \mathrm{E}$ & $\mathbf{I}$ & $\mathbf{A}$ & $\chi$ & $\boldsymbol{\eta}$ & $\mathbf{S}$ & $\Delta \mathbf{N m a x}$ & $\boldsymbol{\omega}$ & $\boldsymbol{\omega}-$ & $\boldsymbol{\omega}+$ \\
\hline TSC1 & 7.410 & 8.501 & 1.091 & 4.796 & 3.705 & 0.270 & -2.294 & 3.104 & 5.965 & 1.169 \\
TSC2 & 7.646 & 8.561 & 0.915 & 4.738 & 3.823 & 0.262 & -2.239 & 2.936 & 5.783 & 1.045 \\
TSC3 & 7.667 & 8.556 & 0.889 & 4.723 & 3.834 & 0.261 & -2.232 & 2.909 & 5.749 & 1.027 \\
\hline
\end{tabular}

Table 4. Antibacterial and antifungal activities of the synthesized thiosemicarbazone compounds

\begin{tabular}{|c|c|c|c|c|c|c|c|c|}
\hline \multirow{2}{*}{$\begin{array}{l}\text { Concentration } \\
(\mu \mathrm{g} / \mathrm{ml})\end{array}$} & \multicolumn{3}{|c|}{ Gram positive } & \multicolumn{3}{|c|}{ Gram negative } & \multicolumn{2}{|c|}{ Fungi } \\
\hline & $\begin{array}{l}\text { Bacillus } \\
\text { subtillis }\end{array}$ & $\begin{array}{l}\text { Staphylococcus } \\
\text { aureus }\end{array}$ & $\begin{array}{l}\text { Streptococcus } \\
\text { faecalis }\end{array}$ & $\begin{array}{l}E . \\
\text { coli }\end{array}$ & $\begin{array}{l}\text { Neisseria } \\
\text { gonorrhoeae }\end{array}$ & $\begin{array}{l}\text { Pseudomonas } \\
\text { aereuguinosa }\end{array}$ & $\begin{array}{c}\text { Aspergillus } \\
\text { flavus }\end{array}$ & $\begin{array}{l}\text { Candida } \\
\text { albicans }\end{array}$ \\
\hline TSC1 & 14 & 13 & 17 & 17 & 12 & 21 & 0 & 30 \\
\hline TSC3 & 0 & 0 & 13 & 11 & 0 & 0 & 0 & 0 \\
\hline TSC4 & 0 & 0 & 0 & 0 & 0 & 0 & 0 & 0 \\
\hline Ampicillin & 26 & 21 & 27 & 25 & 28 & 26 & - & - \\
\hline Amphotericin & - & - & - & - & - & - & 16 & 19 \\
\hline
\end{tabular}

Ampicillin: Standard antibacterial agent, Amphotericin: Standard antifungal agent

Table 5. Antitumor activity of the synthesized thiosemicarbazone compounds.

\begin{tabular}{lccc}
\hline Concentration $(\boldsymbol{\mu g} / \mathbf{m l})$ & TSC1 & TSC2 & TSC3 \\
\hline Liver cancer cell line $($ HepG2) & 100 & 100 & 100 \\
5 & 35.3 & 67 & 22.5 \\
25 & 27.4 & 48.7 & 19 \\
50 & 29.4 & 46 & 25 \\
IC $_{50}$ & & & 77.6 \\
Breast cancer cell line $(\mathbf{M C F - 7 )}$ & & 95 & 72 \\
5 & 83.8 & 86.5 & 65.4 \\
25 & 79.5 & 83 & 107 \\
50 & 70.7 & 172.9 & \\
IC $_{50}$ & 122 & & \\
\hline
\end{tabular}


Table 6. Protonation constants for TSC1 ligand at different temperatures.

\begin{tabular}{|l|c|l|l|}
\hline \multirow{2}{*}{ Reaction } & \multicolumn{3}{|c|}{$\log \mathrm{K}( \pm \sigma)^{\mathrm{a}}$} \\
\cline { 2 - 4 } & $15{ }^{\circ} \mathrm{C}$ & $25^{\circ} \mathrm{C}$ & \multicolumn{1}{|c|}{$35^{\circ} \mathrm{C}$} \\
\hline $\mathrm{L}+\mathrm{H}=\mathrm{HL}$ & $8.02(0.09)$ & $7.81(0.05)$ & $7.64(0.03)$ \\
\hline $\mathrm{HL}+\mathrm{H}=\mathrm{H}_{2} \mathrm{~L}$ & $3.31(0.08)$ & $3.22(0.07)$ & $3.14(0.09)$ \\
\hline $\mathrm{H}_{2} \mathrm{~L}+\mathrm{H}=\mathrm{H}_{3} \mathrm{~L}$ & $3.17(0.04)$ & $3.08(0.06)$ & $3.01(0.05)$ \\
\hline
\end{tabular}

${ }^{\mathrm{a}}(\sigma)$ is the standard deviation;

Table 7. Stepwise stability for the complexes of TSC1 with Cd(II) metal ion in $50 \%$ DMSO-H (V/V) solution.

\begin{tabular}{|l|c|c|c|}
\hline \multirow{2}{*}{ Temp. $\left({ }^{\circ} \mathrm{C}\right)$} & $\log \mathrm{K}_{1}( \pm \sigma)^{\mathrm{a}}$ & $\log \mathrm{K}_{2}( \pm \sigma)$ & $\log \mathrm{K}_{1}-\log \mathrm{K}_{2}$ \\
\cline { 2 - 4 } & $\mathrm{CdL}$ & $\mathrm{CdL}_{2}$ & $\mathrm{Cd}(\mathrm{II})$ complex \\
\hline $15^{\circ} \mathrm{C}$ & $9.82(0.07)$ & $2.80(0.03)$ & 7.02 \\
$25^{\circ} \mathrm{C}$ & $9.74(0.03)$ & $2.75(0.06)$ & 6.99 \\
$35^{\circ} \mathrm{C}$ & $9.57(0.06)$ & $2.71(0.09)$ & 6.86 \\
\hline
\end{tabular}

a $(\sigma)$ is the standard deviation;

Definitions of stability constants: $\mathrm{K}_{1}=[\mathrm{CdL}] /[\mathrm{Cd}][\mathrm{L}] ; \mathrm{K}_{2}=\left[\mathrm{CdL}_{2}\right] /[\mathrm{CdL}][\mathrm{L}]$; $(\mathrm{L}=\mathrm{TSC} 1$ thiosemicarbazone ligand); (Charges are omitted for simplicity).

Table 8. Thermodynamic parameters for the protonation of ligand (TSC1) in $50 \%$ DMSO- $\mathrm{H}_{2} \mathrm{O}$ (V/V) solution.

\begin{tabular}{|c|c|c|c|c|c|c|c|c|c|}
\hline \multirow[t]{3}{*}{ Parameter $^{a}$} & \multicolumn{9}{|c|}{ Reaction } \\
\hline & \multicolumn{3}{|c|}{$\mathrm{L}+\mathrm{H}=\mathrm{HL}^{\mathrm{a}}$} & \multicolumn{3}{|c|}{$\mathrm{L}+2 \mathrm{H}=\mathrm{H}_{2} \mathrm{~L}$} & \multicolumn{3}{|c|}{$\mathrm{L}+3 \mathrm{H}=\mathrm{H}_{3} \mathrm{~L}$} \\
\hline & $15^{\circ} \mathrm{C}$ & $25^{\circ} \mathrm{C}$ & $35^{\circ} \mathrm{C}$ & $15^{\circ} \mathrm{C}$ & $25^{\circ} \mathrm{C}$ & $35^{\circ} \mathrm{C}$ & $15^{\circ} \mathrm{C}$ & $25^{\circ} \mathrm{C}$ & $35^{\circ} \mathrm{C}$ \\
\hline$-\Delta G$ & 44.25 & 44.59 & 45.08 & 17.49 & 17.58 & 17.82 & 18.26 & 18.38 & 18.47 \\
\hline$-\Delta H$ & \multicolumn{3}{|c|}{32.33} & \multicolumn{3}{|c|}{15.29} & \multicolumn{3}{|c|}{12.77} \\
\hline$\Delta S$ & \multicolumn{3}{|c|}{41.16} & \multicolumn{3}{|c|}{10.30} & \multicolumn{3}{|c|}{16.27} \\
\hline
\end{tabular}

$\Delta \mathrm{G}:$ Gibbs energy/kJ.mol ${ }^{-1} ; \Delta \mathrm{H}:$ Enthalpy/kJ.mol $^{-1} ; \Delta \mathrm{S}:$ Entropy/J.mol $^{-1} \cdot \mathrm{K}^{-1}$ 
Table 9. Thermodynamic parameters for $\mathrm{Cd}(\mathrm{II})-\mathrm{TSC} 1$ complexes in $50 \%$ DMSO- $\mathrm{H}_{2} \mathrm{O}(\mathrm{V} / \mathrm{V})$ solution.

\begin{tabular}{|l|c|c|c|c|c|c|}
\hline \multirow{3}{*}{ Parameter $^{\mathbf{a}}$} & \multicolumn{5}{|c|}{ Reaction } \\
\cline { 2 - 7 } & \multicolumn{3}{|c|}{$\mathrm{Cd}+\mathrm{L}=\mathrm{CdL}$} & \multicolumn{3}{c|}{$\mathrm{Cd}+2 \mathrm{~L}=\mathrm{CdL}_{2}$} \\
\cline { 2 - 7 } & $15^{\circ} \mathrm{C}$ & $25^{\circ} \mathrm{C}$ & $35^{\circ} \mathrm{C}$ & $15^{\circ} \mathrm{C}$ & $25^{\circ} \mathrm{C}$ & $35^{\circ} \mathrm{C}$ \\
\hline$-\Delta \boldsymbol{G}$ & 54.18 & 55.60 & 56.45 & 15.45 & 15.70 & 15.99 \\
\hline$-\Delta \boldsymbol{H}$ & \multicolumn{3}{|c|}{21.15} & & 7.66 \\
\hline$\Delta \boldsymbol{S}$ & \multicolumn{3}{|c|}{114.88} & \multicolumn{3}{c|}{26.99} \\
\hline
\end{tabular}

${ }^{a} \Delta \mathrm{G}:$ Gibbs energy/kJ.mol ${ }^{-1} ; \Delta \mathrm{H}:$ Enthalpy $/ \mathrm{kJ} \cdot \mathrm{mol}^{-1} ; \Delta \mathrm{S}:$ Entropy $/ \mathrm{J} \cdot \mathrm{mol}^{-1} \cdot \mathrm{K}^{-1}$. 


\section{TSC2 Compound CIF structure and checkcif report}

THIS REPORT IS FOR GUIDANCE ONLY. IF USED AS PART OF A REVIEW

PROCEDURE FOR PUBLICATION, IT SHOULD NOT REPLACE THE EXPERTISE OF AN EXPERIENCED CRYSTALLOGRAPHIC REFEREE.

No syntax errors found.

CIF dictionary

Please wait while processing ....

Interpreting this

report

$\underline{\text { Structure factor report }}$

\section{Datablock: ahmed1_a}

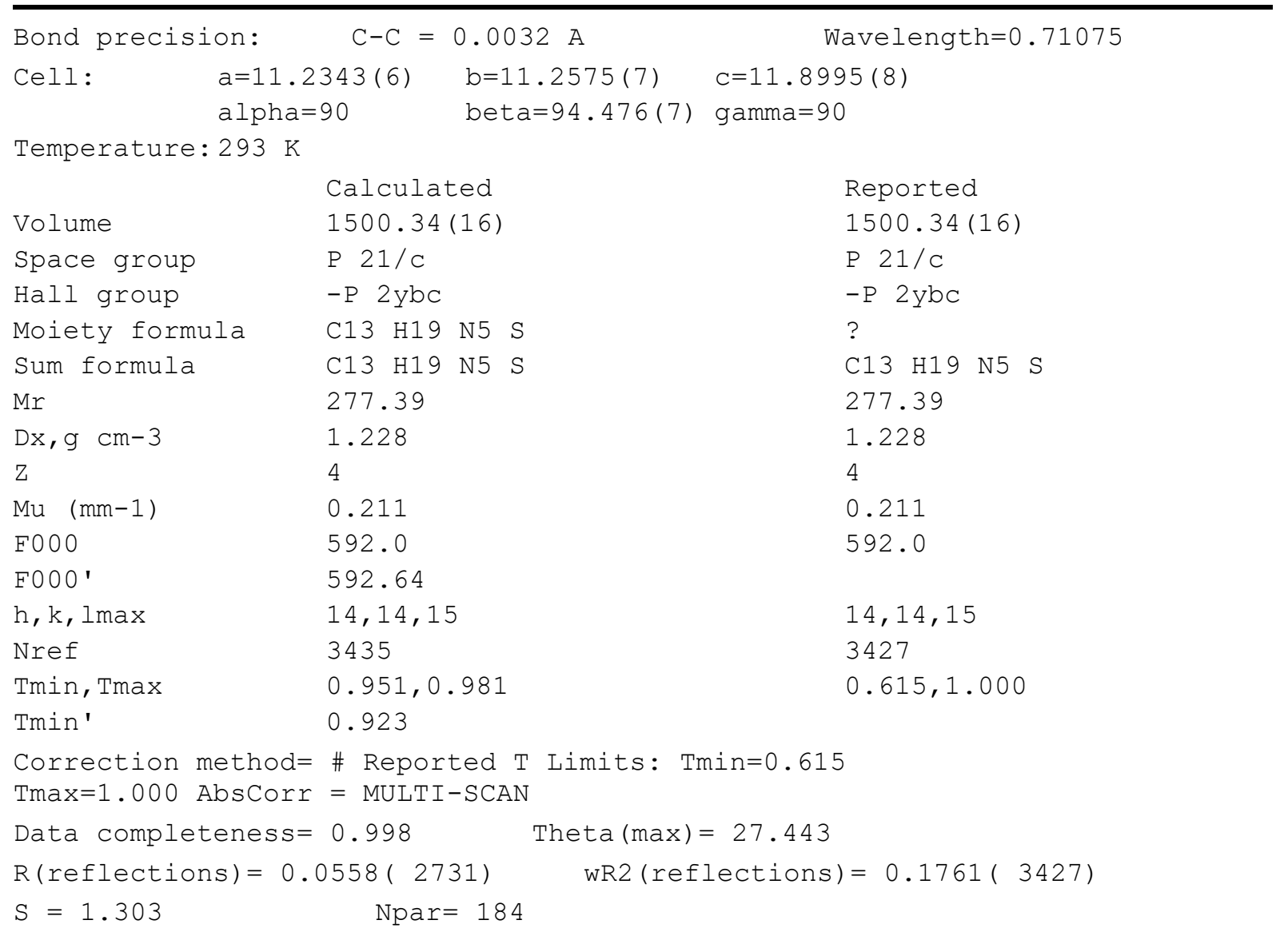

The following ALERTS were generated. Each ALERT has the format test-name_ALERT_alert-type_alert-level.

Click on the hyperrlinks for more details of the test.

\section{Alert level C}

ABSTY02 ALERT 1 C An_exptl_absorpt_correction_type has been given without a literature citation. This should be contained in the exptl_absorpt_process_details field.

$\bar{A}$ bsorption correction $\bar{g}$ iven as multi-scan

PLAT085 ALERT 2 C SHELXL Default Weighting Scheme is not Optimized Please Check

PLAT220 ALERT 2 C NonSolvent Resd 1 C Ueq (max)/Ueq(min) Range

3.1 Ratio

PLAT241 ALERT 2 C High 'MainMol' Ueq as Compared to Neighbors of

C12 Check 
PLAT242 ALERT 2 C LOW 'MainMol' Ueq as Compared to Neighbors of N5 Check

PLAT250 ALERT 2 C Large U3/U1 Ratio for Average U(i,j) Tensor .... 2.1 Note

PLAT360 ALERT 2 C Short C (sp3)-C(sp3) Bond C12 - C13

$1.43 \mathrm{Ang}$.

PLAT906 ALERT $3 \mathrm{C}$ Large $\mathrm{K}$ Value in the Analysis of Variance ..... 3.847 Check

\section{Alert level G}

PLAT002 ALERT 2 G Number of Distance or Angle Restraints on AtSite 6 Note

PLAT172 ALERT 4 G The CIF-Embedded .res File Contains DFIX Records

1 Report

PLAT199 ALERT 1 G Reported_cell_measurement_temperature ..... (K)

293 Check

PLAT200 ALERT_1_G Reported_diffrn_ambient_temperature ..... (K)

293 Check

PLAT860 ALERT $3 \mathrm{G}$ Number of Least-Squares Restraints ..........

3 Note

PLAT883 ALERT 1 G No Info/Value for_atom_sites_solution_primary .

Please Do !

PLAT910 ALERT 3 G Missing \# of FCF Reflection(s) Below Theta(Min).

1 Note

PLAT912 ALERT 4 G Missing \# of FCF Reflections Above STh/L= 0.600

8 Note

PLAT933 ALERT 2 G Number of OMIT Records in Embedded.res File...

1 Note

PLAT941 ALERT 3 G Average HKL Measurement Multiplicity .........

4.1 LOW

PLAT965 ALERT 2 G The SHELXL WEIGHT Optimisation has not Converged

Please Check

PLAT978 ALERT 2 G Number C-C Bonds with Positive Residual Density.

7 Info

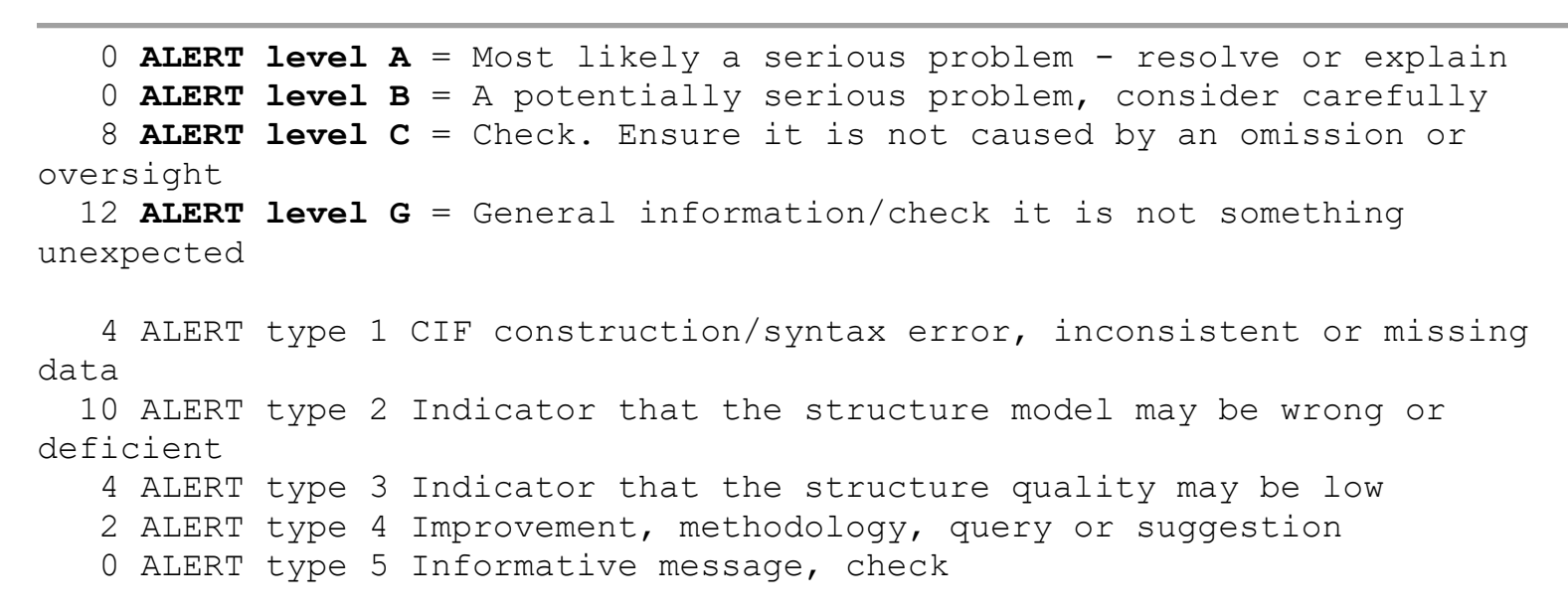

\section{PLATON version of 10/08/2020; check.def file version of $06 / 08 / 2020$ \\ Datablock ahmed1_a - ellipsoid plot}




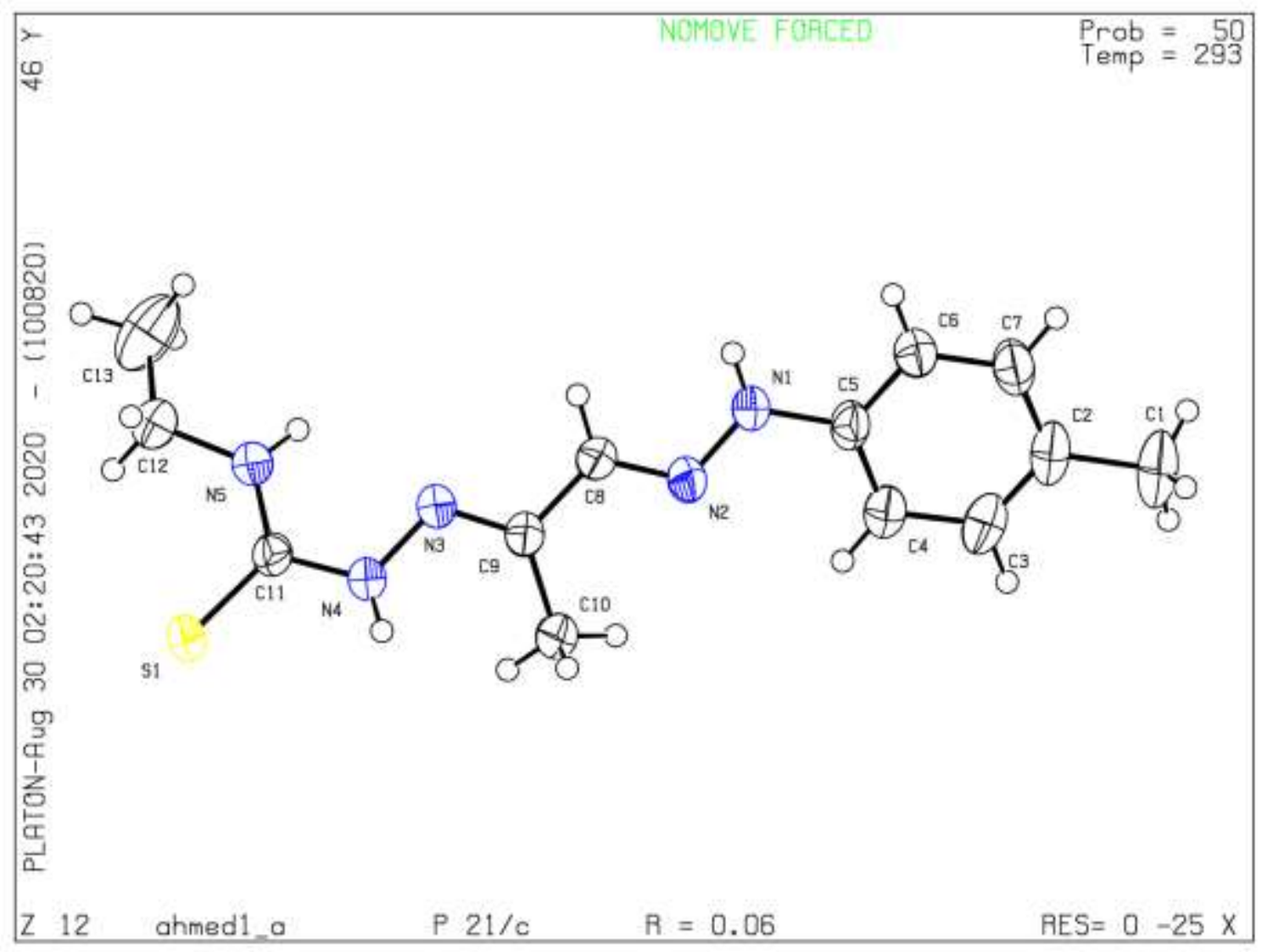




\section{TSC3 Compound CIF structure and checkcif report}

THIS REPORT IS FOR GUIDANCE ONLY. IF USED AS PART OF A REVIEW

PROCEDURE FOR PUBLICATION, IT SHOULD NOT REPLACE THE EXPERTISE OF AN EXPERIENCED CRYSTALLOGRAPHIC REFEREE.

No syntax errors found.

CIF dictionary

Please wait while processing ....

Interpreting this

report

$\underline{\text { Structure factor report }}$

\section{Datablock: I}

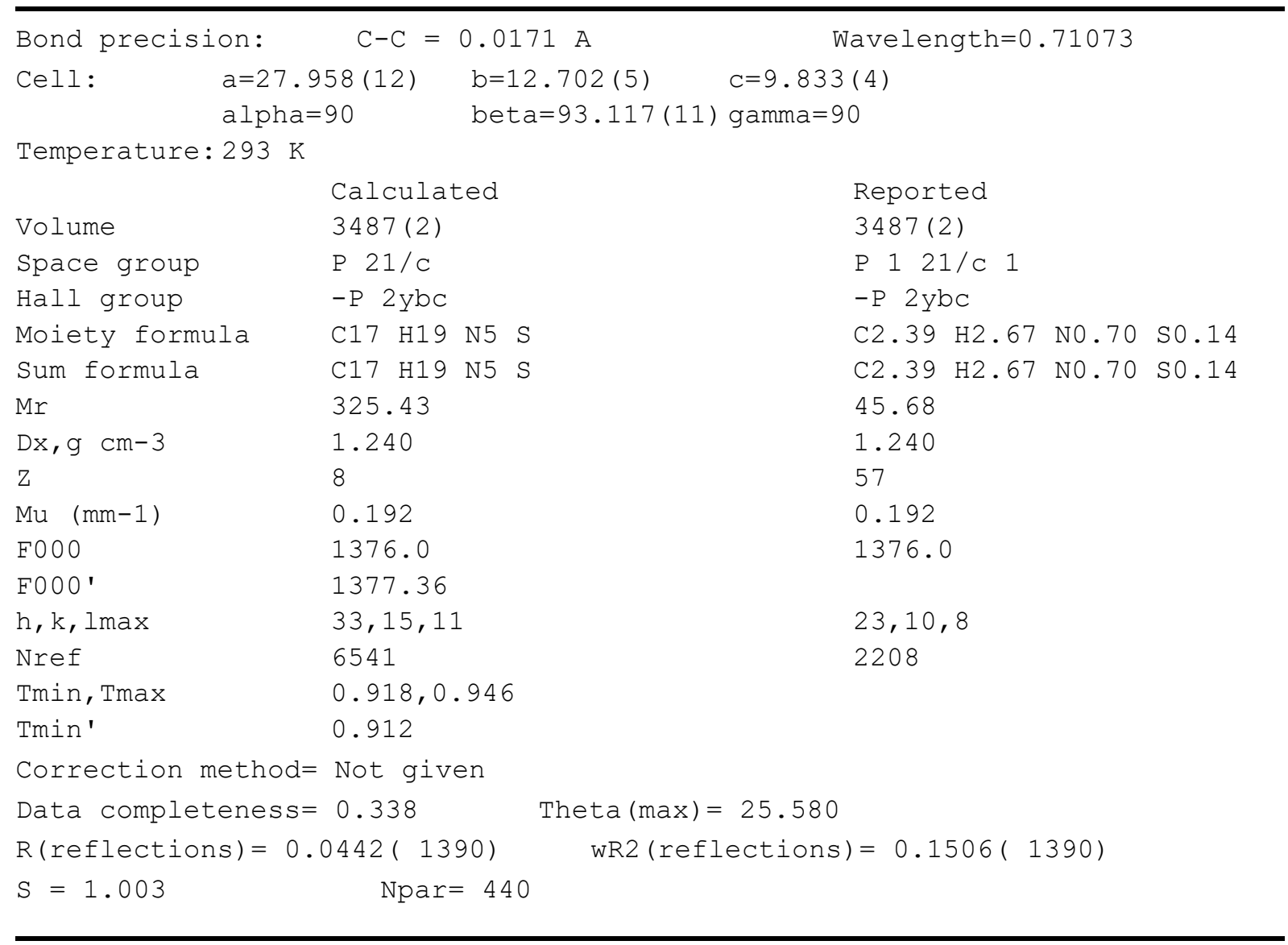

The following ALERTS were generated. Each ALERT has the format test-name_ALERT_alert-type alert-level.

click on the hyperink $\bar{s}$ for more details of the test.

QAlert level A

PLAT183 ALERT 1 A Missing_cell_measurement_reflns_used Value ....

Please Do !

PLAT184 ALERT 1 A Missing_cell_measurement_theta_min Value .....

Please Do!

PLAT185 ALERT 1 A Missing _cell_measurement_theta_max Value ..... Please Do!

PLAT902 ALERT 1 A No (Interpretable) Reflections Found in FCF .... Please Check

Alert level B 
PLAT031 ALERT 4 B Refined Extinction Parameter Within Range ..... 2.000 Sigma

PLAT340 ALERT 3 B Low Bond Precision on $\mathrm{C}-\mathrm{C}$ Bonds ........... 0.01713 Ang.

\section{Alert level C}

PLAT230 ALERT 2 C Hirshfeld Test Diff for $5.2 \mathrm{~s} . \mathrm{u}$.

PLAT230 ALERT 2 C Hirshfeld Test Diff for N33

N10

$--\mathrm{N} 11$

$5.2 \mathrm{~s} . \mathrm{u}$.

PLAT234_ALERT_4_C Large Hirshfeld Difference N10

0.19 Ang.

And 15 other PLAT234 Alerts

PLAT234_ALERT 4_C Large Hirshfeld Difference N11

0.16 Ang.

PLAT234_ALERT 4_C Large Hirshfeld Difference C4

0.19 Ang.

PLAT234_ALERT 4_C Large Hirshfeld Difference C7

0.20 Ang.

PLAT234_ALERT_4_C Large Hirshfeld Difference C8

0.22 Ang.

PLAT234 ALERT 4 C Large Hirshfeld Difference C12

0.16 Ang.

PLAT234_ALERT 4_C Large Hirshfeld Difference N33

0.17 Ang.

PLAT234 ALERT 4 C Large Hirshfeld Difference N34

PLAT234 ALERT 4 C Large Hirshfeld Difference C27 0.23 Ang.

PLAT234_ALERT 4_C Large Hirshfeld Difference C27

0.20 Ang.

PLAT234_ALERT 4_C Large Hirshfeld Difference C28

PLAT234_ALERT 4_C Large Hirshfeld Difference C29

PLAT234_ALERT 4_C Large Hirshfeld Difference C30 0.19 Ang.

PLAT234_ALERT 4_C Large Hirshfeld Difference C31 0.20 Ang. 
PLAT234_ALERT_4_C Large Hirshfeld Difference C35

0.18 Ang.

PLAT234_ALERT_4_C Large Hirshfeld Difference C43

0.18 Ang.

PLAT242 ALERT 2 C Low 'MainMol' Ueq as Compared to Neighbors of

C4 Check

PLAT331 ALERT 2 C Small Aver Phenyl C-C Dist C4 --C9

1.37 Ang.

$\frac{\text { PLAT331 ALERT 2 C Small Aver Phenyl C-C Dist C27 - C32 }}{1.37 \text { Ang. }}$

PLAT420 ALERT 2 C D-H Without Acceptor N33 --H331.

Please Check

\section{Alert level $G$}

CELLZ01 ALERT 1 G Difference between formula and atom_site contents detected.

CELLZ01 ALERT 1 G WARNING: H atoms missing from atom site list. Is this intentional?

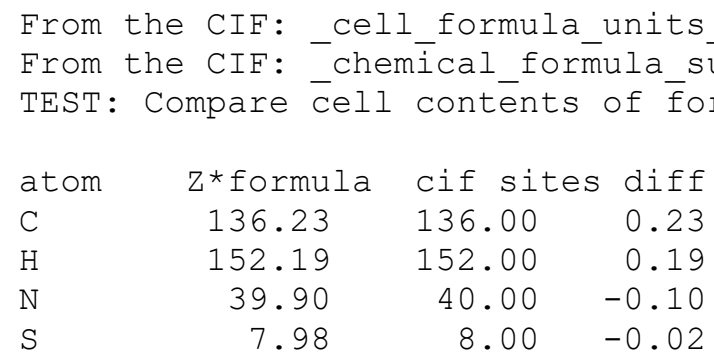

PLAT002 ALERT 2 G Number of Distance or Angle Restraints on AtSite 22 Note

PLAT042 ALERT $1 \mathrm{G}$ Calc. and Reported MoietyFormula Strings Differ Please Check

PLAT045 ALERT 1 G Calculated and Reported Z Differ by a Factor... 0.14 Check

PLAT199 ALERT 1_G Reported_cell_measurement_temperature ..... (K)

293 Check

PLAT200 ALERT 1 G Reported__iffrn_ambient_temperature ..... (K)

293 Check

PLAT380 ALERT 4 G Incorrectly? Oriented X(sp2)-Methyl Moiety .... C22 Check

PLAT380_ALERT 4_G Incorrectly? Oriented X(sp2)-Methyl Moiety .... C44 Check

PLAT769 ALERT 4 G CIF Embedded explicitly supplied scattering data Please Note

PLAT790 ALERT 4 G Centre of Gravity not Within Unit Cell: Resd. \#

2 Note

C17 H19 N5 S

PLAT808 ALERT 5 G No Parseable SHELXL Style Weighting Scheme Found Please Check

PLAT860 ALERT $3 \mathrm{G}$ Number of Least-Squares Restraints ......... 24 Note

PLAT882 ALERT 1 G No Datum for_diffrn_reflns_av_unetI/netI ..... Please Do !

4 ALERT level $\mathbf{A}=$ Most likely a serious problem - resolve or explain

2 ALERT level B = A potentially serious problem, consider carefully

22 ALERT level $\mathbf{C}=$ Check. Ensure it is not caused by an omission or

oversight 
14 ALERT level $\mathbf{G}=$ General information/check it is not something unexpected

11 ALERT type 1 CIF construction/syntax error, inconsistent or missing data

7 ALERT type 2 Indicator that the structure model may be wrong or deficient

2 ALERT type 3 Indicator that the structure quality may be low

21 ALERT type 4 Improvement, methodology, query or suggestion

1 ALERT type 5 Informative message, check

\section{PLATON version of 10/08/2020; check.def file version of $06 / 08 / 2020$}

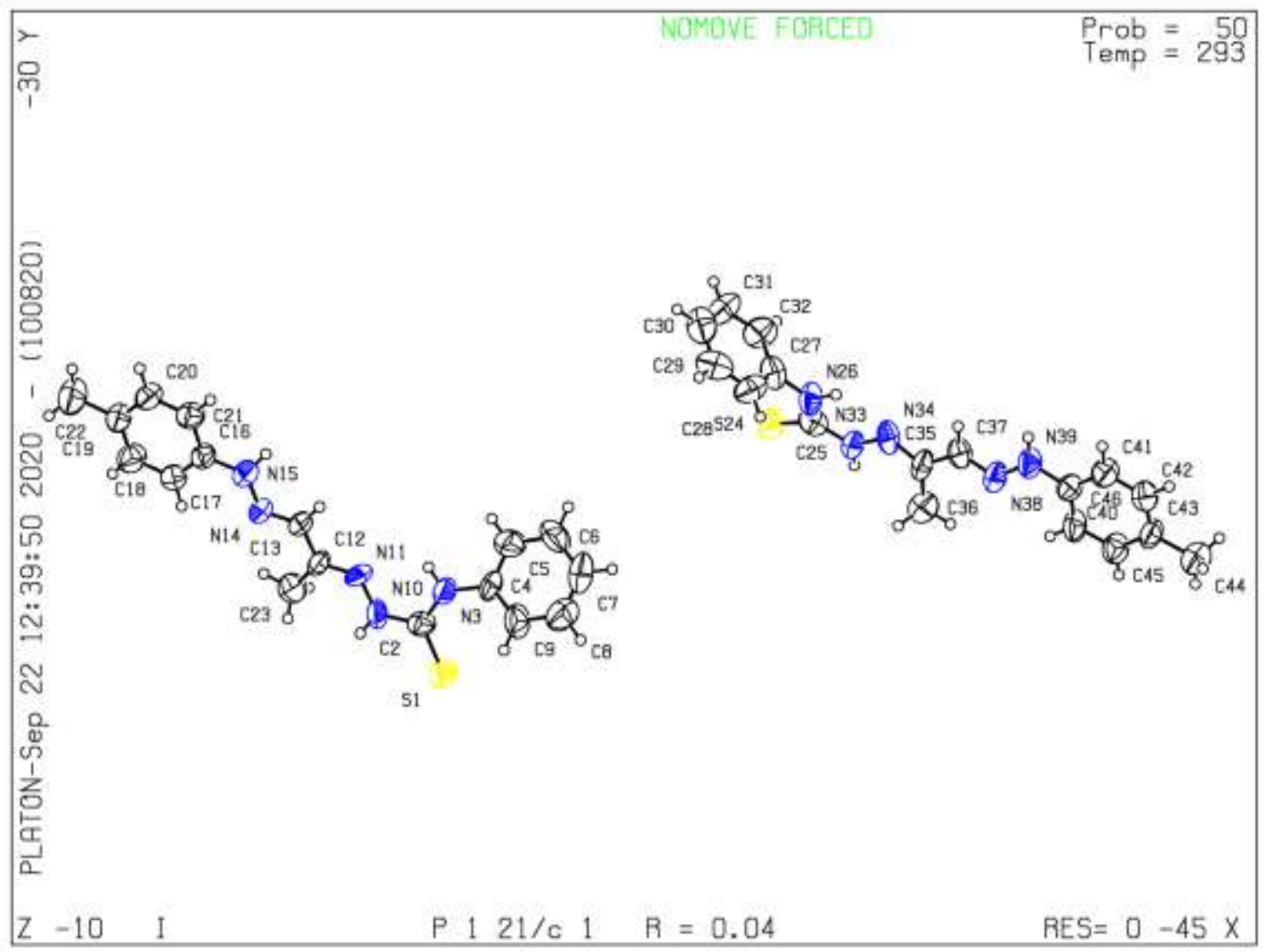




\title{
TSC2 Compound CIF File (Structure without hkl data)
}

\author{
_audit_creation_method \\ 'SHELXL-2018/3' \\ _shelx_SHELXL_version_number '2018/3' \\ _chemical_name_systematic ? \\ _chemical_name_common? \\ _chemical_melting_point ? \\ _chemical_formula_moiety ? \\ _chemical_formula_sum \\ 'C13 H19 N5 S' \\ _chemical_formula_weight 277.39 \\ loop_ \\ _atom_type_symbol \\ _atom_type_description \\ _atom_type_scat_dispersion_real \\ _atom_type_scat_dispersion_imag \\ _atom_type_scat_source \\ 'C' 'C' $0.0033 \quad 0.0016$ \\ 'International Tables Vol C Tables 4.2.6.8 and 6.1.1.4' \\ 'H' 'H' $0.0000 \quad 0.0000$ \\ 'International Tables Vol C Tables 4.2.6.8 and 6.1.1.4' \\ 'N' 'N' $0.0061 \quad 0.0033$ \\ 'International Tables Vol C Tables 4.2.6.8 and 6.1.1.4' \\ 'S' 'S' $0.1246 \quad 0.1234$ \\ 'International Tables Vol C Tables 4.2.6.8 and 6.1.1.4' \\ _space_group_crystal_system \\ _space_group_IT_number \\ monoclinic \\ _space_group_name_H-M_alt 'P 21/c' \\ _space_group_name_Hall_ '-P 2ybc' \\ _shelx_space_group_comment \\ ; \\ The symmetry employed for this shelxl refinement is uniquely defined \\ by the following loop, which should always be used as a source of \\ symmetry information in preference to the above space-group names. \\ They are only intended as comments. \\ ; \\ loop_ \\ _space_group_symop_operation_xyz \\ 'x, y, z' \\ '-x, $y+1 / 2,-z+1 / 2$ '
}




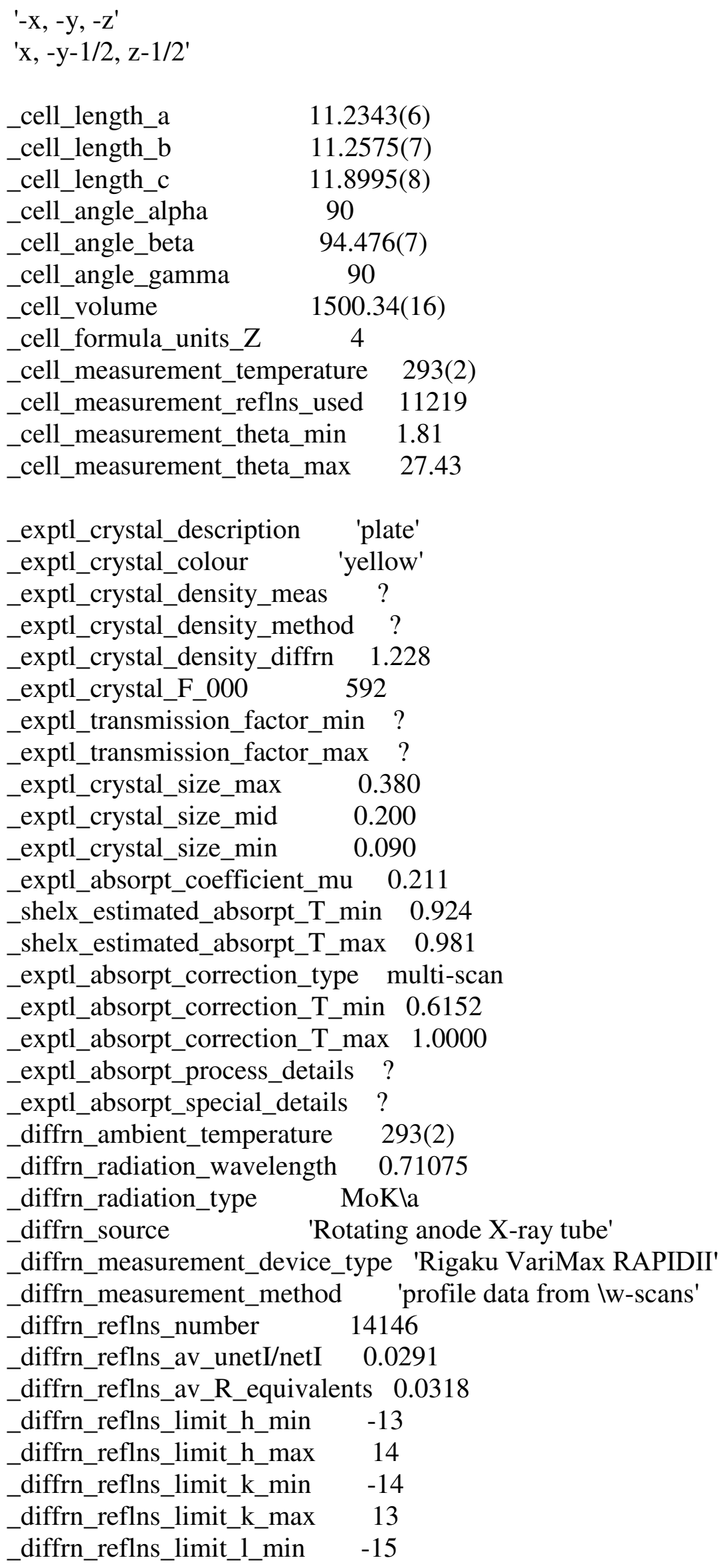




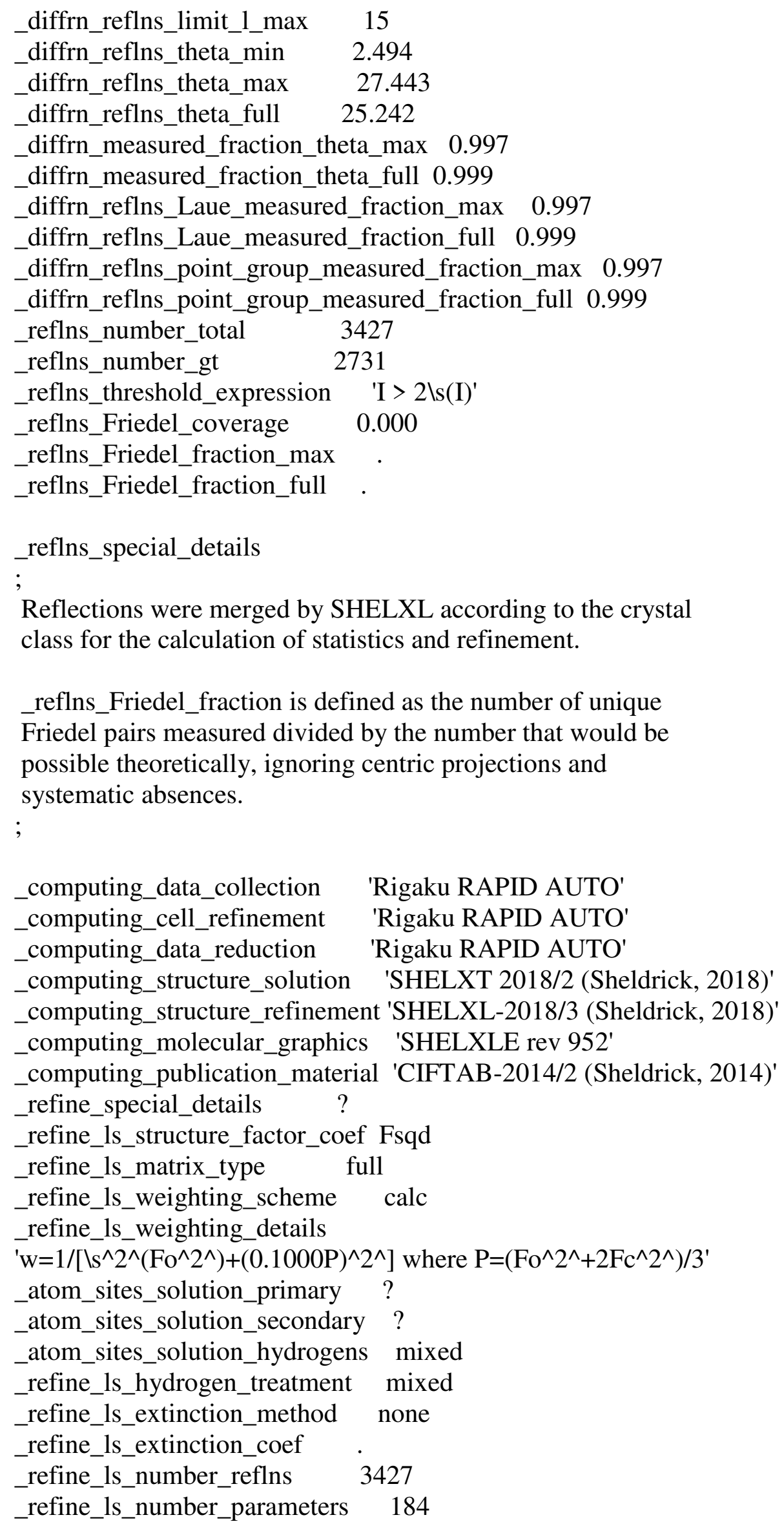


_refine_ls_number_restraints 3

_refine_ls_R_factor_all $\quad 0.0688$

_refine_ls_R_factor_gt $\quad 0.0558$

_refine_ls_wR_factor_ref $\quad 0.1761$

_refine_ls_wR_factor_gt 0.1679

_refine_ls_goodness_of_fit_ref 1.303

_refine_ls_restrained_S_all 1.302

_refine_ls_shift/su_max $\quad 0.001$

_refine_ls_shift/su_mean $\quad 0.000$

loop_

_atom_site_label

_atom_site_type_symbol

_atom_site_fract_x

_atom_site_fract_y

_atom_site_fract_z

_atom_site_U_iso_or_equiv

_atom_site_adp_type

_atom_site_occupancy

_atom_site_site_symmetry_order

_atom_site_calc_flag

_atom_site_refinement_flags_posn

_atom_site_refinement_flags_adp

_atom_site_refinement_flags_occupancy

_atom_site_disorder_assembly

_atom_site_disorder_group

S1 S 0.32591(4) 0.56067(4) 1.03601(4) 0.0481(2) Uani $11 \mathrm{~d} \ldots \ldots$

N1 N 0.68511(15) 0.75290(15) 0.46644(13) 0.0471(4) Uani $11 \mathrm{~d} \mathrm{D} \mathrm{.} \mathrm{.} \mathrm{.}$

H14 H 0.6795(19) 0.8271(9) 0.4803(17) 0.057 Uiso $11 \mathrm{~d} \mathrm{D} \mathrm{U} \mathrm{.} \mathrm{.}$

$\mathrm{N} 2 \mathrm{~N}$ 0.63686(13) 0.67170(14) 0.53219(12) 0.0401(4) Uani $11 \mathrm{~d} \ldots \ldots$

N3 N 0.46564(14) 0.67628(13) 0.76474(12) 0.0413(4) Uani $11 \mathrm{~d} \ldots .$.

N4 N 0.43152(14) 0.60082(14) 0.84903(13) 0.0426(4) Uani $11 \mathrm{~d} \mathrm{D} \mathrm{.} \mathrm{.} \mathrm{.}$

H15 H 0.4828(15) 0.5491(15) 0.8750(16) 0.051 Uiso $11 \mathrm{~d}$ D U . .

N5 N 0.29717(17) 0.74135(15) 0.89309(17) 0.0589(5) Uani $11 \mathrm{~d} \mathrm{D} \mathrm{.} \mathrm{.} \mathrm{.}$

H16 H 0.301(2) 0.767(2) 0.8257(11) 0.071 Uiso $11 \mathrm{~d} \mathrm{D} \mathrm{U} \mathrm{.} \mathrm{.} \mathrm{.}$

C1 C 0.9615(2) 0.6150(3) 0.10378(19) 0.0756(8) Uani $11 \mathrm{~d} \ldots .$.

H1A H 0.9506090 .6719860 .0438530 .113 Uiso 11 calc R U . . .

H1B H 0.9361220 .5381260 .0764460 .113 Uiso 11 calc R U . .

H1C H 1.0444050 .6118480 .1302970 .113 Uiso 11 calc R U . . .

C2 C 0.88835(17) 0.6512(2) 0.19936(16) 0.0536(5) Uani $11 \mathrm{~d} . . .$.

C3 C 0.82973(19) 0.5679(2) 0.25959(18) 0.0568(6) Uani $11 \mathrm{~d} \ldots \ldots$

H3 H 0.8351960 .4882970 .2398200 .068 Uiso 11 calc R U . . .

C4 C 0.76262(18) 0.59836(19) 0.34890(17) 0.0496(5) Uani $11 \mathrm{~d} \ldots \ldots$

H4 H 0.7245570 .5398220 .3880300 .060 Uiso 11 calc R U . . .

C5 C 0.75313(16) 0.71686(17) 0.37889(14) 0.0417(4) Uani $11 \mathrm{~d}$. . . .

C6 C 0.81120(18) 0.80226(19) 0.31888(16) 0.0492(5) Uani $11 \mathrm{~d} \ldots .$.

H6 H 0.8057020 .8820020 .3382450 .059 Uiso 11 calc R U . . .

C7 C 0.87712(18) 0.7693(2) 0.23052(17) 0.0536(5) Uani $11 \mathrm{~d} \ldots \ldots$

H7 H 0.9148780 .8276810 .1909700 .064 Uiso 11 calc R U . . . 
C8 C 0.57274(16) 0.71098(16) 0.60970(15) 0.0417(4) Uani $11 \mathrm{~d} . . .$. H8 H 0.5563590 .7917050 .6146670 .050 Uiso 11 calc R U . . .

C9 C 0.52647(16) 0.62817(16) 0.68895(14) 0.0384(4) Uani $11 \mathrm{~d} \ldots .$. C10 C 0.55503(18) 0.49883(17) 0.68002(16) 0.0470(5) Uani $11 \mathrm{~d} \ldots .$. H10A H 0.5652620 .4792770 .6028370 .071 Uiso 11 calc R U . . . H10B H 0.4908080 .4526410 .7060260 .071 Uiso 11 calc R U . . . H10C H 0.6273570 .4815940 .7254610 .071 Uiso 11 calc R U . . . C11 C 0.35214(16) 0.64045(15) 0.92035(15) 0.0402(4) Uani $11 \mathrm{~d} \ldots \ldots$ C12 C 0.2111(3) 0.7985(3) 0.9615(3) 0.1174(15) Uani $11 \mathrm{~d} \ldots .$. H12A H 0.1579080 .7383220 .9874520 .141 Uiso 11 calc R U . . . H12B H 0.2539070 .8332701 .0274330 .141 Uiso 11 calc R U . . . C13 C 0.1409(3) 0.8892(3) 0.9035(3) 0.0956(10) Uani $11 \mathrm{~d} \ldots .$. H13A H 0.1918890 .9535720 .8848500 .143 Uiso 11 calc R U . . . H13B H 0.0820900 .9178770 .9511620 .143 Uiso 11 calc R U . . . H13C H 0.101857 0.856907 0.835644 0.143 Uiso 11 calc R U . . .

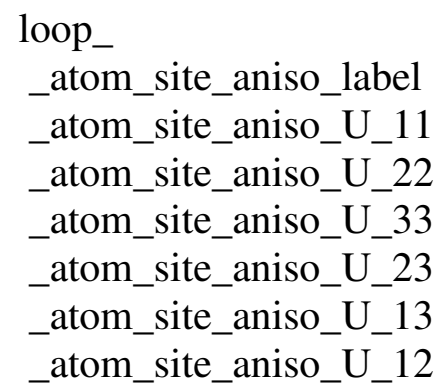

S1 0.0537(3) 0.0439(3) 0.0500(3) 0.0048(2) 0.0254(2) 0.0002(2) N1 0.0628(10) 0.0416(9) 0.0399(9) 0.0029(7) 0.0229(8) 0.0080(7) $\mathrm{N} 20.0446(8) 0.0447(8) 0.0321(8) 0.0021(6) 0.0096(6) 0.0033(6)$ N3 0.0451(8) 0.0403(8) 0.0405(8) 0.0044(6) 0.0152(7) 0.0044(6) N4 0.0483(9) 0.0382(8) 0.0439(9) 0.0049(7) 0.0195(7) 0.0057(6) N5 0.0670(11) 0.0428(9) 0.0724(13) 0.0150(8) 0.0401(10) 0.0131(8) C1 0.0592(14) 0.119(2) 0.0519(14) -0.0193(14) 0.0224(11) 0.0065(14) C2 0.0397(10) 0.0844(16) 0.0376(10) -0.0083(10) 0.0089(8) 0.0075(10) C3 0.0526(12) 0.0671(14) 0.0518(13) $-0.0196(10)$ 0.0114(10) 0.0053(10) C4 0.0510(11) 0.0544(11) 0.0451(11) -0.0046(9) 0.0143(9) 0.0033(8) C5 0.0426(10) 0.0530(11) 0.0302(9) 0.0006(7) 0.0072(7) 0.0081(8) C6 0.0539(11) 0.0528(11) 0.0425(11) 0.0055(8) 0.0141(9) 0.0068(9) C7 0.0501(11) 0.0711(14) 0.0412(11) 0.0078(10) 0.0146(9) 0.0062(10) C8 0.0491(10) 0.0393(9) 0.0381(9) 0.0021(7) 0.0113(8) 0.0091(7) C9 0.0393(9) 0.0411(10) 0.0357(9) 0.0001(7) 0.0088(7) 0.0034(7) C10 0.0598(12) 0.0398(10) 0.0435(10) -0.0023(8) 0.0171(9) 0.0033(8) C11 0.0399(9) 0.0339(9) 0.0487(10) -0.0021(7) 0.0164(8) -0.0025(7) C12 0.146(3) 0.0753(19) 0.147(3) 0.0477(19) 0.109(2) 0.058(2) C13 0.0587(15) 0.113(2) 0.115(3) -0.026(2) 0.0057(16) 0.0306(16)

_geom_special_details ; All esds (except the esd in the dihedral angle between two l.s. planes) are estimated using the full covariance matrix. The cell esds are taken into account individually in the estimation of esds in distances, angles 
and torsion angles; correlations between esds in cell parameters are only used when they are defined by crystal symmetry. An approximate (isotropic) treatment of cell esds is used for estimating esds involving 1.s. planes.

;

loop_

_geom_bond_atom_site_label_1

_geom_bond_atom_site_label_2

_geom_bond_distance

_geom_bond_site_symmetry_2

_geom_bond_publ_flag

S1 C11 1.6885(18) . ?

N1 N2 1.345(2). ?

N1 C5 1.399(2) . ?

N1 H14 0.854(9) . ?

$\mathrm{N} 2 \mathrm{C} 81.292(2)$. ?

N3 C9 1.292(2) . ?

N3 N4 1.391(2). ?

N4 C11 1.354(2) . ?

N4 H15 0.859(9) . ?

N5 C11 1.321(2) . ?

N5 C12 1.460(3) . ?

N5 H16 0.856(9) . ?

C1 C2 1.511(3) . ?

C1 H1A 0.9600.?

C1 H1B 0.9600 . ?

C1 H1C 0.9600 . ?

C2 C3 1.378(3) . ?

C2 C7 1.388(3) . ?

C3 C4 1.393(3) . ?

C3 H3 0.9300 . ?

C4 C5 1.387(3) . ?

C4 H4 0.9300 . ?

C5 C6 1.390(3) . ?

C6 C7 1.383(3) . ?

C6 H6 0.9300.?

C7 H7 0.9300 . ?

C8 C9 1.451(2) . ?

C8 H8 0.9300 . ?

C9 C10 1.497(3) . ?

C10 H10A 0.9600 . ?

C10 H10B 0.9600 . ?

C10 H10C 0.9600 . ?

C12 C13 1.434(4) . ?

C12 H12A 0.9700 . ?

C12 H12B 0.9700 . ?

C13 H13A 0.9600 . ?

C13 H13B 0.9600 . ?

C13 H13C 0.9600 . ? 
loop _geom_angle_atom_site_label_1 _geom_angle_atom_site_label_2 _geom_angle_atom_site_label_3 _geom_angle

_geom_angle_site_symmetry_1 _geom_angle_site_symmetry_3 _geom_angle_publ_flag N2 N1 C5 120.30(16) .. ? N2 N1 H14 120.9(14) . .? C5 N1 H14 118.7(14) . . ? C8 N2 N1 117.09(15) .. ? C9 N3 N4 115.96(15) .. ? C11 N4 N3 118.87(15). . ? C11 N4 H15 117.0(14) . . ? N3 N4 H15 117.3(14) .. ?

C11 N5 C12 123.98(18) . . ?

C11 N5 H16 117.8(17) . . ?

C12 N5 H16 116.9(17) . . ?

C2 C1 H1A 109.5 .. ?

C2 C1 H1B 109.5 . .?

H1A C1 H1B 109.5 . . ?

C2 C1 H1C 109.5 . . ?

H1A C1 H1C 109.5 . . ?

H1B C1 H1C 109.5 . . ?

C3 C2 C7 117.08(17) . . ?

C3 C2 C1 121.2(2) .. ?

C7 C2 C1 121.7(2) . . ?

C2 C3 C4 122.6(2) .. ?

C2 C3 H3 118.7 . . ?

C4 C3 H3 118.7 .. ?

C5 C4 C3 119.3(2) .. ?

C5 C4 H4 120.3 . . ?

C3 C4 H4 120.3 . . ?

C4 C5 C6 118.97(17) . . ?

C4 C5 N1 121.85(18) . . ?

C6 C5 N1 119.16(18) . . ?

C7 C6 C5 120.35(19) . . ?

C7 C6 H6 119.8 . . ?

C5 C6 H6 119.8 . . ?

C6 C7 C2 121.68(19) . . ?

C6 C7 H7 119.2 . . ?

C2 C7 H7 119.2 . . ?

N2 C8 C9 119.48(16) . . ?

N2 C8 H8 120.3 . . ?

C9 C8 H8 120.3 ..?

N3 C9 C8 114.84(16) .. ?

N3 C9 C10 125.83(16) . . ? 
C8 C9 C10 119.29(15) . . ?

C9 C10 H10A 109.5 . . ?

C9 C10 H10B 109.5 . . ?

H10A C10 H10B 109.5 .. ?

C9 C10 H10C 109.5 ..?

H10A C10 H10C 109.5 . . ?

H10B C10 H10C 109.5 . . ?

N5 C11 N4 116.59(16) . . ?

N5 C11 S1 123.33(13) . . ?

N4 C11 S1 120.08(13) . . ?

C13 C12 N5 114.1(2) . . ?

C13 C12 H12A 108.7 .. ?

N5 C12 H12A 108.7 . . ?

C13 C12 H12B 108.7 . . ?

N5 C12 H12B $108.7 \ldots$ ?

H12A C12 H12B 107.6 . . ?

C12 C13 H13A 109.5 . . ?

C12 C13 H13B 109.5 . . ?

H13A C13 H13B 109.5 . . ?

C12 C13 H13C 109.5 .. ?

H13A C13 H13C 109.5 .. ?

H13B C13 H13C 109.5 . . ?

_refine_diff_density_max 0.427

_refine_diff_density_min -0.366

_refine_diff_density_rms 0.061

_shelx_res_file

;

TITL ahmed1_a.res in P2(1)/c

ahmed1_a.res

created by SHELXL-2018/3 at 18:41:38 on 04-Apr-2019

REM Old TITL

REM SHELXT solution in P2(1)/c: R1 0.188, Rweak 0.054, Alpha 0.024

$\mathrm{REM}\langle\mathrm{I} / \mathrm{s}>0.739$ for 165 systematic absences, Orientation as input

REM Formula found by SHELXT: C14 N4 S

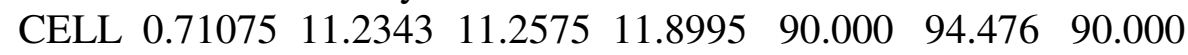

$\begin{array}{llllllll}\text { ZERR } & 4.000 & 0.0006 & 0.0007 & 0.0008 & 0.000 & 0.007 & 0.000\end{array}$

LATT 1

SYMM -X, 1/2+Y, 1/2-Z

SFAC C H N S

UNIT 5276204

L.S. 20

SIZE 0.380 .200 .09

BOND \$h

LIST 6

FMAP 2

PLAN 20

OMIT $1 \quad 2 \quad 2$ 
ACTA

DFIX 0.86 0.01 N1 H14 N4 H15 N5 H16

WGHT 0.100000

FVAR $\quad 0.35726$

$\begin{array}{llllllll}\text { S1 } & 4 & 0.325908 & 0.560673 & 1.036013 & 11.00000 & 0.05375 & 0.04387=\end{array}$ $\begin{array}{llll}0.05004 & 0.00477 & 0.02544 & 0.00024\end{array}$

$\begin{array}{llllllll}\mathrm{N} 1 & 3 & 0.685111 & 0.752904 & 0.466437 & 11.00000 & 0.06285 & 0.04165=\end{array}$ $\begin{array}{llll}0.03987 & 0.00286 & 0.02293 & 0.00804\end{array}$

$\begin{array}{lllllll}\mathrm{H} 14 & 2 & 0.679529 & 0.827073 & 0.480316 & 11.00000 & -1.20000\end{array}$

$\begin{array}{llllllll}\mathrm{N} 2 & 3 & 0.636861 & 0.671699 & 0.532192 & 11.00000 & 0.04461 & 0.04467=\end{array}$ $\begin{array}{llll}0.03209 & 0.00205 & 0.00965 & 0.00332\end{array}$

$\begin{array}{llllllll}\mathrm{N} 3 & 3 & 0.465640 & 0.676284 & 0.764739 & 11.00000 & 0.04507 & 0.04025=\end{array}$ $\begin{array}{llll}0.04046 & 0.00442 & 0.01522 & 0.00436\end{array}$

$\begin{array}{llllllll}\mathrm{N} 4 & 3 & 0.431521 & 0.600822 & 0.849029 & 11.00000 & 0.04827 & 0.03818=\end{array}$ $\begin{array}{llll}0.04392 & 0.00494 & 0.01952 & 0.00572\end{array}$

$\begin{array}{lllllll}\mathrm{H} 15 & 2 & 0.482774 & 0.549149 & 0.874972 & 11.00000 & -1.20000\end{array}$

$\begin{array}{llllllll}\mathrm{N} 5 & 3 & 0.297166 & 0.741352 & 0.893094 & 11.00000 & 0.06697 & 0.04282=\end{array}$ $\begin{array}{llll}0.07240 & 0.01498 & 0.04011 & 0.01308\end{array}$

$\begin{array}{lllllll}\mathrm{H} 16 & 2 & 0.300615 & 0.767125 & 0.825724 & 11.00000 & -1.20000\end{array}$

$\begin{array}{llllllll}\mathrm{C} 1 & 1 & 0.961540 & 0.614991 & 0.103780 & 11.00000 & 0.05922 & 0.11859=\end{array}$ $\begin{array}{llll}0.05185 & -0.01933 & 0.02237 & 0.00646\end{array}$

AFIX 137

$\begin{array}{lllllll}\text { H1A } & 2 & 0.950609 & 0.671986 & 0.043853 & 11.00000 & -1.50000 \\ \text { H1B } & 2 & 0.936122 & 0.538126 & 0.076446 & 11.00000 & -1.50000 \\ \text { H1C } & 2 & 1.044405 & 0.611848 & 0.130297 & 11.00000 & -1.50000\end{array}$

AFIX 0

$\begin{array}{llllllll}\mathrm{C} 2 & 1 & 0.888346 & 0.651201 & 0.199363 & 11.00000 & 0.03966 & 0.08440=\end{array}$ $\begin{array}{llll}0.03763 & -0.00828 & 0.00888 & 0.00753\end{array}$

$\begin{array}{llllllll}\mathrm{C} 3 & 1 & 0.829727 & 0.567924 & 0.259588 & 11.00000 & 0.05260 & 0.06705=\end{array}$ $\begin{array}{llll}0.05177 & -0.01959 & 0.01138 & 0.00525\end{array}$

AFIX 43

$\begin{array}{lllllll}\mathrm{H} 3 & 2 & 0.835196 & 0.488297 & 0.239820 & 11.00000 & -1.20000\end{array}$

AFIX 0

$\begin{array}{llllllll}\text { C4 } & 1 & 0.762616 & 0.598356 & 0.348901 & 11.00000 & 0.05104 & 0.05436=\end{array}$ $\begin{array}{llll}0.04512 & -0.00459 & 0.01433 & 0.00330\end{array}$

AFIX 43

$\begin{array}{lllllll}\mathrm{H} 4 & 2 & 0.724557 & 0.539822 & 0.388030 & 11.00000 & -1.20000\end{array}$

AFIX 0

$\begin{array}{llllllll}\text { C5 } & 1 & 0.753129 & 0.716863 & 0.378888 & 11.00000 & 0.04264 & 0.05297=\end{array}$ $\begin{array}{llll}0.03021 & 0.00056 & 0.00722 & 0.00810\end{array}$

$\begin{array}{llllllll}\text { C6 } & 1 & 0.811200 & 0.802265 & 0.318880 & 11.00000 & 0.05393 & 0.05281=\end{array}$ $\begin{array}{llll}0.04252 & 0.00545 & 0.01409 & 0.00680\end{array}$

AFIX 43

$\begin{array}{lllllll}\text { H6 } & 2 & 0.805702 & 0.882002 & 0.338245 & 11.00000 & -1.20000\end{array}$ AFIX 0

$\begin{array}{llllllll}\text { C7 } & 1 & 0.877117 & 0.769274 & 0.230518 & 11.00000 & 0.05014 & 0.07112=\end{array}$ $\begin{array}{llll}0.04123 & 0.00785 & 0.01463 & 0.00620\end{array}$

AFIX 43

$\begin{array}{lllllll}\text { H7 } & 2 & 0.914878 & 0.827681 & 0.190970 & 11.00000 & -1.20000\end{array}$ 
AFIX 0

$\begin{array}{llllllll}\mathrm{C} 8 & 1 & 0.572736 & 0.710979 & 0.609705 & 11.00000 & 0.04906 & 0.03928=\end{array}$ $\begin{array}{llll}0.03814 & 0.00207 & 0.01130 & 0.00908\end{array}$

AFIX 43

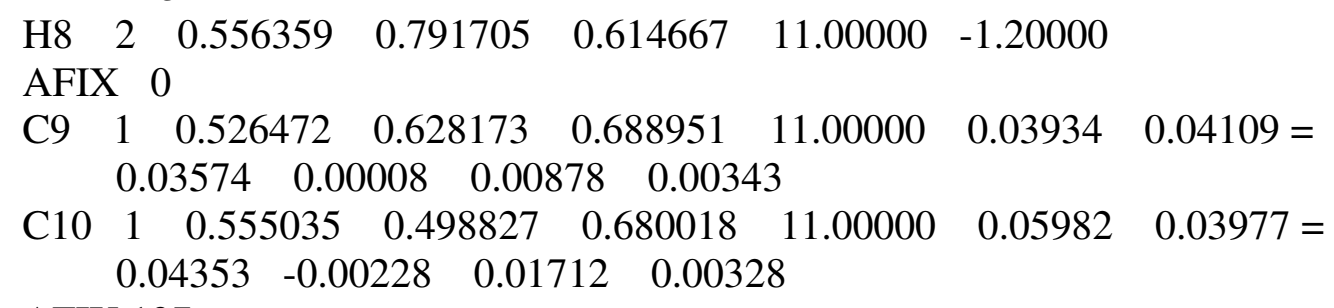
AFIX 137

$\begin{array}{lllllll}\text { H10A } & 2 & 0.565262 & 0.479277 & 0.602837 & 11.00000 & -1.50000 \\ \text { H10B } & 2 & 0.490808 & 0.452641 & 0.706026 & 11.00000 & -1.50000 \\ \text { H10C } & 2 & 0.627357 & 0.481594 & 0.725461 & 11.00000 & -1.50000\end{array}$

AFIX 0

$\begin{array}{llllllll}\mathrm{C} 11 & 1 & 0.352143 & 0.640453 & 0.920351 & 11.00000 & 0.03991 & 0.03389=\end{array}$ $\begin{array}{llll}0.04875 & -0.00209 & 0.01640 & -0.00249\end{array}$

$\begin{array}{llllllll}\mathrm{C} 12 & 1 & 0.211143 & 0.798501 & 0.961491 & 11.00000 & 0.14584 & 0.07529=\end{array}$ $\begin{array}{llll}0.14661 & 0.04767 & 0.10944 & 0.05818\end{array}$

AFIX 23

$\begin{array}{lllllll}\text { H12A } & 2 & 0.157908 & 0.738322 & 0.987452 & 11.00000 & -1.20000 \\ \text { H12B } & 2 & 0.253907 & 0.833270 & 1.027433 & 11.00000 & -1.20000\end{array}$

AFIX 0

$\begin{array}{llllllll}\mathrm{C} 13 & 1 & 0.140945 & 0.889209 & 0.903495 & 11.00000 & 0.05874 & 0.11290=\end{array}$ $\begin{array}{llll}0.11513 & -0.02626 & 0.00572 & 0.03063\end{array}$

AFIX 137

$\begin{array}{lllllll}\text { H13A } & 2 & 0.191889 & 0.953572 & 0.884850 & 11.00000 & -1.50000 \\ \text { H13B } & 2 & 0.082090 & 0.917877 & 0.951162 & 11.00000 & -1.50000 \\ \text { H13C } 2 & 0.101857 & 0.856907 & 0.835644 & 11.00000 & -1.50000\end{array}$

REM \#\#\#\#\#

REM \#\#\#\#\#

AFIX 0

HKLF 4

REM ahmed1_a.res in P2(1)/c

REM wR2 $=0.1761, \mathrm{GooF}=\mathrm{S}=1.303$, Restrained $\mathrm{GooF}=1.302$ for all data REM R1 $=0.0558$ for $2731 \mathrm{Fo}>4 \operatorname{sig}(\mathrm{Fo})$ and 0.0688 for all 3427 data

REM 184 parameters refined using 3 restraints

END

WGHT $\quad 0.0921 \quad 0.4882$

REM Highest difference peak 0.427 , deepest hole -0.366 , 1 -sigma level 0.061

$\begin{array}{llllllll}\text { Q1 } & 1 & 0.3173 & 0.5831 & 0.9659 & 11.00000 & 0.05 & 0.43\end{array}$

$\begin{array}{llllllll}\text { Q2 } & 1 & 0.1603 & 0.7608 & 0.8904 & 11.00000 & 0.05 & 0.42\end{array}$

$\begin{array}{llllllll}\text { Q3 } & 1 & 0.1775 & 0.8614 & 0.9865 & 11.00000 & 0.05 & 0.35\end{array}$

$\begin{array}{llllllll}\mathrm{Q} 4 & 1 & 0.4511 & 0.6515 & 0.7971 & 11.00000 & 0.05 & 0.31\end{array}$

$\begin{array}{llllllll}\text { Q5 } & 1 & 0.7135 & 0.7364 & 0.4214 & 11.00000 & 0.05 & 0.31\end{array}$ 


\begin{tabular}{|c|c|c|c|c|c|c|c|}
\hline Q6 & 1 & 0.2601 & 0.7192 & 0.8333 & 11.00000 & 0.05 & 0.30 \\
\hline Q7 & 1 & 0.7598 & 0.7543 & 0.3288 & 11.00000 & 0.05 & 0.29 \\
\hline Q8 & 1 & 0.6132 & 0.6902 & 0.5843 & 11.00000 & 0.05 & 0.29 \\
\hline Q9 & 1 & 0.5410 & 0.6627 & 0.6437 & 11.00000 & 0.05 & 0.29 \\
\hline Q10 & 1 & 0.3854 & 0.6092 & 0.8787 & 11.00000 & 0.05 & 0.29 \\
\hline Q11 & 1 & 0.2039 & 0.7775 & 1.0295 & 11.00000 & 0.05 & 0.28 \\
\hline Q12 & 1 & 0.6529 & 0.7071 & 0.4955 & 11.00000 & 0.05 & 0.28 \\
\hline Q13 & 1 & 0.8224 & 0.5872 & 0.3142 & 11.00000 & 0.05 & 0.27 \\
\hline Q14 & 1 & 0.3553 & 0.5707 & 1.1036 & 11.00000 & 0.05 & 0.27 \\
\hline Q15 & 1 & 0.4866 & 0.6431 & 0.7229 & 11.00000 & 0.05 & 0.27 \\
\hline Q16 & 1 & 0.7463 & 0.6697 & 0.3567 & 11.00000 & 0.05 & 0.26 \\
\hline Q17 & 1 & 0.3280 & 0.5649 & 1.0656 & 11.00000 & 0.05 & 0.25 \\
\hline Q18 & 1 & 0.2874 & 0.5784 & 1.0821 & 11.00000 & 0.05 & 0.25 \\
\hline Q19 & 1 & 0.3413 & 0.7874 & 0.8632 & 11.00000 & 0.05 & 0.25 \\
\hline Q20 & 1 & 0.5320 & 0.5693 & 0.6844 & 11.00000 & 0.05 & 0.23 \\
\hline
\end{tabular}




\section{TSC3 Compound CIF File (Structure without hkl data)}

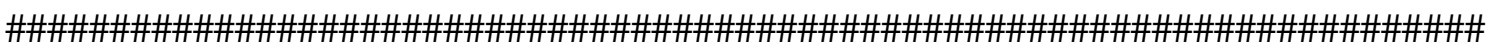

\#

\# This file contains crystal structure data downloaded from the

\# Cambridge Structural Database (CSD) hosted by the Cambridge

\# Crystallographic Data Centre (CCDC).

\#

\# Full information about CCDC data access policies and citation

\# guidelines are available at http://www.ccdc.cam.ac.uk/access/V1

\#

\# Audit and citation data items may have been added by the CCDC.

\# Please retain this information to preserve the provenance of

\# this file and to allow appropriate attribution of the data.

\#

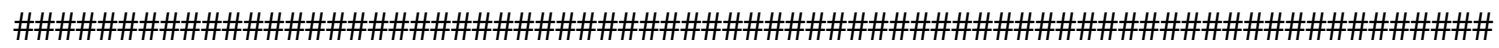

_database_code_depnum_ccdc_archive 'CCDC 2033322'

loop_

The crystal was

placed in the cold stream of an Oxford

Cryosystems open-flow nitrogen cryostat (Cosier \&

Glazer, 1986) with a nominal stability of $0.1 \mathrm{~K}$.

Cosier, J. \& Glazer, A.M., 1986. J. Appl. Cryst. 105-107.

_refine_special_details

\#--

\#_oxford_data items, April 2010:

\# There is some uncertainty about the correct way of forming local data

\# names, e.g.

\#_atom_site_special_shape_oxford

\# or

\# _oxford_atom_site_special_shape

\# see:

\# http://www.iucr.org/resources/cif/spec/version1.1/semantics\#namespace 
\# A reserved prefix, e.g. foo, must be used in the following way

\# " If the data file contains items defined in a DDL1 dictionary, the

\# local data names assigned under the reserved prefix must contain it as

\# their first component, e.g._foo_atom_site_my_item."

\# However, this seems to say the opposite:

\# http://www.iucr.org/_data/iucr/cif/standard/cifstd8.html

\# According to advice from the IUCr, CRYSTALS is correct

\#-

\# End of 'script/refcif.dat'

\#end of refcif

_cell_length_a

27.958(12)

_cell_length_b

12.702(5)

_cell_length_c

9.833(4)

_cell_angle_alpha

90

_cell_angle_beta

93.117(11)

_cell_angle_gamma

90

_cell_volume

$3487(2)$

_symmetry_cell_setting_monoclinic

_symmetry_space_group_name_H-M 'P 1 21/c 1 '

_symmetry_space_group_name_Hall '-P 2ybc '

loop_

_symmetry_equiv_pos_as_xyz

$\mathrm{x}, \mathrm{y}, \mathrm{z}$

$-\mathrm{x},-\mathrm{y},-\mathrm{z}$

$-\mathrm{x}, \mathrm{y}+1 / 2,-\mathrm{z}+1 / 2$

$\mathrm{x},-\mathrm{y}+1 / 2, \mathrm{z}+1 / 2$

loop_

_atom_type_symbol 


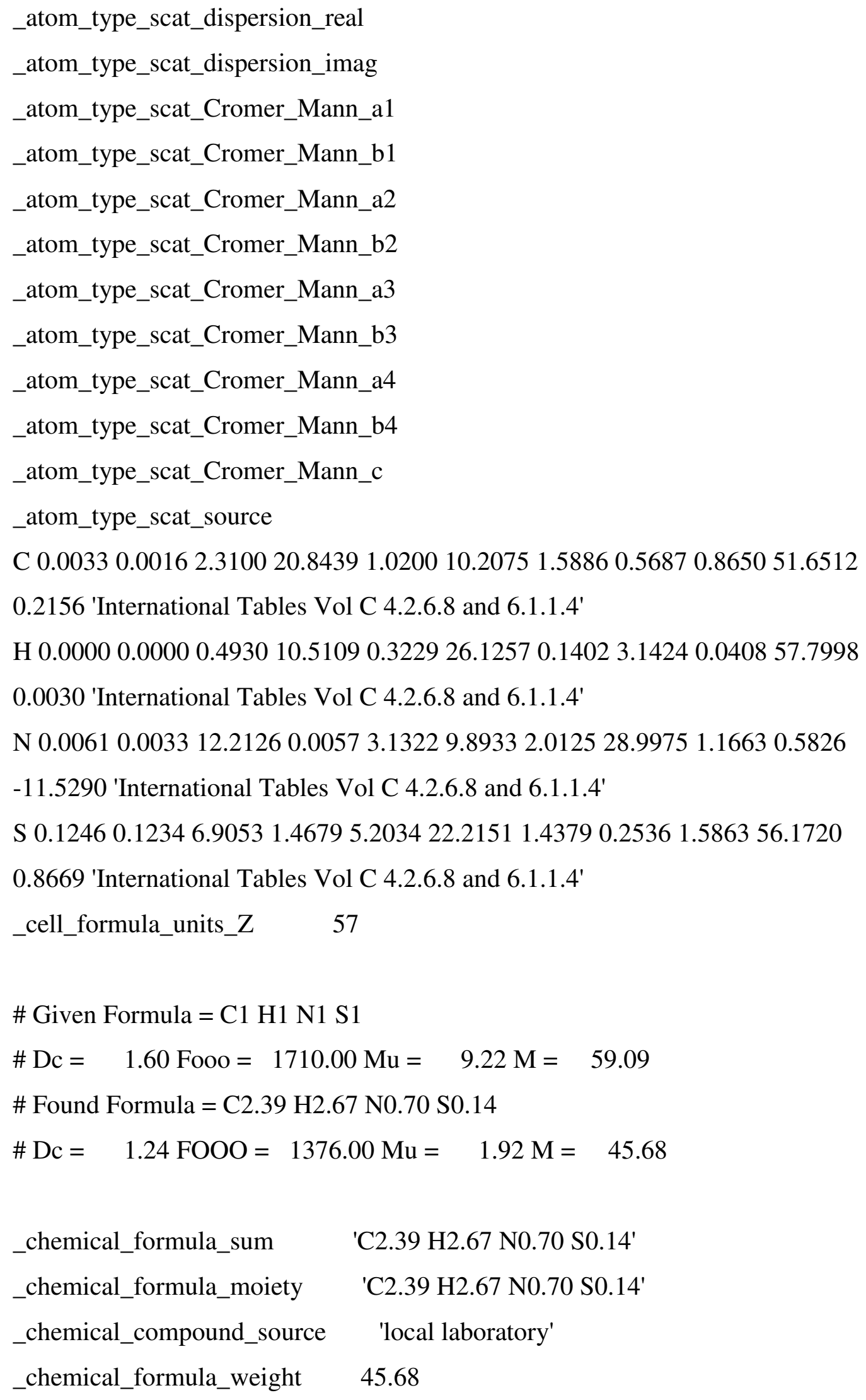


_cell_measurement_reflns_used 0

_cell_measurement_theta_min 0

_cell_measurement_theta_max 0

_cell_measurement_temperature 293

_exptl_crystal_description cube

_exptl_crystal_colour_colourless

_exptl_crystal_size_min 0.290

_exptl_crystal_size_mid $\quad 0.370$

_exptl_crystal_size_max $\quad 0.480$

_exptl_crystal_density_diffrn 1.240

_exptl_crystal_density_meas ?

_exptl_crystal_density_method 'not measured'

\# Non-dispersive F(000):

_exptl_crystal_F_000 1376

_exptl_absorpt_coefficient_mu 0.192

\# Sheldrick geometric approximatio 0.930 .95

_exptl_absorpt_correction_type none

_diffrn_measurement_device_type KappaCCD

_diffrn_measurement_device Serial

_diffrn_radiation_monochromator graphite

_diffrn_radiation_type_ 'Mo Kla'

_diffrn_radiation_wavelength 0.71073

_diffrn_measurement_method Iw

\# If a reference occurs more than once, delete the author

\# and date from subsequent references.

_computing_data_collection 'USER DEFINED DATA COLLECTION'

_computing_cell_refinement 'USER DEFINED CELL REFINEMENT'

_computing_data_reduction 'DENZO/SCALEPACK (Otwinowski \& Minor, 1997)'

_computing_structure_solution 'SIR92 (Altomare et al., 1994)'

_computing_structure_refinement 'CRYSTALS (Betteridge et al., 2003)'

_computing_publication_material 'CRYSTALS (Betteridge et al., 2003)' 
_computing_molecular_graphics 'CAMERON (Watkin et al., 1996)'

_diffrn_standards_interval_time .

_diffrn_standards_interval_count .

_diffrn_standards_number 0

_diffrn_standards_decay_\% ?

_diffrn_ambient_temperature 293

_diffrn_reflns_number 14423

_reflns_number_total 2208

_diffrn_reflns_av_R_equivalents 0.070

\# Number of reflections without Friedels Law is 0

\# Number of reflections with Friedels Law is 2208

\# Theoretical number of reflections is about 4483

_diffrn_reflns_theta_min 0.729

_diffrn_reflns_theta_max 25.580

_diffrn_measured_fraction_theta_max 0.983

_diffrn_reflns_theta_full 25.052

_diffrn_measured_fraction_theta_full 0.995

_diffrn_reflns_limit_h_min -23

_diffrn_reflns_limit_h_max 23

_diffrn_reflns_limit_k_min $\quad-10$

_diffrn_reflns_limit_k_max 10

_diffrn_reflns_limit_1_min -8

_diffrn_reflns_limit_1_max 8

_reflns_limit_h_min $\quad-23$

_reflns_limit_h_max 23

_reflns_limit_k_min 0 
_reflns_limit_k_max $\quad 10$

_reflns_limit_1_min 0

_reflns_limit_1_max 8

_atom_sites_solution_primary direct \#heavy,direct,difmap,geom, iterative

\# _atom_sites_solution_secondary difmap

_atom_sites_solution_hydrogens difmap

_refine_diff_density_min $\quad-0.14$

_refine_diff_density_max $\quad 0.14$

\# The current dictionary definitions do not cover the

\# situation where the reflections used for refinement were

\# selected by a user-defined sigma threshold

\# The values actually used during refinement

_refine_ls_number_reflns 1390

_refine_ls_number_restraints 24

_refine_ls_number_parameters 440

_refine_ls_wR_factor_ref 0.0980

_refine_ls_goodness_of_fit_ref 1.0035

_refine_ls_shift/su_max $\quad 0.0018275$

_refine_ls_shift/su_mean 0.0000630

\# The values computed with all filters except I/sigma 
_refine_ls_R_factor_all 0.0935

_refine_ls_wR_factor_all 0.1506

\# The values computed with a 2 sigma cutoff - a la SHELX

_reflns_threshold_expression I $>2.0 \backslash \mathrm{s}(\mathrm{I})$

_reflns_number_gt 1390

_refine_ls_R_factor_gt 0.0442

_refine_ls_wR_factor_gt $\quad 0.0980$

\# choose from: rm (reference molecule of known chirality), \# ad (anomolous dispersion - Flack), rmad (rm and ad), \# syn (from synthesis), unk (unknown) or . (not applicable).

_chemical_absolute_configuration .

_refine_ls_structure_factor_coef Fsqd

_refine_ls_matrix_type full

_refine_1s_hydrogen_treatment mixed \#undef, noref, refall,

\# refxyz, refU, constr or mixed

_refine_ls_weighting_scheme calc

_refine_ls_weighting_details

Method, part 1, Chebychev polynomial, (Watkin, 1994, Prince, 1982)

[weight $\left.]=1.0 /[\mathrm{A} \sim 0 \sim * \mathrm{~T} \sim 0 \sim(\mathrm{x})+\mathrm{A} \sim 1 \sim * \mathrm{~T} \sim 1 \sim(\mathrm{x}) . . .+\mathrm{A} \sim \mathrm{n}-1 \sim]^{*} \mathrm{~T} \sim \mathrm{n}-1 \sim(\mathrm{x})\right]$

where $\mathrm{A} \sim \mathrm{i} \sim$ are the Chebychev coefficients listed below and $\mathrm{x}=$ Fcalc/Fmax

Method $=$ Robust Weighting (Prince, 1982)

$\mathrm{W}=[$ weight $] *\left[1-\left(\operatorname{deltaF} / 6^{*} \operatorname{sigmaF}\right)^{\wedge} 2^{\wedge}\right]^{\wedge} 2^{\wedge}$

$\mathrm{A} \sim \mathrm{i} \sim$ are:

4.045 .842 .490 .530

\# Uequiv $=$ arithmetic mean of Ui i.e. Ueqiv $=(\mathrm{U} 1+\mathrm{U} 2+\mathrm{U} 3) / 3$ 
\# Replace last . with number of unfound hydrogen atoms attached to an atom.

\# ..._refinement_flags_...

\# . no refinement constraints $\quad \mathrm{S}$ special position constraint on site

\# $\mathrm{G}$ rigid group refinement of site $\mathrm{R}$ riding atom

\# D distance or angle restraint on site $\mathrm{T}$ thermal displacement constraints

\# U Uiso or Uij restraint (rigid bond) P partial occupancy constraint

loop_

_atom_site_label

_atom_site_type_symbol

_atom_site_fract_x

_atom_site_fract_y

_atom_site_fract_z

_atom_site_U_iso_or_equiv

_atom_site_occupancy

_atom_site_adp_type

_atom_site_refinement_flags_posn

_atom_site_refinement_flags_adp

_atom_site_refinement_flags_occupancy

_atom_site_disorder_assembly

_atom_site_disorder_group

_atom_site_attached_hydrogens

S1 S 0.55448(8) 0.58862(18) 1.0980(2) 0.08471 .0000 Uani . . . . .

C2 C 0.5318(4) 0.6895(8) 1.0025(9) 0.06101 .0000 Uani D . . . .

N3 N 0.5471(3) 0.7891(7) 1.0109(7) 0.06591 .0000 Uani D . . . .

C4 C 0.5865(4) 0.8352(10) 1.0822(12) 0.06211 .0000 Uani D . . . .

C5 C 0.6102(5) 0.9168(10) 1.0233(10) 0.09481 .0000 Uani ... . . .

C6 C 0.6480(5) 0.9680(8) 1.0919(17) 0.10521 .0000 Uani ..... .

C7 C 0.6621(4) 0.9343(13) 1.2206(16) 0.10161 .0000 Uani ......

C8 C 0.6388(6) 0.8536(12) 1.2780(11) 0.10381 .0000 Uani ..... .

C9 C 0.6008(4) 0.8050(8) 1.2095(14) 0.08741 .0000 Uani ... . . . 
N10 N 0.4952(3) 0.6727(6) 0.9084(9) 0.06481 .0000 Uani D . . . .

N11 N 0.4743(3) 0.7551(6) 0.8382(10) 0.06751 .0000 Uani D . . . .

C12 C 0.4450(4) 0.7363(9) 0.7353(12) 0.05871 .0000 Uani ..... .

C13 C 0.4228(4) 0.8254(7) 0.6721(12) 0.06181 .0000 Uani ... . . .

N14 N 0.3912(3) 0.8149(6) 0.5761(10) 0.06501 .0000 Uani D . . . .

N15 N 0.3717(3) 0.9018(7) 0.5210(9) 0.07521 .0000 Uani D . . . .

C16 C 0.3391(3) 0.8959(10) 0.4098(11) 0.06071 .0000 Uani D . . . . .

C17 C 0.3227(3) 0.8018(8) 0.3567(11) 0.06601 .0000 Uani . . . . .

C18 C 0.2907(4) 0.8003(8) 0.2438(12) 0.07891 .0000 Uani . . . . .

C19 C 0.2739(3) 0.8909(12) 0.1827(9) 0.07201 .0000 Uani ... . . .

C20 C 0.2908(4) 0.9855(9) 0.2368(12) 0.07301 .0000 Uani . . . . .

C21 C 0.3226(4) 0.9874(8) 0.3494(12) 0.06711 .0000 Uani ......

C22 C 0.2378(3) 0.8923(7) 0.0615(9) 0.10481 .0000 Uani ......

C23 C 0.4345(3) 0.6281(7) 0.6808(8) 0.07991 .0000 Uani . . . . . .

S24 S 0.92736(9) 1.09072(19) 0.9319(2) 0.08491 .0000 Uani . . . . .

C25 C 0.9481(4) 1.1701(9) 1.0574(9) 0.06711 .0000 Uani D . . . .

N26 N 0.9295(3) 1.2657(8) 1.0827(7) 0.07701 .0000 Uani D . . . .

C27 C 0.8895(5) 1.3151(7) 1.0099(14) 0.06901 .0000 Uani D . . . .

C28 C 0.8483(6) 1.3280(8) 1.0788(10) 0.08531 .0000 Uani ......

C29 C 0.8090(5) 1.3761(9) 1.0161(17) 0.09671 .0000 Uani . . . . .

C30 C 0.8110(4) 1.4112(8) 0.8852(18) 0.09231 .0000 Uani . . . . .

C31 C 0.8513(6) 1.3992(8) 0.8165(10) 0.09381 .0000 Uani ......

C32 C 0.8911(4) 1.3523(9) 0.8805(13) 0.08581 .0000 Uani ..... .

N33 N 0.9851(3) 1.1425(6) 1.1463(10) 0.06651 .0000 Uani D . . . .

N34 N 1.0052(3) 1.2149(6) 1.2341(11) 0.06731 .0000 Uani D . . . .

C35 C 1.0341(4) 1.1826(9) 1.3327(12) 0.06511 .0000 Uani ... . . .

C36 C 1.0437(3) 1.0684(8) 1.3636(8) 0.08601 .0000 Uani . . . . .

C37 C 1.0572(4) 1.2623(7) 1.4134(14) 0.06511 .0000 Uani . . . . .

N38 N 1.0868(4) 1.2406(7) 1.5111(11) 0.06731 .0000 Uani D . . . .

N39 N 1.1084(3) 1.3199(6) 1.5786(10) 0.06991 .0000 Uani D . . . .

C40 C 1.1429(4) 1.2974(10) 1.6816(11) 0.05761 .0000 Uani D . . . .

C41 C 1.1646(4) 1.3799(8) 1.7513(13) 0.07271 .0000 Uani . . . . .

C42 C 1.1991(4) 1.3590(10) 1.8513(12) 0.07751 .0000 Uani ... . . . 
C43 C 1.2135(3) 1.2588(12) 1.8843(9) 0.07061 .0000 Uani . . . . . C44 C 1.2528(3) 1.2381(7) 1.9934(8) 0.09611 .0000 Uani . . . . .

C45 C 1.1911(4) 1.1774(8) 1.8143(11) 0.07521 .0000 Uani . . . . . C46 C 1.1562(4) 1.1945(9) 1.7125(10) 0.07381 .0000 Uani ..... . H51 H 0.6007 0.93720.9329 0.1178 1.0000 Uiso R . . . . H61 H 0.66381 .02591 .05310 .13441 .0000 Uiso R . . . . H71 H 0.68820 .96731 .26960 .11451 .0000 Uiso R . . . . H81 H 0.64910 .83001 .36660 .12901 .0000 Uiso R . . . . . H91 H 0.58390 .74991 .25090 .11861 .0000 Uiso R . . . . H131 H 0.43270 .89320 .70310 .08841 .0000 Uiso R . . . . H171 H 0.33290 .73800 .39970 .08881 .0000 Uiso R . . . . H181 H 0.2809 0.7337 0.2085 0.1013 1.0000 Uiso R . . . . H201 H 0.27921 .04840 .19460 .09991 .0000 Uiso R . . . . H211 H 0.33331 .05370 .38370 .08721 .0000 Uiso R . . . . H221 H 0.23240 .96420 .03890 .12291 .0000 Uiso R . . . . H222 H $0.24980 .8566-0.01440 .12291 .0000$ Uiso R . . . . H223 H 0.20850 .86090 .08480 .12291 .0000 Uiso R . . . . H231 H 0.41170 .63200 .60570 .11451 .0000 Uiso R . . . . H232 H 0.46330 .59790 .65190 .11451 .0000 Uiso R . . . . H233 H 0.42220 .58580 .75040 .11451 .0000 Uiso R . . . . H281 H 0.84801 .30191 .16930 .10921 .0000 Uiso R . . . . H291 H 0.78081 .38341 .06490 .12741 .0000 Uiso R . . . . H301 H 0.78371 .44570 .84440 .11661 .0000 Uiso R . . . . H311 H 0.85171 .42320 .72510 .11691 .0000 Uiso R . . . . H321 H 0.91991 .34420 .83430 .11571 .0000 Uiso R . . . . H361 H 1.0654 1.0588 1.4402 0.1169 1.0000 Uiso R . . . . H362 H 1.05661 .03771 .28540 .11691 .0000 Uiso R . . . . H363 H 1.01401 .03561 .38030 .11691 .0000 Uiso R . . . . H371 H 1.05001 .33381 .39230 .08591 .0000 Uiso R . . . . H411 H 1.1562 1.4508 1.73100.0903 1.0000 Uiso R . . . . H421 H 1.2139 1.4155 1.90110.0992 1.0000 Uiso R . . . . H441 H 1.2586 1.1648 2.0038 0.1259 1.0000 Uiso R . . . . H442 H 1.28121 .27231 .96850 .12591 .0000 Uiso R . . . . 
H443 H 1.24301 .26642 .07700 .12591 .0000 Uiso R . . . . .

H451 H 1.1998 1.1069 1.8365 0.1008 1.0000 Uiso R . . . .

H461 H 1.1406 1.1380 1.6650 0.1002 1.0000 Uiso R . . . .

H151 H 0.3889(13) 0.958(2) 0.527(5) 0.090(2) 1.0000 Uiso D . . . .

H101 H 0.4840(18) 0.6104(19) 0.896(6) 0.078(2) 1.0000 Uiso D . . . .

H31 H 0.5319(17) 0.831(2) 0.954(5) 0.079(2) 1.0000 Uiso D . . . .

H391 H 1.103(2) 1.3842(17) 1.554(5) 0.084(2) 1.0000 Uiso D . . . .

H331 H 0.994(2) 1.078(2) 1.150(6) 0.080(2) 1.0000 Uiso D . . . .

H261 H 0.9470(15) 1.305(2) 1.134(6) 0.092(2) 1.0000 Uiso D . . . .

loop_

_atom_site_aniso_label

_atom_site_aniso_U_11

_atom_site_aniso_U_22

_atom_site_aniso_U_33

_atom_site_aniso_U_23

_atom_site_aniso_U_13

_atom_site_aniso_U_12

S1 0.0867(17) 0.0643(17) 0.1003(18) 0.0090(16) -0.0198(14) 0.0055(15)

C2 0.063(7) 0.048(8) 0.072(7) 0.006(6) 0.006(6) 0.012(6)

$\mathrm{N} 3$ 0.072(6) 0.056(7) 0.067(6) 0.002(4) -0.025(5) -0.003(5)

C4 0.067(8) 0.072(9) 0.044(8) -0.014(7) -0.020(7) 0.006(7)

C5 0.120(9) 0.064(7) 0.098(8) 0.014(8) -0.017(9) -0.019(7)

C6 0.113(10) 0.091(8) 0.111(11) -0.002(9) -0.006(8) -0.051(8)

C7 0.072(8) 0.142(13) 0.088(10) -0.031(8) -0.022(8) 0.003(9)

C8 0.110(10) 0.122(10) 0.078(8) 0.013(9) -0.011(10) 0.002(8)

C9 0.080(8) 0.107(8) 0.073(10) -0.017(8) -0.012(6) -0.022(7)

N10 0.052(5) 0.070(7) 0.071(5) -0.007(6) -0.017(4) -0.012(5)

N11 0.068(5) 0.064(6) 0.069(6) 0.031(5) -0.010(5) 0.012(5)

C12 0.042(6) 0.089(10) 0.044(7) 0.017(8) -0.006(5) 0.004(7)

C13 0.056(6) 0.057(8) 0.071(7) 0.017(7) -0.014(6) 0.008(6)

N14 0.055(5) 0.070(7) 0.068(6) 0.020(5) -0.015(5) 0.001(5)

N15 0.074(6) 0.071(7) 0.078(6) 0.015(6) -0.021(5) -0.001(5)

C16 0.057(6) 0.050(8) 0.073(7) 0.005(8) -0.010(6) 0.005(7) 
C17 0.064(7) 0.059(9) 0.074(8) 0.009(6) -0.005(6) -0.002(6)

C18 0.097(8) 0.068(9) 0.070(7) -0.004(7) -0.012(7) -0.001(7)

C19 0.064(6) 0.085(9) 0.066(7) 0.004(8) -0.009(6) -0.005(8)

C20 0.069(7) 0.079(10) 0.070(8) 0.016(7) -0.008(6) 0.008(6)

C21 0.074(7) 0.051(8) 0.076(8) 0.002(6) -0.002(7) 0.008(6)

C22 0.095(7) 0.117(8) 0.099(7) -0.010(7) -0.026(7) 0.002(7)

C23 0.088(7) 0.070(7) 0.081(6) -0.004(6) -0.005(5) -0.008(6)

S24 0.1056(19) 0.0761(18) 0.0708(16) -0.0077(16) -0.0165(14) -0.0066(15)

C25 0.087(8) 0.064(8) 0.051(7) -0.016(6) 0.014(7) -0.017(7)

N26 0.070(6) 0.082(7) 0.076(6) -0.020(5) -0.022(5) -0.007(5)

C27 0.061(9) 0.073(7) 0.074(10) -0.031(7) 0.009(8) -0.005(6)

C28 0.112(10) 0.071(7) 0.072(7) 0.008(6) -0.008(10) 0.015(7)

C29 0.114(12) 0.080(8) 0.099(10) 0.007(7) 0.030(8) -0.008(8)

C30 0.071(9) 0.066(7) 0.139(13) -0.018(8) -0.005(8) 0.018(6)

C31 0.126(10) 0.087(8) 0.066(7) -0.002(6) -0.025(10) 0.030(8)

C32 0.110(11) 0.109(8) 0.040(8) -0.009(6) 0.018(7) -0.003(8)

N33 0.064(5) 0.074(6) 0.059(5) 0.002(6) -0.019(4) -0.007(5)

N34 0.064(5) 0.083(6) 0.054(5) -0.037(6) -0.004(4) -0.017(5)

C35 0.048(7) 0.103(12) 0.043(7) -0.005(8) -0.007(6) 0.004(7)

C36 0.088(7) 0.094(9) 0.075(7) 0.002(6) -0.002(5) 0.006(6)

C37 0.068(7) 0.063(7) 0.063(7) -0.021(7) -0.004(6) -0.011(7)

N38 0.059(6) 0.090(8) 0.052(6) -0.009(6) -0.010(5) 0.002(5)

N39 0.071(5) 0.067(6) 0.070(6) -0.014(6) -0.020(5) -0.005(6)

C40 0.064(7) 0.062(9) 0.046(7) -0.006(7) 0.000(6) 0.004(8)

C41 0.077(7) 0.066(9) 0.073(7) -0.004(8) -0.009(6) 0.006(7)

C42 0.077(8) 0.078(10) 0.076(8) -0.006(6) -0.009(7) -0.011(7)

C43 0.062(7) 0.094(10) 0.054(7) 0.004(7) -0.017(6) 0.000(8)

C44 0.094(7) 0.109(8) 0.083(7) 0.005(6) -0.012(7) -0.001(6)

C45 0.079(7) 0.065(8) 0.079(7) -0.012(7) -0.014(6) 0.001(7)

C46 0.066(7) 0.077(10) 0.075(7) -0.016(6) -0.019(6) -0.005(6)

_refine_ls_extinction_coef 26(13)

_refine_ls_extinction_method 'Larson (1970), Equation 22' 
loop_

_geom_bond_atom_site_label_1

_geom_bond_site_symmetry_1

_geom_bond_atom_site_label_2

_geom_bond_site_symmetry_2

_geom_bond_distance

_geom_bond_publ_flag

S1 . C2 . 1.692(8) yes

C2 . N3 . 1.337(9) yes

C2 . N10 . 1.358(9) yes

N3 . C4 . 1.401(10) yes

N3 . H31 . 0.863(19) no

C4 . C5 . 1.375(11) yes

C4 . C9 . 1.350(11) yes

C5 . C6 . 1.383(12) yes

C5 . H51 . 0.950 no

C6 . C7 . 1.373(12) yes

C6 . H61 . 0.950 no

C7 . C8 . 1.355(12) yes

C7 . H71 . 0.950 no

C8 . C9 . 1.372(12) yes

C8 . H81 . 0.950 no

C9 . H91 . 0.950 no

N10 . N11 . 1.368(8) yes

N10 . H101 . 0.857(19) no

N11 . C12 . 1.288(9) yes

C12 . C13 . 1.419(11) yes

C12 . C23 . 1.498(10) yes

C13 . N14 . 1.263(9) yes

C13 . H131 . 0.950 no

N14 . N15 . 1.334(9) yes

N15 . C16 . 1.387(10) yes 
N15 . H151 . 0.857(19) no

C16 . C17 . 1.373(10) yes

C16 . C21 . 1.374(10) yes

C17 . C18 . 1.388(10) yes

C17 . H171 . 0.950 no

C18 . C19 . 1.369(10) yes

C18 . H181 . 0.950 no

C19 . C20 . 1.386(10) yes

C19 . C22 . 1.520(10) yes

C20 . C21 . 1.381(10) yes

C20 . H201 . 0.950 no

C21 . H211 . 0.950 no

C22 . H221 . 0.950 no

C22. H222 . 0.950 no

C22. H223 . 0.950 no

C23 . H231 . 0.950 no

C23 . H232 . 0.950 no

C23 . H233 . 0.950 no

S24 . C25 . 1.673(9) yes

C25 . N26 . 1.350(9) yes

C25 . N33 . 1.362(10) yes

N26 . C27 . 1.438(11) yes

N26 . H261 . 0.851(19) no

C27 . C28 . 1.377(11) yes

C27 . C32 . 1.361(11) yes

C28 . C29 . 1.375(12) yes

C28 . H281 . 0.950 no

C29 . C30 . 1.366(12) yes

C29 . H291 . 0.950 no

C30 . C31 . 1.352(12) yes

C30 . H301 . 0.950 no

C31 . C32 . 1.385(11) yes

C31 . H311 . 0.950 no 
C32. H321 . 0.950 no

N33 . N34 . 1.361(8) yes

N33 . H331 . 0.856(19) no

N34 . C35 . 1.295(9) yes

C35 . C36 . 1.503(11) yes

C35 . C37 . 1.420(12) yes

C36 . H361 . 0.950 no

C36 . H362 . 0.950 no

C36 . H363 . 0.950 no

C37 . N38 . 1.265(10) yes

C37 . H371 . 0.950 no

N38 . N39 . 1.333(9) yes

N39 . C40 . 1.388(10) yes

N39 . H391 . 0.864(19) no

C40 . C41 . 1.376(10) yes

C40 . C46 . 1.388(11) yes

C41 . C42 . 1.364(10) yes

C41 . H411 . 0.950 no

C42 . C43 . 1.369(11) yes

C42 . H421 . 0.950 no

C43 . C44 . 1.516(10) yes

C43 . C45 . 1.374(10) yes

C44 . H441 . 0.950 no

C44 . H442 . 0.950 no

C44 . H443 . 0.950 no

C45 . C46 . 1.376(10) yes

C45 . H451 . 0.950 no

C46 . H461 . 0.950 no

loop_

_geom_angle_atom_site_label_1

_geom_angle_site_symmetry_1

_geom_angle_atom_site_label_2

_geom_angle_site_symmetry_2 
_geom_angle_atom_site_label_3

_geom_angle_site_symmetry_3

_geom_angle

_geom_angle_publ_flag

S1 . C2 . N3 . 124.9(8) yes

S1 . C2 . N10 . 120.3(9) yes

N3 . C2 . N10 . 114.7(7) yes

C2 . N3 . C4 . 131.9(8) yes

C2 . N3 . H31 . 113.3(14) no

C4 . N3 . H31 . 114.4(14) no

N3 . C4 . C5 . 119.2(11) yes

N3 . C4 . C9 . 122.0(12) yes

C5 . C4 . C9 . 118.6(9) yes

C4 . C5 . C6 . 121.4(9) yes

C4 . C5 . H51 . 118.9 no

C6 . C5 . H51 . 119.7 no

C5 . C6 . C7 . 118.5(9) yes

C5 . C6 . H61 . 121.9 no

C7 . C6 . H61 . 119.6 no

C6 . C7 . C8 . 119.9(10) yes

C6 . C7 . H71 . 120.3 no

C8 . C7 . H71 . 119.8 no

C7 . C8 . C9 . 120.8(10) yes

C7 . C8 . H81 . 119.5 no

C9 . C8 . H81 . 119.7 no

C8 . C9 . C4 . 120.7(10) yes

C8 . C9 . H91 . 120.8 no

C4 . C9 . H91 . 118.5 no

C2 . N10 . N11 . 120.6(7) yes

C2 . N10 . H101 . 119.8(14) no

N11 . N10 . H101 . 119.5(14) no

N10 . N11 . C12 . 119.3(8) yes

N11 . C12 . C13 . 116.2(9) yes 
N11 . C12 . C23 . 123.7(9) yes

C13 . C12 . C23 . 120.1(8) yes

C12 . C13 . N14 . 121.0(9) yes

C12 . C13 . H131 . 118.0 no

N14 . C13 . H131 . 121.0 no

C13 . N14 . N15 . 118.0(8) yes

N14 . N15 . C16 . 120.8(8) yes

N14 . N15 . H151 . 116.2(17) no

C16 . N15 . H151 . 116.2(17) no

N15 . C16 . C17 . 122.6(10) yes

N15 . C16 . C21 . 119.1(11) yes

C17 . C16 . C21 . 118.3(9) yes

C16 . C17 . C18 . 120.2(8) yes

C16 . C17 . H171 . 119.2 no

C18 . C17 . H171 . 120.5 no

C17 . C18 . C19 . 122.0(8) yes

C17 . C18 . H181 . 117.7 no

C19 . C18 . H181 . 120.2 no

C18 . C19 . C20 . 117.3(8) yes

C18 . C19 . C22 . 123.4(12) yes

C20 . C19 . C22 . 119.2(12) yes

C19 . C20 . C21 . 120.9(8) yes

C19 . C20 . H201 . 117.4 no

C21 . C20 . H201 . 121.7 no

C20 . C21 . C16 . 121.2(8) yes

C20 . C21 . H211 . 118.5 no

C16 . C21 . H211 . 120.3 no

C19. C22 . H221 . 106.5 no

C19. C22 . H222 . 111.3 no

H221 . C22 . H222 . 109.5 no

C19. C22 . H223 . 110.5 no

H221 . C22 . H223 . 109.5 no

H222 . C22 . H223 . 109.5 no 
C12 . C23 . H231 . 109.9 no

C12 . C23 . H232 . 109.0 no

H231 . C23 . H232 . 109.5 no

C12 . C23 . H233 . 109.5 no

H231 . C23 . H233 . 109.5 no

H232 . C23 . H233 . 109.5 no

S24 . C25 . N26 . 123.8(9) yes

S24 . C25 . N33 . 122.6(10) yes

N26 . C25 . N33 . 113.6(7) yes

C25 . N26 . C27 . 126.7(8) yes

C25 . N26 . H261 . 115.4(15) no

C27 . N26 . H261 . 116.3(15) no

N26 . C27 . C28 . 117.1(12) yes

N26 . C27 . C32 . 123.5(12) yes

C28 . C27 . C32 . 119.4(10) yes

C27 . C28 . C29 . 120.1(10) yes

C27 . C28 . H281 . 118.0 no

C29 . C28 . H281 . 121.8 no

C28 . C29 . C30 . 119.7(10) yes

C28 . C29 . H291 . 118.8 no

C30 . C29 . H291 . 121.5 no

C29 . C30 . C31 . 120.8(10) yes

C29 . C30 . H301 . 118.3 no

C31 . C30 . H301 . 120.9 no

C30 . C31 . C32 . 119.5(9) yes

C30 . C31 . H311 . 119.3 no

C32. C31 . H311 . 121.1 no

C31 . C32 . C27 . 120.5(9) yes

C31 . C32 . H321 . 120.7 no

C27 . C32 . H321 . 118.8 no

C25 . N33 . N34 . 120.4(8) yes

C25 . N33 . H331 . 119.1(14) no

N34 . N33 . H331 . 120.4(14) no 
N33 . N34 . C35 . 118.7(8) yes

N34 . C35 . C36 . 123.6(10) yes

N34 . C35 . C37 . 116.0(10) yes

C36 . C35 . C37 . 120.3(9) yes

C35 . C36 . H361 . 112.6 no

C35 . C36 . H362 . 107.7 no

H361 . C36 . H362 . 109.5 no

C35 . C36 . H363 . 108.1 no

H361 . C36 . H363 . 109.5 no

H362 . C36 . H363 . 109.5 no

C35 . C37 . N38 . 121.9(10) yes

C35 . C37 . H371 . 118.4 no

N38 . C37 . H371 . 119.7 no

C37 . N38 . N39 . 118.3(8) yes

N38 . N39 . C40 . 119.1(8) yes

N38 . N39 . H391 . 120.3(14) no

C40 . N39 . H391 . 120.5(14) no

N39 . C40 . C41 . 118.5(11) yes

N39 . C40 . C46 . 121.4(11) yes

C41 . C40 . C46 . 120.1(9) yes

C40 . C41 . C42 . 119.1(9) yes

C40 . C41 . H411 . 121.3 no

C42 . C41 . H411 . 119.6 no

C41 . C42 . C43 . 122.6(8) yes

C41 . C42 . H421 . 119.7 no

C43 . C42 . H421 . 117.7 no

C42 . C43 . C44 . 121.4(12) yes

C42 . C43 . C45 . 117.4(8) yes

C44 . C43 . C45 . 121.1(12) yes

C43 . C44 . H441 . 111.1 no

C43 . C44 . H442 . 108.8 no

H441 . C44 . H442 . 109.5 no

C43 . C44 . H443 . 108.5 no 
H441 . C44 . H443 . 109.5 no

H442 . C44 . H443 . 109.5 no

C43 . C45 . C46 . 122.1(8) yes

C43 . C45 . H451 . 119.4 no

C46 . C45 . H451 . 118.6 no

C40 . C46 . C45 . 118.7(9) yes

C40 . C46 . H461 . 119.6 no

C45 . C46. H461 . 121.7 no

_iucr_refine_instructions_details

;

\#

\# Punched on 22/09/20 at 12:02:33

\#

\#LIST 12

BLOCK

CONT SCALE

CONT S ( $\left.1, X^{\prime} S, U^{\prime} S\right)$ UNTIL C ( 46 )

CONT H ( 151, X'S,U[ISO]) UNTIL H ( 261 )

CONT EXTPARAM

RIDE C $\left(5, X^{\prime} S\right) H \quad\left(51, X^{\prime} S\right)$

RIDE C $\left(6, X^{\prime} S\right) H \quad\left(61, X^{\prime} S\right)$

RIDE C $\left(7, X^{\prime} S\right) H \quad\left(71, X^{\prime} S\right)$

RIDE C $\left(8, X^{\prime} S\right) H \quad\left(81, X^{\prime} S\right)$

RIDE C ( 9,X'S) H (91,X'S)

RIDE C $\left(13, X^{\prime} S\right) H \quad\left(131, X^{\prime} S\right)$

RIDE C $\left(17, X^{\prime} S\right) H \quad\left(171, X^{\prime} S\right)$

RIDE C $\left(18, X^{\prime} S\right) H \quad\left(181, X^{\prime} S\right)$

RIDE C ( 20,X'S) H (201,X'S)

RIDE C ( 21,X'S) H (211,X'S)

RIDE C ( 22,X'S)H (221,X'S)H (222,X'S)H (223,X'S)

RIDE C $\quad\left(23, X^{\prime} S\right) H \quad(231, X ' S) H \quad(232, X ' S) H \quad(233, X ' S)$ 


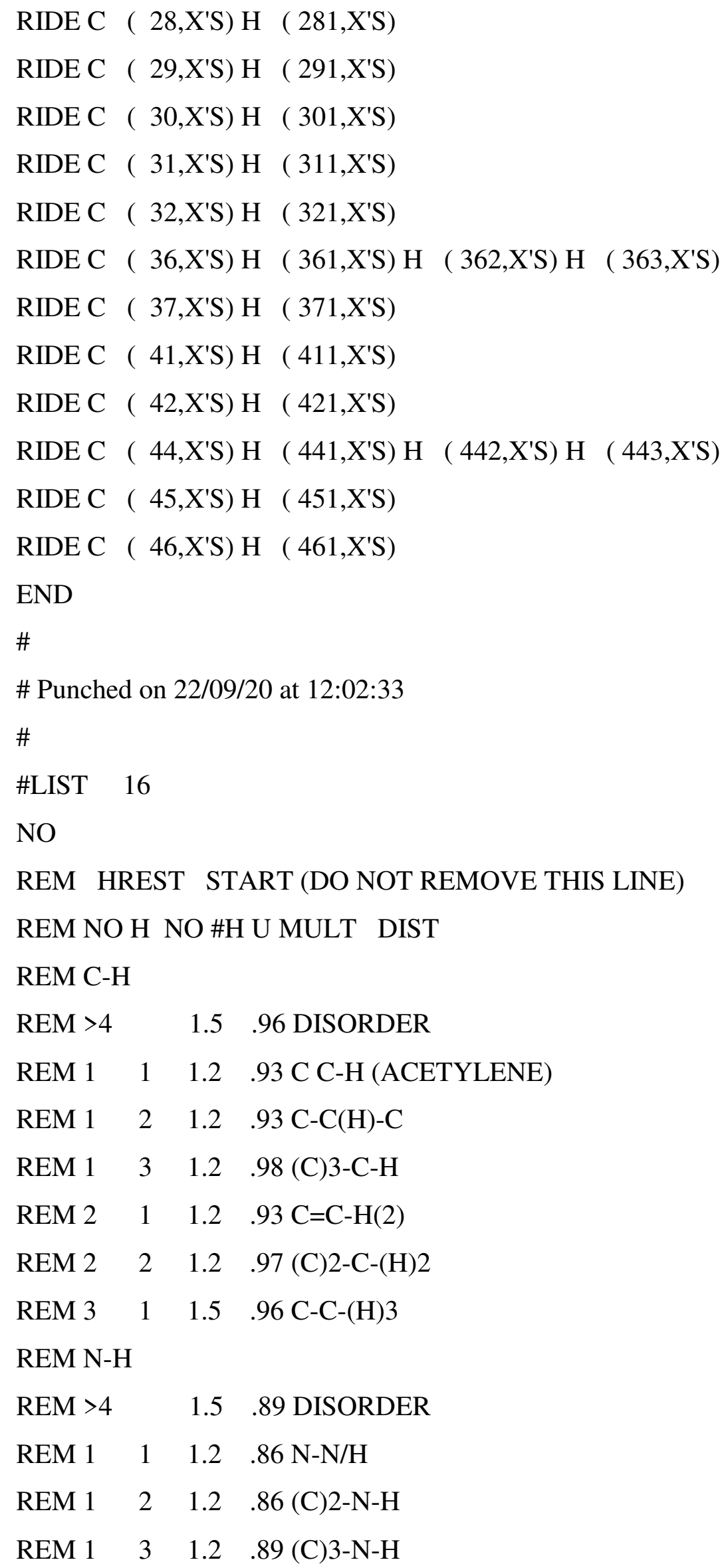




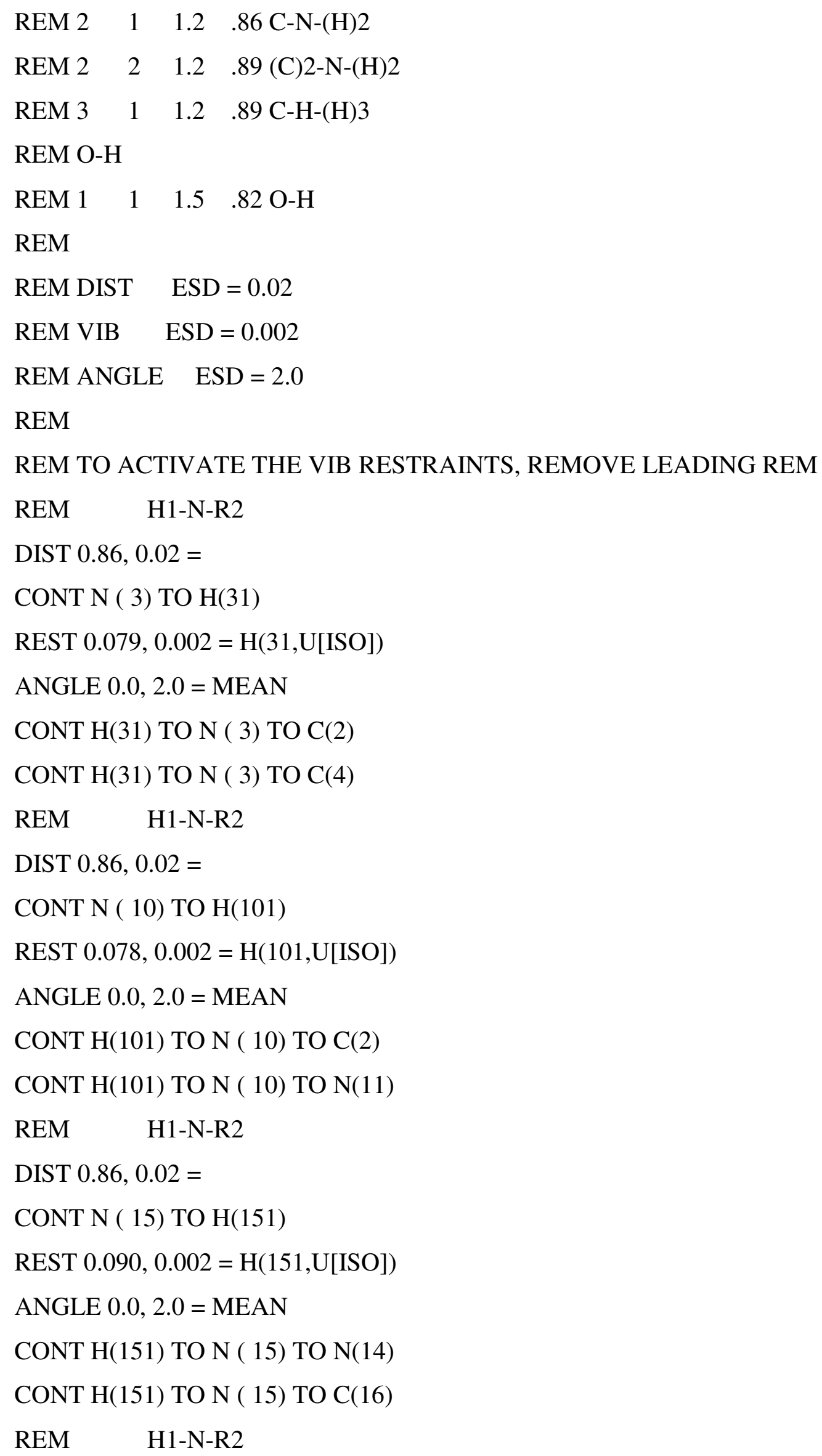


DIST $0.86,0.02=$

CONT N ( 26) TO H(261)

REST 0.092, $0.002=\mathrm{H}(261, \mathrm{U}[\mathrm{ISO}])$

ANGLE 0.0, 2.0 = MEAN

CONT H(261) TO N ( 26) TO C(25)

CONT H(261) TO N ( 26) TO C(27)

REM H1-N-R2

DIST $0.86,0.02=$

CONT N ( 33) TO H(331)

REST 0.080, $0.002=\mathrm{H}(331, \mathrm{U}[\mathrm{ISO}])$

ANGLE 0.0, 2.0 = MEAN

CONT H(331) TO N ( 33) TO C(25)

CONT H(331) TO N ( 33) TO N(34)

REM H1-N-R2

DIST $0.86,0.02=$

CONT N ( 39) TO H(391)

REST 0.084, $0.002=\mathrm{H}(391, \mathrm{U}[\mathrm{ISO}])$

ANGLE 0.0, 2.0 = MEAN

CONT H(391) TO N ( 39) TO N(38)

CONT H(391) TO N ( 39) TO C(40)

REM HREST END (DO NOT REMOVE THIS LINE)

END 